\title{
Women who inject drugs: barriers to their access of Needle Exchange services, and gendered experiences
}

\author{
By
}

Kirsten Mary Gibson

\begin{abstract}
A thesis submitted to the Victoria University of Wellington in fulfilment of the requirements for the degree of Master of Arts in Criminology
\end{abstract}

Social and Cultural Studies

Victoria University of Wellington

2016 


\section{Table of contents}

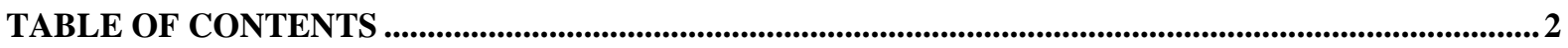

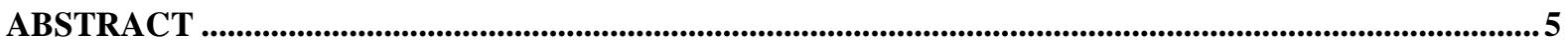

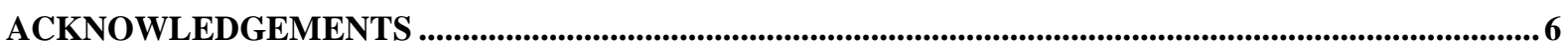

THESIS OVERVIEW .............................................................................................................................................

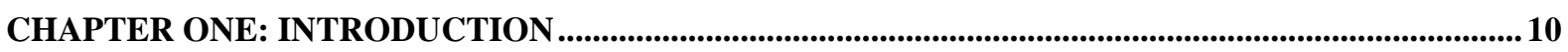

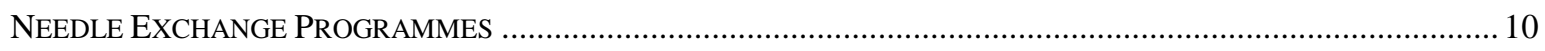

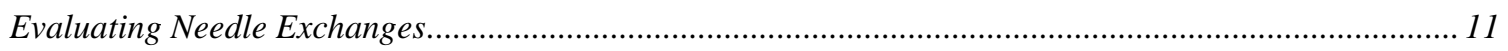

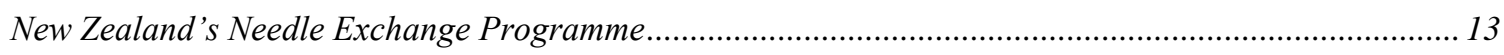

CHAPTER TWO: LITERATURE REVIEW ....................................................................................................16

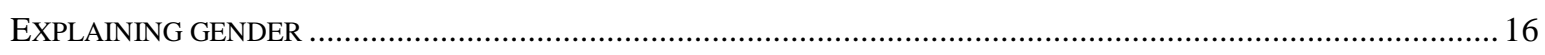

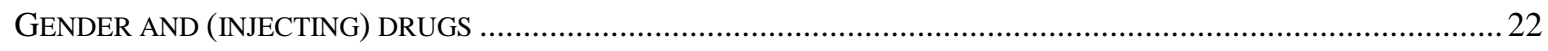

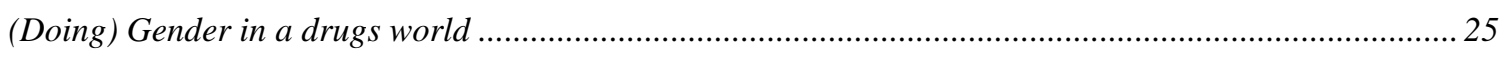

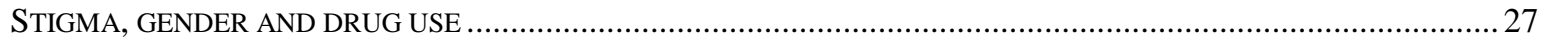

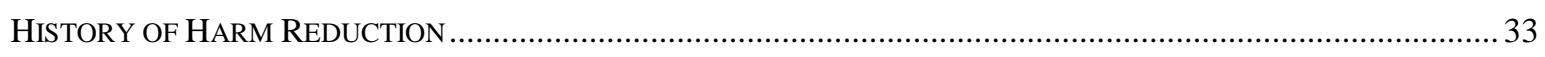

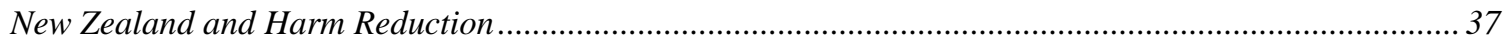

CHAPTER THREE: METHODOLOGICAL FRAMEWORK ....................................................................... 40

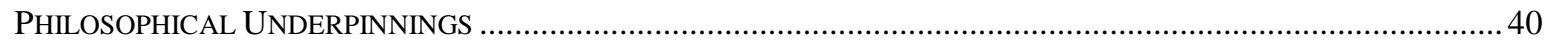

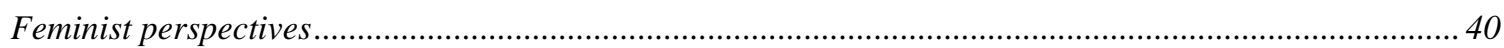

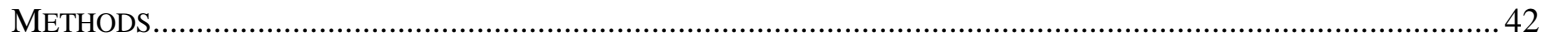

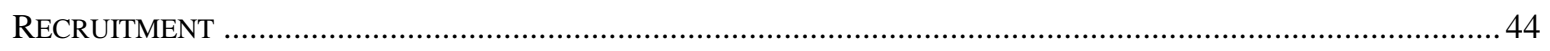

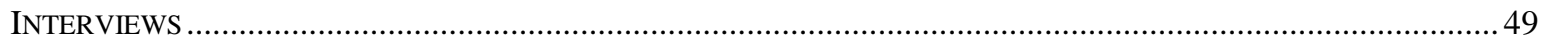

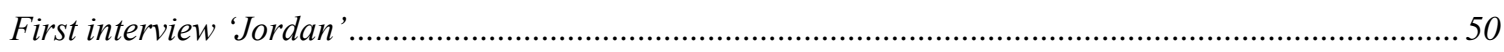

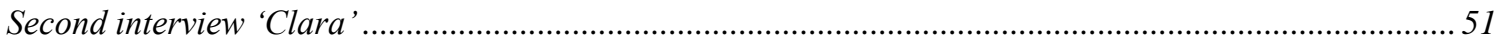




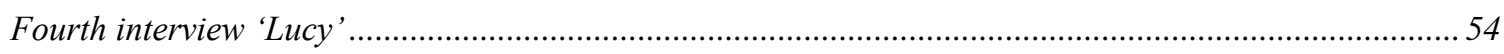

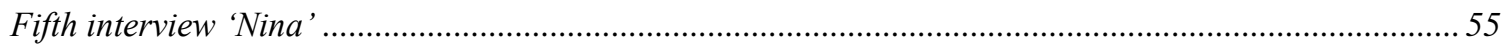

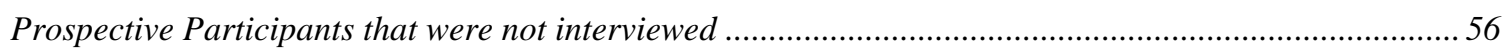

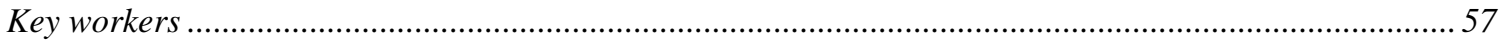

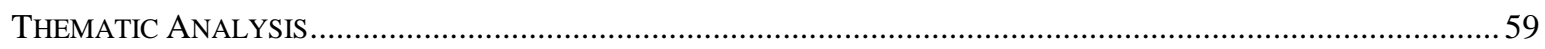

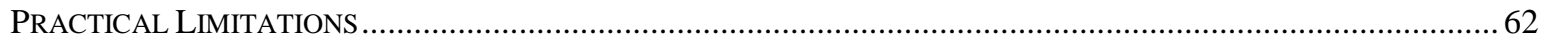

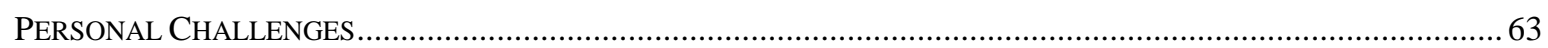

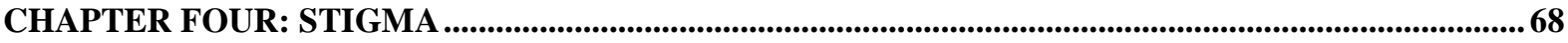

'FeELING THE STIGMA' - How THE 'MASTER StATUS’ OF BEING A WWID IS EXPERIENCED ..........................69

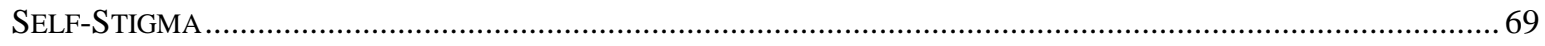

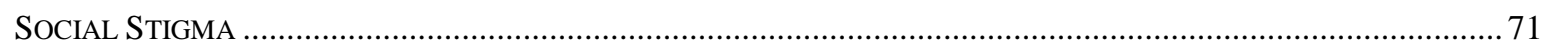

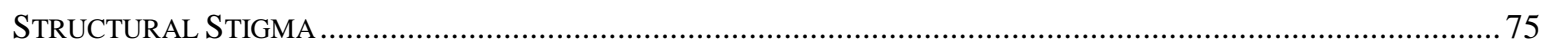

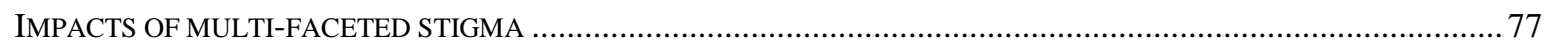

EXPERIENCES OF STIGMA DIRECTLY RELATED TO THE NEEDLE EXCHANGE ............................................... 84

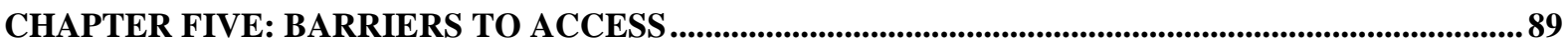

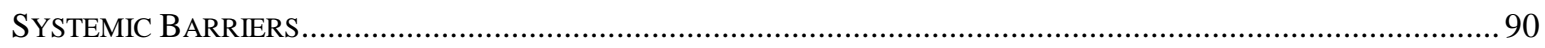

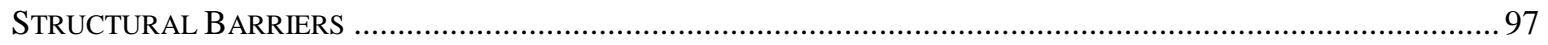

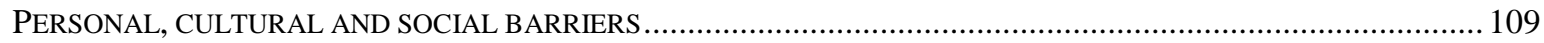

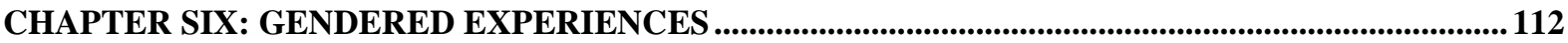

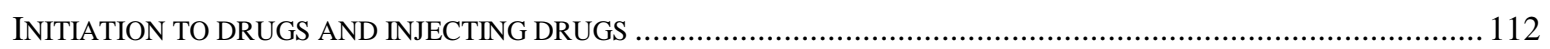

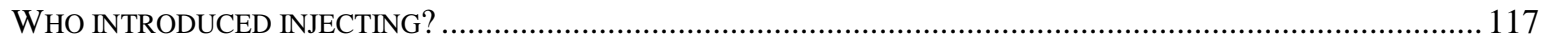

Regular using within a masculine context ....................................................................................... 123

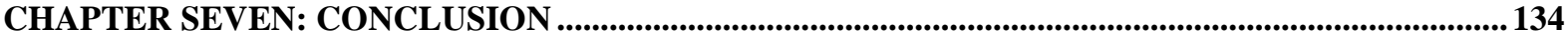

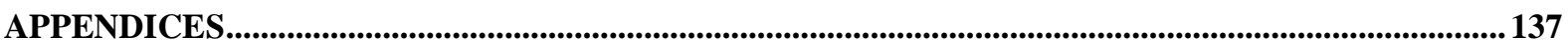

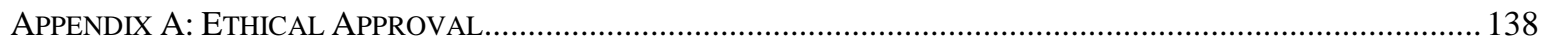

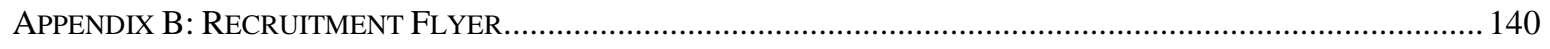

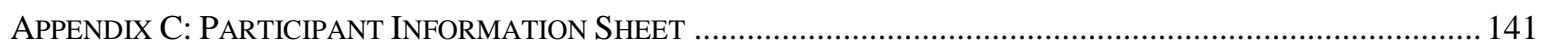


APPENDIX D: PARTICIPANT CONSENT FORM

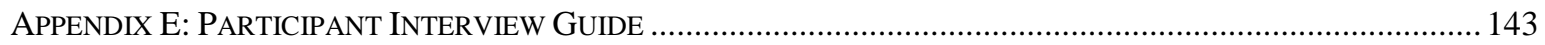

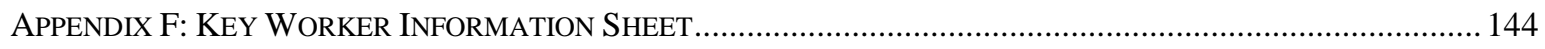

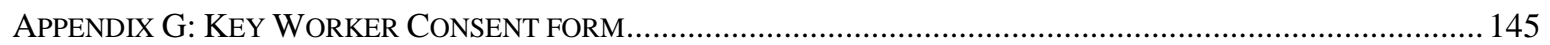

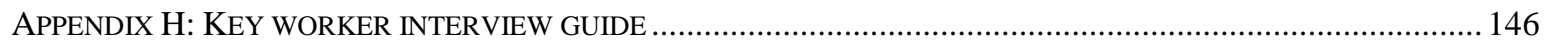

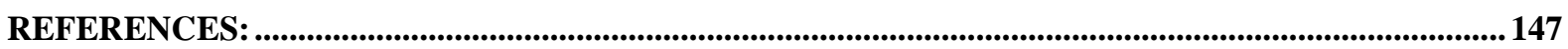




\section{$\underline{\text { Abstract }}$}

This thesis examines the gendered experiences of women who inject drugs, and barriers they face when accessing needle exchange services. Globally, studies suggest women access needle exchange services less than men. In New Zealand, the evidence suggests a similar situation. From the little that is known about women's experiences in this context, studies are often quantitative, medically-based, or lack the voices of women who inject. This thesis aims to understand the gendered factors affecting the experiences of women who inject drugs. This study is a feminist, qualitative study, and employed semi-structured interviews as the data collection method. Five key participants who had injected drugs and four key informants who work with people who inject drugs were interviewed. The data from the interviews were analysed using thematic analysis.

This study found that stigma presented as an overwhelming, pervasive barrier to the participants, not only in their access to needle exchange services, but also as a harm in other facets of their lives. Additionally, other barriers such as location also affected their access. The data confirms the significance of gender in their experiences and how, within a drugs context, gendered issues mirror wider society. The findings provide a platform for further research in this field and contribute to the academic understanding of a marginalised and stereotyped population. They also support the implementation of women-sensitive initiatives within needle exchange services. 


\section{Acknowledgements}

This thesis has by far been the most challenging work I have undertaken, not only academically, but personally as well. I am immensely grateful for the support and encouragement received throughout the journey (it was a 'journey’ as Murray Wilson reminded me!)

First and foremost I would like to thank the women who took the time out to share their stories with me. I hope this thesis represents your experiences and voices accurately and fairly. I'd also like to acknowledge the women who I was not able to meet or interview. Your interest and efforts are appreciated.

Thank you to the key workers who also shared their experience ad views with me. Thank you for giving me your time, your thoughts and words are gratefully appreciated. I'd also like to thank the various organisations who supported the research and allowed flyers to be placed in their reception areas.

I wish to acknowledge and thank my supervisor who guided, encouraged and supported me beyond belief, and provided me with great laughs, tea and most importantly, chocolate. I could not have completed this thesis without you Fiona Hutton, and I will always remember it. And to all the lecturers and staff in the Criminology Department at Vic - you inspire me and have taught me a huge amount.

My partner Nico who puts up with, and supports, my never-ending studying - "no puedo decir gracias suficiente, pero gracias. Besos". Of course, thank you to 'the mother', Eileen, and in your words "my brilliance must have come from you". My sister, Fiona for your practical support particularly in the second half of my thesis and for always encouraging me. And gracias a Paco, for getting me outside and enjoying walks when I needed to de-stress. Sarah Binner for those words of encouragement along the way when I needed them. 
Thank you to my team of amazing proof-readers - Nigel, Cara and Sam - alongside your friendship, your eye for detail and feedback has been invaluable.

Thanks Gina for the hospitality and company during my stays.

Shanna Bosley - my office mate and so much more. Our anti-procrastination contracts and 'save the world' sessions gave me so much more than just inspiration and motivation. Thanks to those study buddies and 'pomo' friends throughout the journey - Nequilla Wisely, Sunshine Prior, Sam Keene and Loren Ebbett. 


\section{Thesis Overview}

The objective of this study is to examine the barriers that women who inject drugs experience while accessing needle exchange services. The research focuses on the gendered factors that women navigate, the impact of drug and harm reduction policies and how these policies are informed by gender constructions.

This thesis draws upon the experiences of women who have injected drugs, in their own words, alongside the perspectives of professionals who work within organisations that provide services to women who inject drugs. The following key research questions ${ }^{1}$ were used to guide the research process:

1.) To what extent, if any, do women who inject drugs experience gendered barriers in accessing needle exchange services?

2.) If experienced, how have women who inject drugs navigated and responded to barriers in accessing the needle exchange?

The majority of the current literature is limited in providing a platform for women who inject drugs to express their own views and experiences, particularly in a New Zealand context. Therefore, this research is largely qualitative, feminist, and provides a valuable insight into women's experiences of needle exchange services, alongside an exploration of how they can navigate daily life with gendered actions.

This research is undertaken with the hope that it contributes to a wider awareness and appreciation of the issues women who inject drugs face. There is also an anticipation that this

\footnotetext{
${ }^{1}$ The original proposal for this research included an examination of facilitators for women in accessing needle exchange services, however due to space restrictions, it is necessary to omit facilitators from this thesis. Though, it is worth noting that facilitators to the needle exchange are often the converse of barriers.
} 
research can provide insight to needle exchange management. The structure of this thesis is largely framed around the data collected, its analysis, and results. The introduction provides a background to Needle Exchanges, in a global and New Zealand context and what is understood about women's experiences with them. Following this, a review of relevant literature regarding gender constructs, notions of 'deviant' women, drugs, those who use drugs, injecting drug use and harm reduction is in Chapter Two. Chapter Three discusses the methodological approach used in this study, outlining the research methods used as well as the ethical issues and practical limitations. A detailed description of each key participant is also included here. The results chapters commence with Chapter Four, which explores theory around stigma, women who inject drugs and the significant reality stigma has on the participants in this thesis. Chapter Five analyses other known barriers to harm reduction services and how the women in this study experienced them. The final results chapter, Chapter Six, examines how women's experiences of a drug world are gendered and how that reflects wider society. Chapter Seven concludes this thesis. 


\section{Chapter One: Introduction}

\section{Needle Exchange Programmes}

Needle Exchange Programmes (NEPs) or Needle and Syringe Exchange Programmes $(\text { NSEPs) })^{2}$ have been operating globally since the 1980s. Established as a harm reduction response to an increasing HIV/AIDS crisis during the 1980s, the main aim was to reduce transmission of HIV and other blood borne viruses (BBVs) (Aitken, 2002). The main function of NSEPs is prevention and reduction of risky injecting practices, and the sharing of injecting equipment (Ashton, 2004). This is achieved through the provision of services for people who inject drugs (PWID) to obtain sterile injecting equipment and safely dispose of used needles (Aitken, 2002).

As of 2014, from at least 158 countries documenting injecting drug use, 90 countries have implemented NEP/NSEP programmes in various forms (United Nations Office on Drugs and Crime (UNODC), 2015). As PWID comprise a marginalised and hidden population, data is often difficult to obtain and verify (Cao \& Treloar, 2006). One current estimate of the global injecting drug population ranges from 8.9 to 22.4 million people (Harm Reduction International, 2014). Due to the lack of disaggregation by gender of data around injecting drug use, it is even more difficult to ascertain information about women who inject drugs (WWID). The scarce data that does exist suggests women are a significant minority of the drug injecting population (Pinkham, Stoicescu, \& Myers, 2012b). This is to likely be an underestimate, as WWID are marginalised and more likely to conceal their injecting use than their male counterparts (UNODC, 2015). Furthermore, statistics, are not representative of the daily struggles

\footnotetext{
${ }^{2}$ NEPs (Needle Exchange Programmes) and NSEPs (Needle and Syringe Programmes) are terms used interchangeably throughout the literature.
} 
PWID experience and their access of harm reduction services (Harm Reduction International, 2014).

Global estimates of the proportion of PWID that access NSEPs are difficult to obtain due to the range of methods to collect data internationally (Harm Reduction International, 2014). Some global estimates are as low as five percent of PWID being able to access needle exchange services and difficulties in access are well documented (Gay Men's Health Crisis, 2009). At an international level, there is a dearth of research relating to needle exchange services for WWID. Despite this, it is widely accepted that WWID are more affected by barriers to accessing needle exchange services than men (UNODC, 2015).

Global level evaluations of NSEPs are rare, services are more likely to be reviewed regionally (Harm Reduction International, 2014). Despite numerous assessments of NSEP efficacy, WWID remain ignored or neglected in programme reviews and evaluations, which overwhelmingly lack inclusion of WWID's needs (UNODC, 2015).

\section{Evaluating Needle Exchanges}

As the fundamental aim for the implementation of NSEPs was to reduce the prevalence of HIV/AIDS and other BBVs, other harms relating to the injecting of drugs have been neglected (Gay Men's Health Crisis, 2009). Wodak and Cooney (2005) completed the first detailed international review examining the effectiveness of needle and syringe programmes. The only mention of women in the review refers to research in the context of prison or sex work. Furthermore, evaluations undertaken have largely focused on drug treatment programmes rather than needle exchange services and there is very little research around the effectiveness of drug services for women (Pinkham et al., 2012b).

Effectiveness is also measured in economic terms. Although methods vary, the evidence suggests that NEPs are cost-effective (Wodak \& Cooney, 2005). Every $\$ 1$ spent on New 
Zealand's NSEP saved \$3.35 in health care costs between 1988 and 2001 (Aitken, 2002). While it is generally accepted that Harm Reduction programmes like Needle Exchanges are successful, some criticism remains. Ashton (2004) acknowledges the existence of some negative assessments of needle exchange programmes, however he also notes that criticisms of increasing $\mathrm{BBV}$ rates are correlative and stops short of labelling needle exchanges ineffective.

The majority of Needle Exchange programme evaluations have been assessed based on infection rates of BBVs such as Hepatitis B, C and HIV/AIDS (Gay Men's Health Crisis, 2009). The literature suggests that the goals of NEPs are placed in a hierarchy where protecting the public from BBVs is predominantly the most important goal. Therefore the majority of reviews and evaluations of NEPs have largely ignored other possible objectives. Furthermore, as the bulk of NEP evaluations are within a medical or biomedical framework (Gay Men's Health Crisis, 2009), the prioritisation of reducing infection rates of BBVs continues. While this is promoted as a positive goal for NEPs, the notion of protecting the public from 'dirty users' or those who inject drugs can perpetuate the stigma that women who inject drugs face.

Although research from the 1980s highlighted the need for an examination of and focus upon gender-specific needs within NEPs and related services, little has been done since (European Monitoring Centre for Drugs and Drug Addiction (EMCDDA) 2006). This continues to be noted as a salient issue in designing services for women who use drugs, however, a gap remains regarding gendered, or women-focussed services. Research and evaluation of harm reduction services indicate that women-focussed services can increase access and utilisation of services such as the needle exchange. Very few studies compare men and women's access of NEPs, however the few that do, lack qualitative data (Ksobiech, Somlai, Kelly, Benotsch, GoreFelton, McAuliffe, Ostrovski, \& Kozlov, 2004). 
Only recently has this gap in services for WWID attracted more direct focus. In 2012, a global report included a discussion that was devoted to the development of effective harm reduction services for WWID (Pinkham, Myers, \& Stoicescu, 2012a). Whilst overdue, this research has several limitations. One of the first sections is largely devoted to sexual and reproductive health. Even though this is an important aspect, this could further propagate stereotypical views and studies focusing on women's bodies and motherhood. Despite this, one report, although an examination of primary health and wider harm reduction services rather than NEs, is significant (VANDU Women CARE Team, 2009). This is due to its rare use of a qualitative framework this report gives a voice to a group of marginalised people.

Barriers to accessing needle exchanges are not a prominent feature of most evaluations. However, in assessing the success of harm reduction programmes, it is essential to identify and understand factors that restrict people's access to the service. The evidence available suggests that needle exchange services are disproportionately accessed by men compared with women, and though statistics vary globally, the disparity between the estimates of WWID and women who access needle exchange services and other drug services persists (Pinkham et al., 2012a).

\section{New Zealand's Needle Exchange Programme}

New Zealand implemented the world's first national needle exchange programme for PWID in 1988. Since then, it has remained an important service for PWID, it has been regarded as one of the most effective public health initiatives in New Zealand (NEP National Office, 2013). The New Zealand Ministry of Health $(\mathrm{MOH})$ contracts drug user groups to run individual Needle Exchanges (NEs). There are four stakeholder groups: the MOH, Needle Exchange NZ (NENZ), the Pharmacy Guild and the Pharmaceutical Society (Aitken, 2002). NENZ is the controlling stakeholder in the programme and is also responsible for peer-based, stand-alone NENZ outlets. They offer a complete range of needles, syringes, and other injecting equipment and are run by drug users, for drug users, in order to offer detailed advice about safer drug use 
(Aitken, 2002). The Needle and Syringe Exchange Programme (NSEP) allows NEs, pharmacies, medical practitioners and authorised representatives to provide sterile needles and syringes. The programme is based on a harm reduction philosophy, which acknowledges that people will inject drugs therefore it is better to reduce harm from injecting than attempt to curtail drug use (Aitken, 2002).

Less than a handful of reviews have been undertaken assessing the New Zealand NEP (Aitken, 2002; NEP National Office, 2013). The last extensive evaluation was in 2002 and was mainly a cost/benefit analysis (Aitken, 2002). Effectiveness is firstly measured by BBV numbers in New Zealand and secondly by a decline in needle-sharing statistics (Aitken, 2002). Although this large scale review revealed 16 recommendations to improve Needle Exchange services, such as more staff training, no recommendations related to gender specific practices were put forward.

The New Zealand NEP is largely divided into two type of outlets, either within a pharmacy or in a dedicated stand-alone outlet. Barriers to access are often dependent on the type of outlet. However, evaluations of the New Zealand Needle Exchange reflect the global context with sparse data exploring barriers to access, women's needs and experiences with regards to these issues (Pinkham et al., 2012b).

A review of pharmacy-based services identified an issue relating to the lack of specific training for staff and the provision of needle exchange services (Sheridan, Henderson, Greenhill, \& Smith, 2005a). This has been recognised as a barrier to accessing services by PWID, and even more so for WWID due to the different needs of women. While pharmacists may be intent on providing efficient and effective services, it is unlikely that their knowledge around injecting needs will be extensive (Sheridan et al., 2005a), let alone the needs of WWID. Additionally, 
the review only sought data from staff (Sheridan et al., 2005a), and failed to ask WWID, limiting the understanding around barriers. 


\section{Chapter Two: Literature Review}

\section{Explaining gender}

To understand women's experiences of drug use and accessing needle exchange services, it is necessary to understand women's experiences in general, in a non-drug environment and how women navigate their environment while negotiating expectations of gender. Gender is a complex social construct that informs women and men's behaviours as well as their thoughts and emotions, which are predominantly ascribed to be feminine or masculine traits (Connell, 2002). Conventional feminine qualities attributed to women include being passive, nurturing, and risk averse, whereas examples of conventional masculine traits are dominance, riskiness and pleasure-seeking (Connell, 2002). Expressing one's gender can be enacted in diverse ways in varied contexts. Broadly, masculine roles are attributed to the authoritarian role in the family and this extends to other institutions such as government (Anderson, 2008). Feminine roles, with 'emphasised femininity', are more likely to be associated with tasks that are subordinated relative to masculinity (Connell, 2002). Roles including domestic duties, such as nurturing others and putting others' health first, typify what is accepted as feminine (Heidensohn, 1985).

It is important to note that 'doing gender' can be diverse and situational (Shiner, 2006) and expressing gender is an inter-relational action (Butler, 2004). The diverse contexts in which 'gender' is expressed can include working in an office, going to a restaurant, or activities deemed to be 'deviant' such as using illegal drugs. Furthermore, factors such as age, social class and ethnicity can also influence how gender is expressed, or how someone might "do gender" (Connell, 2002). As Connell (2002) posits, despite bifurcated images of gender, the reality is significantly more fluid, varied and diverse. While Connell (2002) asserts that theories of gender cannot explain all women's behaviour as their actions and experiences are heterogeneous, society's gendered constructs are reflected in the drug world (Anderson, 2013). 
Anderson (2013) attests that women predominantly maintain a gendered role within this world and often fulfil fundamental tasks such as providing housing, purchasing drugs and subsidising men's drug use.

Gender is governed at, and permeates through different levels within society. Butler (2004) links Foucault's (1977) mode of 'discipline and surveillance' with the regulation of gender and the normalisation of ascribed gender traits. While Foucault's (1977) work around power, discipline and surveillance failed to focus on gender or objectification of women's bodies and has been criticised on this basis, his work has been applied extensively in feminist literature to explanations of the persistent policing and control of women's bodies and their actions (King, 2004).

Foucault (1977) challenged traditional notions of power as being held by one person over another, instead power is seen as a different form of truth possessed by those who hold the power to define subjects and position them within society (Beals, 2002). Power is an important factor as regulation of gender is supported and enforced by mechanisms, such as cultural norms around expected behaviour, and more importantly, various institutions, bureaucracies and other groups such as the media (Danaher, Schirato, \& Webb, 2000). Foucault (1975) argues that power is exerted through these institutions in the form of discipline and policing supported by the state's desire to maintain a productive, hard-working and healthy population (Danaher et al., 2000). This is achieved firstly through the accepted sources of truth, such as disciplines like social sciences, to provide knowledge and secondly, via administrative tools that govern and police, such as the criminal justice system (Danaher et al., 2000). As King (2004) argues, gender, and the knowledge held by such institutions about gender and femininity, is a discipline that constructs, perpetuates and controls notions of women's bodies and identities. 
Although Foucault's theories around body, bio-politics and power have been used to explain how women's bodies are controlled and disciplined through the mechanisms of the state and other institutions, criticisms have also been highlighted throughout feminist literature for the reduction of social agents, in this case women, into passive subjects with little agency, in addition to the lack of explanation around people's individual actions (McNay, 1992).

However, Butler (2004) argues that what are regarded as normal gender behaviours can undo a person's self-identity. Although traditional qualities ascribed to gender have been described above, gender does not alone define what an individual is nor is it simply something they have; it is far more complex (Butler, 2004). Assuming gender as a binary concept is problematic and reductionist, as it assumes a person must fit or correspond with one gender or another (Butler, 2004). Not only does it affect how cis-gendered ${ }^{3}$ women can be identified and treated, it can also negate someone's gender experiences if they do not fit into the binary (Butler, 2004). In deviating from gender norms, individuals risk being abused by governing powers such as the medical or psychiatric professions (Butler, 2004). This risk can be associated particularly with the stigma and discrimination that women who use drugs experience, and this will be explored further in this chapter.

Gender practices are reinforced and replicated through bodily actions (Butler, 2004) with corporeality and gender affecting men and women in different ways. Women's bodies have been judged throughout history far more closely than men's (Ettorre, 1992). Reinforcing the notion of women being 'not men', women's bodies have historically been perceived as inherently abnormal as they were contrasted against men's bodies (Carlen \& Worrall, 1987). This is a legacy from the Victorian era, where the notion of good health was considered innately male and, as a result, pathologising women became the norm (Carlen \& Worrall, 1987).

\footnotetext{
${ }^{3}$ Cis-gender is used to describe individuals whose gender assignment at birth and gender identity are the same (Tate, 2012).
} 
Although cis-women's bodies ${ }^{4}$ can be capable of more than men's, such as giving birth, they are regarded as less reliable, as menstruation, pregnancy, childbirth and menopause are considered to be hormone imbalances rather than normal occurrences (Carlen \& Worrall, 1987).

Judgement of women's bodies has also come alongside the policing of women's bodies, particularly when women are violating gender norms and are judged to be harming their own bodies. Corporeality is important in discourses on drugs. Body ideals are embedded in cultural norms and develop from historical, scientific, and medicinal professions (Ettorre, 2004). Drug use is considered to be a form of "embodied deviance" (p. 29) where the body is tarnished by drug consumption (Ettorre, 2007). The damaged body is marked and then becomes identified with an individual of a lower social class and associated with immoral actions (Ettorre, 2004). Self-control is highly associated with the body, with individuals displaying how they control their everyday bodily tasks such as eating, and their desires (Ettorre, 2004). Ettorre (2004) posits that drug users are characterised as 'other' to the rest of society due to the additional work drug users and their bodies must do. Extra work revolves around managing their drug use, such as obtaining drugs and the consumption of drugs (Ettorre, 2007). While Ettorre (2007) is largely referring to problematic drug use here, all individuals who consume drugs face being tarnished as immoral and lacking in self-control. While there is insufficient space in this thesis to include the complexities within the political, social, and medical debates about what is regarded to be problematic drug use, it is important to note that there is no clear definition of problematic drug use (Buchanan, 2006). For the purposes of this thesis, the term problematic drug use will largely refer to notions of use, particularly injecting use, of illicit and/or licit drugs on a regular basis over a long period of time, combined with dependence of

\footnotetext{
${ }^{4}$ Note: trans-women and cis-women who are unable to re-produce children are still women.
} 
drug use that may be causing psychological, legal, social and/or physical harms to the person that uses or those around them (EMCDDA, 2006).

Women are arguably affected by judgements around embodiment more than men and this is even more apparent in discourses surrounding women, drug using and reproduction. Women's drug using bodies transform into "lethal foetal containers" (Ettorre, 2007, p. 351) during pregnancy. Women's bodies, drug use, and babies are not considered compatible. Ettorre (2004) argues that this judgement is motivated by various moral and medical reasons. Drug use during pregnancy is deemed to add medical risks, for both mother and foetus, though research also suggest that adverse conditions for women who are pregnant and use drugs, are more often linked to issues such as poverty (Stengel, 2014). Additionally, the moral-based decisions used against women who use drugs and who reproduce often contrast evidence around the physical risks of harm to the foetus or the mother (Ettorre, 1992). The governing views around women and their bodies amount to the reduction of women's basic human rights with regards to reproduction as women who use drugs are directed to have terminations, be sterilised (Ettorre, 2004), or have to prove to social services and society that they are capable mothers despite their consumption of drugs.

The management and portrayals of women's bodies in relation to drug use are largely reductionist, so harm reduction initiatives require acknowledgement of the gendered needs of women. Ettorre (2004) advocates that understanding the complexities of genderedembodiment contributes to the ability of designing gender-sensitive harm reduction policies and philosophies. The subjective level addresses the need for harm reduction initiatives to be implemented where self-image and good health are respected in association with drug use (Ettorre, 2004). This is illustrated in such initiatives as abortion being an option for women who inject drugs and are pregnant, and also services that assist reduced or maintained consumption of drugs (Ettorre, 2004). The treatment level works within the notion that harm 
reduction methods act as instruments of empowerment (Ettorre, 2004). This is crucial for women who inject drugs as their social position in a patriarchal society is heavily marginalised. In this level, Ettorre (1992) emphasises how important a flexible system is in instilling selfconfidence and esteem in WWID. The relationship level seeks to address issues around intimate relationships and how relational femininity is embodied, with the suggestion that women are more at risk regarding unprotected sex and preserving relationships rather than prioritising their own bodies and health (Ettorre, 2004). This is supported by research that suggests some couples share injecting equipment as a sign of trust, which affects women more due to the increased likelihood of WWID having a sexual partner that injects drugs compared with men who inject drugs (MWID) (Pinkham et al., 2012b). However, Ettorre (2004) asserts that in implementing harm reduction at the relationship level, the self-identities that women possess must not be regarded as 'at risk' by those accessing harm reduction services. Implementing strategies that deny women's self-perceptions can hinder harm reduction strategies. For this reason, Ettorre (2004) argues it is essential to appreciate the complexities around embodiment, gendered rules and relationships. Stereotypes of women engaging in sex work to fund their problematic injecting drug use are perpetuated by popular media and public discussion which contributes to further stigmatisation (Phoenix, 2006). Furthermore, although there is a significant amount of research that explores the correlation of women who inject drugs and street-based sex work, the reality is that women who inject drugs have a variety of means to fund drug use and not all sex workers use drugs (Taylor, 1993). The occupational level of harm reduction services, as Ettorre (2004) describes, though aimed predominantly at sex workers and therefore perpetuating stereotypes, it also is harm reduction associated with corporeality and employment hazards. Lastly, in developing a gender-sensitive harm reduction policy, the leisure level emphasises the need to recognise that, while within a drugs environment women can experience subordinate roles, they can also use drugs as a pleasurable 
activity (Ettorre, 2004). Harm reduction programmes need to embrace the notion that women's drug consumption can include a sense of self-esteem and fortitude alongside risk-taking actions, which are part of life (Ettorre, 2004).

\section{Gender and (injecting) drugs}

Humans have used drugs for millennia with records suggesting opium use occurred 5000 years ago (Durrant, Adamson, Todd, \& Sellman, 2009). The reasons for drug use are diverse: for hedonistic reasons, cultural or religious practices, the alleviation of physical and/or psychological pain, or to prevent withdrawal (Anderson, 2001). Despite this, the view of illegal drug use is heavily associated with problematic, chaotic use and crime. The perception of illegal use equalling problematic use only fully emerged in the twentieth century (Seddon, 2010).

New Zealand's history of drug use largely reflects other western colonised nations. While there is no known use of recreational drugs before Europeans arrived, their settlement was accompanied by multiple psychoactive substances including alcohol (Eldred-Grigg, 1984). From the mid eighteenth century, alcohol and other drugs were used for various purposes including: alcohol as a substitute where potable ${ }^{5}$ water was lacking or milk risked disease exposure, taking cannabis products for medicinal purposes, or drinking laudanum ${ }^{6}$ for recreational purposes (Phillips, 2015). Attitudes towards drugs were relatively tolerant until the early 1900 s when the social purity movement turned its attentions towards control and legislation against various drugs (Eldred-Grigg, 1984). Drug use by women in New Zealand's early colonial period was often associated with a lack of morality and increased attention was directed to their roles as mothers. The use of narcotic syrups by mothers to sooth babies led to knee jerk reactions, with those in authority proclaiming that mothers were "killing hundreds of

\footnotetext{
5 'potable' refers to water that is safe to drink

${ }^{6}$ A tincture of alcohol and opium, consumed as a drink for medicinal or recreational purposes.
} 
babies... and poisoning natural virility" (Eldred-Grigg, 1984, p. 235). At the beginning of the early twentieth century attitudes towards, and controls of, alcohol and other drugs had become stricter, and drugs were perceived to be far more sinister with the potential to threaten the nation's strength (Eldred-Grigg, 1984). From the early to the mid-twentieth century New Zealand's drug scene reflected that of many other Western nations (Luke, 2007).

The 1960s and 1970s saw the emergence of the sociology of drugs as a new discourse around drugs and drug use, challenging previous mainstream social theories that framed drug users as deviants whose behaviour resulted from individual or social pathology (Shiner, 2006). Due to the influences of Howard Becker (1963) and Jock Young (1971), the socially constructed views of drug use as a disease were contested. Becker (1963) argued that there is no inherent quality in individuals who consume illegal drugs that makes them 'deviant', but rather, their status of 'outsider' is constructed, bound in moral judgements and perpetuated through social labelling. Becker (1963) and Young (1971) apportion responsibility of the perpetuation of the constructed label of 'deviant' to governmental institutions and significantly, the media. In addition to the constructed notion of 'deviant' being challenged, the categorisation of drugs as illegal due to perceived harmfulness has been increasingly recognised and criticised as based on an ideology lacking in scientific and pharmacological evidence (Taylor, 2008).

The widely accepted definition of 'drug' is in reality, a social construct. The reality is that substances categorised as illegal drugs cannot be pharmacologically differentiated from legal drugs (Bancroft, 2009) and the illegal versus legal drugs divide is a reductionist model based on poor science (Boland, 2008). This has been confirmed by transparent and evidence based research, which ranks many legal drugs as more dangerous than some illegal substances (Nutt, 
King, \& Phillips, 2010). Overly-simplistic notions around drugs, such as the bifurcation ${ }^{7}$ of their legal status, have faced extensive criticisms.

Though criticisms of reductionist theories around drug use and those who used drugs continued from the twentieth into the twenty first century, women's presence in the literature remains notably absent. Although in literature such as Heidensohn's (1985) and Smart's $(1976,1977)$ a shift had been seen in criminological thought regarding women's 'deviance', the lens focused largely on criminal or deviant activities other than the consumption of drugs. Ettorre (2004) argues that, despite the invisibility of women in discourses about drugs being highlighted in the 1970s, it has essentially continued into contemporary times. Where women are included in research on drugs and drug use, it is either secondary or the focus has been restricted to select issues such as the effects on child birth, pregnancy, motherhood or the common presumption of sex work and funding of drug use (Neale, 2004). This issue is epitomised by the increased research focusing on women who injected drugs, sex workers and mothers who use drugs, in the 1980s at the time of the HIV/AIDS pandemic (Measham, 2002).

While studies have recognised the power of gender in drug cultures, women's experiences still lag behind men's in research around drugs (Ettorre, 2004). Injecting drugs is considered risky and reckless behaviour, therefore women who inject drugs contradict accepted gender norms (Ettorre, 2004). Women are judged more harshly for injecting drugs than men and are considered to be abusing their bodies (Malloch, 2004). Notions of corporeality relating to women's bodies and drug use are impacted on and compounded by gender constructs (Ettorre, 2007).

Gender was once considered a predictor of illicit drugs use, with statistics suggesting that the large majority of those using illegal drugs are men (Measham, 2002). However, in the last 30

\footnotetext{
${ }^{7}$ Bifurcation of drugs is a reductionist framework and refers the legal and political framework that presents illegal drugs as harmful and legal drugs, in comparison, not considered drugs and relatively safe.
} 
years, estimates show that this is no longer the case with the gender gap in illicit drug use decreasing (Measham, 2002; Poole \& Dell, 2005). Ettorre (1992) and Henderson (1997) both link women's drug use to their changing position in society and they acknowledge benefits such as a feeling of pleasure, and disadvantages such as bad after-effects, in drug consumption. Regarding injecting use, the proportion of women who inject is unknown due to issues such as researching a stigmatised population, scant data and the lack of a disaggregated data and global systematic review of WWID (Oretti \& Gregory, 2005; Pinkham et al., 2012b).

As previously mentioned, evidence suggests WWID are a significant proportion of PWID, with estimates ranging from ten percent to 33\% (Pinkham et al., 2012b). Some statistics suggest that in New Zealand, women as a proportion of the injecting population varied from $45 \%$ to $27 \%$ from 2006 to 2009 (Wilkins, Sweetsur, \& Griffiths, 2011). When considering injecting use in the previous 12 months, there was no significant difference between men and women (Ministry of Health, 2010). New Zealand Needle Exchange surveys revealed $31 \%$ of users accessing the services were women in 1999 and 39.9\% in 2002 (Aitken, 2002).

\section{(Doing) Gender in a drugs world}

Some suggest that women in a drug world are faced with structural constraints related to gender, and the impact of gender roles within a drugs world compared with a non-drug environment must be explored (Hunt, Joe-Laidler, \& Evans, 2002). Measham (2002) posits that women's experiences in drug cultures emulate facets of women's position in wider society. Furthermore, women's experiences of accessing, knowledge of, using, and help for problematic drug use are all interwoven with latent and more apparent gendered processes (Ettorre, 2007). Processes within this realm could include maintaining the domestic space, acquiring goods, supporting partner's drug use and participation in the drug economy (Ettorre, 2007, pp. 57-58). Measham (2002) further argues that institutionalised sexism is the most influential factor in women's experiences in a drug world. Hunt et al.'s (2002) research argues that gendered norms 
and practices transfer across to a drug and "gang" world where drug use is also gendered, including quantity of use, the type of drugs and how drugs are consumed. Despite the recognition in literature that women are a significant proportion of PWID, there is a paucity of specific research around the experiences of WWID. While it is acknowledged that gender constructs contribute to women's experiences of drugs, explanations of gendered practices remain scarce. As Taylor (1993) emphasises in her ethnographical research, and this is still the case 22 years later, there is scant sociological research around WWID.

How women "do gender" in the context of drugs and how they are perceived has not remained static. Men's and women's own drug experiences are contextualised in a gendered manner (Ettorre, 1992). Research has revealed that users of psychotropic drugs reported that women in one study revealed their drug use was for 'nerves' whereas men's was for 'stress' (Ettorre, 2007). Drug problems for women appear to be attributed to their private, emotional or relational lives, while men's problematic use is linked to their employment (Ettorre, 2004). The majority of research around WWID is based in North America, Western Europe and Australia, however countries such as those in Eastern Europe and Asia are increasingly undertaking research in this field (Pinkham et al., 2012b). The research that does exist suggests that WWID face some unique barriers, such as relationship factors, reproductive health and custody issues, compared with men in accessing primary health services and treatment for drug problems (Pinkham et al., 2012b).

Women also have different experiences of injecting drugs to men as a result of a mix of biological and social factors (Pinkham et al., 2012a). Some examples of risks that women experience different to men are: higher mortality rates, higher levels of risky-injecting and faster progression from first drug use to problematic use (Pinkham et al., 2012a, p. 1). It is suggested that difficulties in access to harm reduction services and safer drug use for women, can be due to heterosexual relationship factors (Pinkham et al., 2012a). The scant research 
around this suggests this is largely due to the gendered division of labour in a relationship (Roberts, Mathers, \& Degenhardt, 2010). This division may include being in subordinated positions and having more difficulty negotiating safer sex and safer drug practices (Roberts et al., 2010). While gender informs the needs and expectations of users accessing health care services, gender is rarely acknowledged in the design or evaluation of services (VANDU Women CARE Team, 2009). As Ettorre (2004) argues, in order to be effective, services must be designed and implemented in a gender-sensitive manner. The lack of acknowledgement of gender in research around injecting drugs can be partly attributed to the nexus of stigma, gender and injecting drug use.

\section{Stigma, gender and drug use}

Despite a distinct lack of discussion around harm within the drug and harm reduction literature, stigma is a pervasive and damaging presence in the lives of many women who inject drugs. The term stigma refers to an attribute or status that denotes a person as less acceptable by others and society (Lloyd, 2010). While the word originates from branding slaves in ancient Greece (Lloyd, 2010), evidence suggests that groups and individuals have been stigmatised throughout history. This is largely believed to be linked to the perception that some individuals or behaviours are not conducive to the health, survival and continuity of the group (Australian Injecting and Illicit Drug Users League, (AIVL), 2011). Unwritten laws determined which people and behaviours were acceptable with those that violated society's regulations being stigmatised (AIVL, 2011). Stigma is not static. Cultural beliefs and practices, time, and values influence how stigma changes over time (Lloyd, 2010). People who use drugs are the subject of stigma at a pervasive level, and people who inject drugs are stigmatised more so (Lloyd, 2010). Although the ubiquitous stigmatisation of and discrimination against humans under the premise of survival has occurred historically, it does not mean that contemporary forms of stigma, particularly of PWID, are morally just or even functional (AIVL, 2011). 
Defining stigma is complex, problematic and various definitions exist in the literature (Lloyd, 2010). Stigma is also discussed in a range of contexts across multiple academic disciplines and theoretical approaches are diverse (Link \& Phelan, 2001). Often definitions within the literature are oversimplified and refer to stigma simply as the 'marking' of someone (Link \& Phelan, 2001). Goffman's (1963) seminal work that focuses on stigma is frequently cited in contemporary literature with discussions around definitions of stigma (Link \& Phelan, 2001). Goffman posited that stigma can be categorised into three different types: a physical deformity, perceived defects of an individual's character and a link with an individual's group such as their ethnicity, religion or nationality (Lloyd, 2010). The second type, character defects, refer to attributes such as dishonesty, weakness, or dangerousness which can be affiliated with people who have been in prison, have had mental health problems or are known to use drugs (Lloyd, 2010). While stigma has occurred throughout human history, its relevance towards injecting drug users is more recent. Some argue that contemporary stigma towards drug users can be linked to the industrial revolution and was influenced by the disciplinary powers described by Foucault during the $19^{\text {th }}$ century (AIVL, 2011).

Stigma can be explained in relation to the way it is experienced at the self, social or structural level (Livingston, Milne, Fang, \& Amari, 2012). Self-stigma is when individuals go through a subjective process represented by negative self-perceptions, or self-identifying with unfavourable stereotypes as a result of the individual's experiences or expected negative social reactions and interactions (Livingston et al., 2012). For example, the pejorative term "junkie" has been constructed to refer to people who inject drugs and is closely associated with criminal activity. Self-stigma is demonstrated where PWID leave drug treatment initiatives prematurely as a means of avoiding being cemented with the label of "junkie" (Radcliffe \& Stevens, 2008). Social stigma is the process of large social groups upholding and perpetuating stereotypes and devaluing, excluding and acting against stigmatised groups, such as PWID (Livingston et al., 
2012). Structural stigma describes the rules, policies and procedures of political and institutional organisations that block the rights and opportunities of those that are stigmatised (Livingston et al., 2012).

Furthermore, with the professionalisation of the medical industry, doctors and pharmacists can strongly influence what issues of public health concern are discussed and how they should be governed (AIVL, 2011). In the early twentieth century, this resulted in a restriction of opium trades where opiates previously had been publicly available. The former drug controls that had been in place in the nineteenth century had reflected the view that drug use is an individual choice. With the new institutions and controls over opium, drug use began to be viewed as a disease, and an activity that required medical and legal regulation (AIVL, 2011).

Cohen's (1972) notion of moral panics is relevant to the perpetuation of stigma against those who use drugs. Moral panics refer to a misrepresentation of groups and falsification of evidence published by the media (Cohen, 1972). Stigma is argued to be greater when people are considered to be responsible for their own circumstances, which is a common view towards PWID (Lloyd, 2010). Media depictions perpetuate stereotypes, reinforce stigma and fear and cause a disproportionate reaction to those who use drugs. For example, the largest broadsheet newspaper in Ireland published an opinion piece that described PWID as "vermin" and "feral, worthless scumbags" (Bingham, 2012, p. 71). A joint complaint was lodged by three organisations that advocate for PWID's rights to the Press Ombudsman in Ireland regarding the prejudicial language and the inaccuracies used in the column. This was upheld citing that the opinion piece was “...likely to cause grave offence to or stir up hatred against individuals or groups addicted to drugs..." (Bingham, 2012, p. 72).

While the new 'social order' has seen women's drug using practices treated less harshly than previously, gender is still embedded in drug contexts and responses to women consuming 
drugs. While the late 1980s and early 1990s saw the unprecedented exploration of women's 'non-problematic' drug use, the focus was narrowed to specific drugs in distinct contexts (Hutton, 2006; Moore \& Measham, 2013). Despite the slight increase in acceptance of some women's drug use, such as in dance-club cultures, other drug use remains stigmatised and marginalised (Measham, 2002). Injecting drug use is not part of this new 'social order' therefore people who inject are still stigmatised and the discrimination against PWID resulting from stigma is harmful. Significant research undertaken in 2009 examined thoughts and perceptions of PWID and found that people who inject consistently feel marginalised and misjudged (AIVL, 2011). General public and healthcare workers erroneously believe that negative attitudes towards PWID would discourage people from injecting, however evidence suggests the opposite is more likely (AIVL, 2011). Discrimination and stigma are prevalent and found at both institutional and individual levels, and are perpetuated through laws and public polices as well as the public, healthcare professionals (Lloyd, 2010). Due to the negative stereotypes and myths surrounding PWID, stigma can inform individuals' actions in how they treat people who inject drugs.

Although acknowledgement of stigma as a harm is lacking in the harm reduction literature, there are some salient points highlighted by researchers. Stigma harms PWID as it can prevent access to health and other social services (Lloyd, 2010). AVIL's (2011) research found that individuals in the general public hold negative and inaccurate views of PWID, and that healthcare professionals admitted to fearing PWID, believing they can be volatile and unpredictable, alongside a fear that if they facilitated access to services their professional status would be negatively impacted or they would lose other patients. Furthermore, Buchanan and Young, (2000 as cited in Lloyd, 2010), suggest that the effect of stigma causes PWID to feel anxious, excluded and results in an avoidance of contact with non-drug users, alongside the internalisation and self-blame for their circumstances. This, accompanied by a loss of self- 
esteem, becomes a barrier to accessing health and social services such as recovery services (Lloyd, 2010) and harm reduction services (AIVL, 2011).

As AIVL's (2011) research suggests, stigma affects how society interacts with the stigmatised person. Goffman (1963) concurs with this notion and also argued that stigma affects the stigmatised person as they can internalise the same beliefs and identity that society does (as cited in Lloyd, 2010). Goffman's theories allow an analysis of stigma and its transference from a symbolic issue to a social reality (AIVL, 2011). Goffman states that the stigmatised person, in this case PWID, deals with the stigma in various ways in their social interactions. If the stigma is apparent, for example if it is known that a person injects drugs, then Goffman describes the individual as 'discredited', whereas if their drug using status is not obvious, the individual is 'discreditable' (Lloyd, 2010). The 'discreditable' regularly manage information about themselves, interactions and associations to avoid revealing or disclosing about their stigma. Goffman describes this as 'passing' (Lloyd, 2010). Individuals who are stigmatised often work hard to present themselves as a 'normal' member of society (Ingram, 1999). When the stigma is already known, Goffman (1963) posits that the individual often works to draw focus away from the stigma and attempt to 'cover' their status (as cited in Ingram, 1999). Symbolic stigma also transfers to the social in what Goffman refers to as the 'Own' and the 'Wise' (Ingram, 1999), where the 'Own' is a stigmatised individual revealing their status with others who share the stigma. In doing this, a stigmatised individual can find sympathy and support from others with shared experiences. The 'Wise' refers to individuals who do not possess the stigmatising attributes, but offer support to the stigmatised individuals (Ingram, 1999). "Being known" can act as a "double-edged sword": on one hand it can enable being treated with empathy, having a sense of security and alleviating stigma, while on the other it can increase discrimination and stigma (VANDU Women CARE Team, 2009). While some research has cited health workers such as doctors and nurses as exemplifying 'wise' status 
(Ingram, 1999), it is challenged by evidence that suggests that some health workers do not possess sympathetic or non-judgemental attitudes towards all stigmatised persons (AIVL, 2011).

Drug-user stigma is not the only stigma PWID experience. Alongside a drug using status, PWID also reported other stigmatising issues from belonging to a minority ethnic group, having a BBV, mental health problems and being a woman (Lloyd, 2010). As previously mentioned, the 'double deviancy' of stigma for a WWID is attributed to a drug using status and being a woman who uses drugs (Heidensohn, 1987). The scant studies that have explored the complexities of the intersection between stigma, gender and drug use, highlight some significant factors and issues (Ettorre, 2004; Heidensohn, 1985). Women who use drugs tend to experience more stigma and are further marginalised compared to men who use drugs, access to health and social services for women is hindered, and stigma for women who use drugs has led to punitive policies that police women's bodies and result in adverse outcomes (Ettorre, 2007).

Research suggests that the stigma and marginalisation directed at, and experienced by, women who use drugs is worse than for men. This is largely attributed to the notion of violating society's expectations of femininity (Grundetjern, 2015), or 'gender failure' (Campbell, as cited in Stengel, 2014, p. 38). Most of the scant research around women who use drugs and their experiences of stigma focuses on women's bodies, pregnancy and perceptions of risk (Ettorre, 2007). Women who use drugs and are also pregnant or mothers are particularly stigmatised due to these perceptions of failing their gender (Stengel, 2014). The effects of stigma on, and notions of gender failure for WWID, will be explored further in the results chapters. 
It is argued by Link and Phelan (2001) that although definitions vary, it is important to decide clearly what stigma will be defined as for each piece of research. Stigma can be described as a collective confirmation, in the form of social exclusion, of a group of people to be regarded as the "other" or to be disassociated from what is considered the norm (AIVL, 2011). Further to this, Link and Phelan (2001) argue that definitions that ignore the notion of power and the process in which stigma is applied are reductionist. Therefore, for the purposes of this study, the notion of stigma with regards to drug use, equates to the 'othering' of those who use drugs, which encompasses a process of labelling, stereotyping, marginalisation, loss of status, and discrimination and the exercising of power over the stigmatised (Link \& Phelan, 2001, p. 363).

\section{History of Harm Reduction}

Harm reduction has been practiced throughout history. For as long as the use of psychoactive substances has been recorded, so too have harm reduction practices. In the twentieth century, before formal harm reduction policies were implemented, users practiced their own techniques to reduce risk. In his work, Young (1971) explored drug users, their practices and behaviours, and referred to the practices and skills that injecting drug users share with each other around safer injecting. Users were reported as encouraging each other to use disposable needles and sterile water for injecting (Young, 1971). This demonstrates that official implementation of harm reduction initiatives was not the first time users had engaged in harm reduction practices and have, for a long time, attempted to ensure they manage their own risks through peer knowledge and practice.

Harm reduction does not only refer to the pragmatic policies surrounding drug use, but also to the philosophy around the reduction of harms associated with consuming drugs. Previous to the introduction of the term Harm Reduction within drug policies and drug treatment, the focus of managing drug use was generally around abstinence as the only goal, rather than safer drug use. Harm reduction predominantly refers to a philosophy and framework informed by a set 
of beliefs that aim to inform policies and practices responding to drug problems and ultimately reducing potential harm from using drugs (Pates \& Riley, 2012).

Harm reduction was developed from the failure of international policy throughout the twentieth century that enforced prohibition. During the HIV epidemic in the 1980s, harm reduction gained much favour with respect to intravenous (IV) or injecting drug use (Riley et al., 2012). This is largely due to the infection rates of HIV and other BBVs contracted from apparent needle sharing. The goals of harm reduction have shifted from the 1980s through the 1990s and into the 2000s (Stimson \& O'Hare, 2010). The 1980s saw a motivation to reduce harm to the user, but by the 1990s harm reduction was directed to the harm caused by the user. This demonstrates that defining what harm is, is problematic. Harms are predominantly defined as physical or medical harms that are either at risk for the user, society or both (Stimson, 2007). Furthermore, these harms also appear to be placed into a hierarchy.

The literature asserts that harms relate principally to the increased risk of BBVs spreading via injecting drug use. However, some research does highlight social harms and attempts to address them. Stimson and Metrebian's (2003) guide to prescribing heroin specifically describes harms as individual and social. While acknowledging social harms such as legal problems, family difficulties, and employment issues associated with drug use, their research negates identifying stigma as a social harm. Addressing social harms such as stigma that drug users experience is often given lower priority in the hierarchy of harms from drug use when harm reduction is implemented. While discussing what harm reduction means in relation to IV drug use, the literature foremost refers to the reduction of physical harms.

The UNODC World Drug Report (2015) states particular harms related to drug use that can be addressed via harm reduction initiatives. The four main categories of harm are based on literature that is 36 years old, and while they recognise harm to the user and the harms are 
covered widely: from physical health harms such as liver problems, to social problems linked with relationships to legal problems as a result of the drug's illegality, stigma remains absent. Furthermore, the UNODC report (2015) focuses on physical harms such as exposure or increased risk to BBVs throughout.

As Bean (2010) states, the understanding of what "harm" is, varies extensively. Harms, within a drug context, refer to the adverse effects from injecting illicit drugs, although the physical harms tend to be disproportionately highlighted in the literature compared to social harms. Moreover, aims and evaluations of harm reduction focus on physical harms, such as a reduction of BBV infection rates amongst injecting drug users and the wider non-drug using community. Despite this, the needs and priority of preventing the spread of BBVs is often more concerned with non-drug users' physical health than the health of PWID.

Within discourses around harm reduction, the term itself has different meanings. While the terms 'harm reduction' and 'harm minimisation' are often used interchangeably, they are in fact, different concepts. Harm Minimisation is the collective term that encompasses harm reduction, demand reduction and supply reduction (Measham, 2006, p. 1). Demand reduction seeks to motivate users to lower their use with interventions such as increasing the price of a substance, whereas supply reduction concentrates on curtailing the availability of a substance. Harm reduction can be more specifically defined as a philosophy with the aim of reducing potential harms to individuals and society from the use of drugs (Measham, 2006). It is also a belief system that is based on empirical evidence and oriented towards improving the lives of those people who use illicit drugs (Witkiewitz \& Marlatt, 2006). Although debated, the definition also excludes abstinence programmes or policies. According to Stockwell (2006), although abstinence oriented approaches are often argued to be acceptable within a harm reduction framework, including abstinence can 'grey' the meaning of harm reduction. Stockwell (2006) maintains that a salient feature of harm reduction is that it does not 
necessarily reduce drug use. While noting that it is not particularly feasible, the International Harm Reduction Association (2010) state that not only is abstinence an appropriate and acceptable outcome but a desirable one. Others agree with the inclusion of abstinence in harm reduction (Beirness, Jesseman, Notarandrea, \& Perron, 2008). However, those that argue that abstinence can be a part of harm reduction also acknowledge the friction with abstinence in a harm reduction approach (Riley et al., 2012).

Harm reduction in the literature is divided into two main pillars (Pinkham et al., 2012b). The first, which is directed by a pragmatic, public health approach to reduce specific harms associated with illegal drugs, includes evidence-based policies and aims for attainable objectives (Stimson, 2007). Although it is often argued that harm reduction is amoral, the second main pillar demonstrates that there is an ethical and moral basis; human rights are grounded in harm reduction (Stimson, 2007). The second pillar is directed by an advocacy for human rights, which includes the rights of people who use drugs, to life and protection, health and medical services and safety from harms in the community or governing organisations (Stimson, 2007, p. 68). Stafford (2007) argues that stigma and discrimination are key concerns within harm reduction. Stimson (2007) further contends that both pillars share notions of being facilitative, encouraging, supportive, and exclude punishment and judgement in harm reduction initiatives. Harm reduction philosophy has a direct relationship with stigma and attempts to reduce or mitigate it. The International Harm Reduction Association states that those who practise harm reduction disapprove of stigmatisation that is purposefully directed towards people who use drugs (Hunt, 2012). Stigmatising labels for PWID such as "a scourge", “junkies" or "drug abusers" further propagate stereotypes and marginalise people, preventing them from accessing services (Lloyd, 2010).

Harm Reduction International (IHRA), a large non-governmental organisation that promotes and expands support for harm reduction of drug use, defines harm reduction as: 
...policies, programmes and practices that aim primarily to reduce the adverse health, social and economic consequences of the use of legal and illegal psychoactive drugs without necessarily reducing drug consumption. HR benefits people who use drugs, their families and the community. (International Harm Reduction Association, 2010, p. 1)

The main aim of harm reduction is not to reduce drug consumption but to reduce harms related to the use of drugs. For the purposes of this study, the term harm reduction will be used, and while acknowledging the definition varies, the use of this term throughout this thesis will be based around the International Harm Reduction Association (2010) definition discussed previously, and does not include abstinence.

\section{New Zealand and Harm Reduction}

New Zealand's harm reduction policies and practices sit mainly within the first main pillar of harm reduction (Pinkham et al., 2012b), as described earlier, grounded in a pragmatic, public health approach rather than an approach connected with advocacy or human rights.

The New Zealand National Drug Policy 2015-2020 includes an overarching aim of the prevention and reduction of health, social and economic harms related to tobacco, alcohol and other drug use (Inter-Agency Committee on Drugs, 2015; Ministry of Health, 2010). The current National Drug policy has carried over from previous policies regarding its inclusion of harm reduction or "problem limitation" (p. 5) in only one of its three main pillars of "harm minimisation', with the two other groups focusing on supply, control and demand reduction (Inter-Agency Committee on Drugs, 2015). These latter two groups are linked with abstinencebased aims, and as previously discussed, it is complex and problematic, to include harm reduction practices within an abstinence framework. The harm reduction pillar in the national drug policy is broad and despite acknowledging inequalities in healthcare and other socioeconomic factors that relate to drug use for some groups (Inter-Agency Committee on Drugs, 2015), very little is included to specifically address gender or other structural factors 
that may add to issues for drug-related harm, such as ethnicity, disabilities and poverty. These factors contribute to gaps in harm reduction programmes (VANDU Women CARE Team, 2009).

While the literature purports that harm reduction policies and programmes operate in a variety of cultural, social and religious settings (Stimson \& O'Hare, 2010), programmes addressing women's specific needs are often still neglected or ignored. It is noted that harm reduction policies should include tailor-made practices addressing factors that are associated with increased vulnerabilities such as gender, age, or incarceration (International Harm Reduction Association, 2010). As of 2010 there were 93 countries that included harm reduction policies in their drug frameworks (Russell \& McVeigh, 2011), however few included gender specific programmes. As Brown, Luna, Ramirez, Vail, and Williams (2005) state, the importance of including those who will be utilising the programmes, in the planning, running and evaluation of services, is vital. This consultation continues to be largely absent and this is evidenced by the meagre number of women specific programmes currently. Despite this, there has been recognition by some harm reduction groups, such as Harm Reduction International, that there are increasing numbers of women negatively affected by harsh drug policies alongside their exclusion from social and health programmes and services due to a drug using status (Harm Reduction International, 2014). Harm Reduction International (2014) advocate for increased awareness of women's issues within drug harm reduction, accompanied by positive change in policies and practice.

Ettorre (2004), argues that while harm reduction is a commendable undertaking, in order for it to contribute positively to women, a gendered or women sensitive harm reduction approach needs to exist more explicitly than it currently does. Unfortunately, due to the legacy of masculinised research around drug use, scant knowledge exists around how gender processes 
influence and affect women that use drugs (Ettorre, 2004). Despite the post-modern ${ }^{8}$ approach to harm reduction emphasising an inclusion of human rights in its approach, Ettorre (2004) posits that human rights are also gendered and are therefore masculinised and "maleprivileged". Furthermore she argues that the post-modern approach needs to maintain acknowledgement of gender as an issue and those that are marginalised need to be heard. Chapter three moves on to discuss the methodological framework for this thesis.

\footnotetext{
${ }^{8}$ A post-modern framework refers to the acknowledgement of structural barriers, collaboration with PWID and a rejection of the individualised disease approach to understanding drug use (Ettorre, 2007).
} 


\section{Chapter Three: Methodological}

\section{Framework}

This research sought data about women's experiences, in their own voices, around injecting drugs and accessing harm reduction services. This thesis aims to privilege the voices of women who have injected drugs and to focus on their narratives around gendered experiences of drug use and needle exchange access. I considered a qualitative methods design within a feminist framework as the most appropriate approach for the research. This chapter details the underlying methodological and theoretical framework that supported and guided this research.

\section{Philosophical Underpinnings}

\section{Feminist perspectives}

While the overall aim of this research was to examine the existence of gendered factors that WWID experience while accessing needle exchange services, a crucial aim was also to provide a platform to privilege women's voices and accounts. Through this, I hoped to create a space where the women could have a sense of empowerment and that their experiences through their own words were validated in contributing to understanding gendered experiences. It is pertinent within feminist research for participants to have their voices heard, enabling an emphasis on personhood (Sprague, 2005), and hearing participants' lived experiences. As conventional, masculinised accounts of women's drug use and experiences have failed to recognise gendered power structures in society (Ettorre, 1992), feminist perspectives seek to address this and examine how women navigate their lives within a drug context (Ettorre, 2007). With regards to research within a drug context, as asserted by Ettorre (2007), feminist perspectives can seek to explore, understand and respond to the complex ways gender is 
embodied and intersects with drug use.

The legacy of a masculine focus has persisted through research examining women's drug use and experiences (Ettorre, 2007). Despite this, in recent decades, feminist research has gained an increasing recognition with acknowledging how complex and diverse women's experiences with drugs are (Olszewski, Giraudon, Hedrich, \& Montanari, 2009). Feminist research can improve understanding of issues that affect women who use drugs (Anderson, 2008). Within feminist research, gender and other socially constructed categories are recognised as material in people's experiences. Nonetheless, studies under a post-modern framework, particularly those involving women, persist to exclude those who use drugs (Ettorre, 2004). A feminist framework addresses this issue as it acknowledges, appreciates, and privileges the voices and experiences of women who use drugs themselves (Ettorre, 2004).

Due to the stigmatising factors of being a person who uses drugs and a woman who uses drugs, it is important to recognise that WWID are a sensitive population. As feminist methodologies aim to benefit women, addressing the needs of sensitive, stigmatised and marginalised populations within the research is crucial. One of the main aims of feminist research is to inflict no harm on participants (Liamputtong, 2007). Furthermore, in researching people from sensitive populations, it is necessary to protect participants from physical and psychological harm (McCosker, Barnard, \& Gerber, 2001). In this research I endeavoured to maintain a supportive environment where participants were free to share, or not share, certain aspects of their experiences. Semi-structured interviews facilitated the minimisation of harm as they provided flexibility for participants to introduce and discuss additional issues or conversely, decline to share experiences and thoughts they did not wish to (Sutton, 2011). It was important to avoid harm within the research, not solely for the participants, but for the wider population 
that the participants may represent (Sprague, 2005).

Although this small qualitative sample cannot claim to be representative of all WWID, it was important that the research reported their experiences truthfully whilst maintaining confidentiality. A main aim was also to ensure that the results and analysis provided positive ways forward for needle exchange and other services for WWID. The subsequent sections in this chapter will expand on the background of feminist methodologies and the justification for the use of this standpoint in this research.

\section{Methods}

The methods undertaken for this research study aimed to explore the experiences of women who currently or formerly injected drugs (WWID). In addition, key workers who have worked closely with WWID in various ways, such as in counselling, needle exchange services or methadone programmes were interviewed in order to gain some insight into the implementation of harm reductions services with respect to WWID.

The primary method to collect this detailed data was via semi-structured interviews. This is often considered the most advantageous way to collect descriptive and subjective information associated with marginalised groups such as WWID (McCosker et al., 2001). Two interview guides (see Appendices $\mathrm{E}$ and $\mathrm{H}$ ) were compiled, one for women who were currently, or had ever, injected drugs, and one for key workers. Both guides included questions to assist in prompting and encouraging key points related to the research. The questions did not restrict dialogue during any interviews and were there to provide guidance. This was to ensure the basic areas that research questions related to were covered in all interviews and to explore key

themes. Additionally the incorporation of an interview guide also provided validity and 
focused on the main research aims (Hesse-Biber, 2007). Research methods, such as semistructured interviews, that facilitate insightful qualitative data have been recognised as allowing drug use to be viewed with a non-judgemental, less stigmatising lens and importantly, within the social and cultural contexts that people live and where drug use occurs (Taylor, 1998).

Qualitative research methodologies are not only important from a feminist perspective, but they allow WWID to express in their own words, how the significance of drug use and associated experiences, have affected their own lives (Taylor, 1998). Rich detail from women's own voices can contribute to a wider understanding of WWID and their lives and as Taylor (1998) found in her ground-breaking research, challenge negative stereotypes of WWID as 'polluted' or deviant. Orthodox methods, as Sprague (2005) posits, usually objectify participants through language and methods. These methods treat people as though they have no agency, and are not capable of navigating and evaluating their own situations and this is particularly common for marginalised populations (Sprague, 2005). In contrast, in feminist research, it is vital to note the social location and standpoint of the researcher (Stoetzler \& Yuval-Davis, 2002). Sprague (2005) argues that this provides vital information about the researcher's role in relation to the research participants. In this research, I disclosed to participants that I had had no direct experience with injecting drug use. Disclosing this detail, alongside my education, background and other personal details presented the truth about me. It is acknowledged that research with fieldwork presents situations containing power imbalances between the researcher and participant (Harding \& Norberg, 2005). Sharing details about the interviewer aims to create more reciprocity between interviewer and participant (Dickson-Swift, James, Kippen, \& Liamputtong, 2007). It is important to acknowledge, particularly within a feminist framework, the power imbalance in the context of research. In addition to the asymmetrical power 
relationship between researcher and participant in fieldwork, the research process itself presents power differences (Harding \& Norberg, 2005). The researcher holds more power due to their position of being able to select the theories, methods and methodologies through which the research is conducted (Harding \& Norberg, 2005). Due to this, it is pertinent with research examining experiences of silenced populations that the methodologies and methods are chosen to privilege participants' voices and experiences.

Undertaking research that includes face-to-face interviews and explores topics of a sensitive nature requires distinct preparation (Dickson-Swift et al., 2007). It is crucial that reflexivity is practised throughout the research (Hesse-Biber, 2007). Reflexivity is essential in ensuring the researcher is conscious of their and the participant's position (Brooks \& Hesse-Biber, 2007b). Incorporating reflexivity also enables practices where a participant's emotional well-being is respected. Specific techniques in interviews discussing emotional topics can include allowing sufficient time for the participant to express their emotions as well as the acknowledgement of the importance of the participant's well-being (McCosker et al., 2001). This was something I was academically aware of before interviewing, and I was able to experience it directly during moments where participants shared emotional or painful life events. As an interviewer using a feminist methodology I needed to show empathy and ensure the participant's feelings were validated rather than only focus on obtaining "good" data. Although some argue that the researcher being aware of distress cues from participants can distract from the data (Morse \& Field, 1985 as cited in McCosker et al., 2001) it can also be argued that this enhances the depth of the data (Wilde, 1992 as cited in McCosker et al., 2001).

\section{Recruitment}

Gaining access to participants was one of the most challenging elements of this research. As 
discussed previously, WWID are a sensitive and hidden population. Research involving people who use drugs involves various barriers in recruiting participants (Griffiths, Gossop, Powis, \& Strang, 1993), and accessing hard-to-reach people is challenging and problematic (Liamputtong, 2007). Recruitment is difficult as there can be an element of distrust of researchers from people who are marginalised, combined with the effects of stigma and the desire to keep current or past drug use undisclosed (Liamputtong, 2007). Gate-keeper agencies are often utilised in the access to marginalised populations and while some agencies may act to prevent access (Liamputtong, 2007), the stand-alone Needle Exchange ${ }^{9}$ approached for my research was enthusiastic in their assistance to recruit participants.

Initial informal contact was made with a stand-alone Needle Exchange to ascertain reaction to this research and whether any assistance could be offered in participant recruitment. The idea of the research was warmly met. Once the research proposal was accepted and ethics approval was granted, recruitment leaflets were provided to the stand-alone needle exchange, which they displayed in their reception area for potential participants to take if they wished. A larger poster was also displayed on one of the walls in the entrance. All recruitment posters and flyers included details of how WWID could contact me if interested in participating in the research. An official university email address was provided and a contact cell phone number. The cell phone number was not my personal phone number, but belonged to a sim card specifically bought for the research. This was to ensure confidentiality for participants as well as satisfying the Human Ethics Committee requirements about researcher safety and confidentiality. The recruitment posters supplied to the standalone Needle Exchanges also included an invite to potential participants to meet me in a nearby local cafe, at a specific hour each week if they wished. The justification for this was to mitigate any issues of potential participants having

\footnotetext{
9 A stand-alone Needle Exchange outlet is peer-run, and offers a complete range of sterile injecting equipment, with a reduced price or free equipment. Currently there are 21 stand alone and one mobile exchanges in New Zealand.(http://www.needle.co.nz/outlet_types.html/8)
} 
concerns about confidentiality if the Needle Exchange observed them picking up leaflets. As the participants were potentially going to be sharing their experiences of Needle Exchange services, it was important to preserve their anonymity from staff and other clients within the Needle Exchange. Four cafe sessions were set up and I found a quiet table for the hour, however this recruitment approach failed to present any participants. The reasons for this are unknown. There was only one known potential participant who sent a text message saying she had seen the poster in the needle exchange and was eager to meet and speak with me, but was reluctant to come as the cafe was too close to her work location. It was therefore arranged to meet at another location and time. Even though another meeting point was arranged, the participant was unable to meet me and recruitment was unsuccessful.

Recruiting via peer-leaders, such as staff from the stand-alone Needle Exchange can improve access as they are often considered trusted members of the marginalised group. However, accessing participants via the service that they may be sharing their experiences and assessments of, potentially limited the recruitment and it was necessary to widen the search for participants. It is commonplace in researching vulnerable people that a combination of methods is undertaken to gain access to hidden populations (Liamputtong, 2007). This can involve numerous approaches such as placing flyers or posters in community locations, contacting agencies, libraries or utilising personal contacts (Weaver et al., 2005 as cited in Liamputtong, 2007). Posters were also placed around a large educational organisation, on various student notice boards, where other research recruitment posters are often placed, as well as in women's bathrooms. One participant was recruited via this method.

After a period of three weeks, an amendment to the Ethics Approval was sought in order to place the recruitment poster on its own Facebook page. This was to try to attract more potential 
participants from my personal contacts. The link to the page could be 'shared' 10 with other people. Confidentiality was assured as the page was locked from editing so nothing could be posted to it. I asked each participant when I was interviewing them where they saw my posters so I could gain some idea about which recruitment methods were more successful than others. One participant was recruited through this method.

A man who injected drugs (MWID) had also seen the Facebook page and contacted me to recommend that I go to a local women's only Narcotics Anonymous (NA) meeting. I did this and took several recruitment flyers to pass out to potential participants. I was aware that I was not a member of NA and did not want to encroach on the women's space in this meeting. So I approached the person running the meeting before it began to explain who I was and what my research was about. I was acutely aware that the meeting was their space and their time, however I iterated that there was no pressure whatsoever for anyone to take flyers or contact me about my research. Both myself and my flyers were warmly received and I was invited to take part in the meeting that night, though this was only with the full agreement of the small group of women who attended. Agreement was given although the women were asked with me present, and I was aware that this may have presented difficulties for some to voice a negative confirmation about me attending the meeting. The women then asked me to join them. As the meeting started I sat listening as I did not want to interfere in their meeting, however the women all expected me to participate at times. I appreciate this was a generous offering on their part and while I participated where possible, I found it challenging due to my lack of personal experience of drug use. One participant was recruited through this meeting.

A senior member of a drug counselling and treatment organisation, whom I met at a harm

\footnotetext{
10 'Sharing' on Facebook refers to the act of providing or sending a link via private message or on a Facebook timelines. The link can be for varied information such as, photos, websites, and other Facebook pages.
} 
reduction presentation, offered to aid recruitment by placing leaflets in the organisation's reception area. Two participants were recruited in this manner. Flyers were also placed in reception areas in women-friendly harm reduction and health services such as the New Zealand Prostitutes Collective (NZPC) and a national women's health organisation. Initially, there was hesitation to approach the NZPC to request if they would accommodate flyers due to a desire to avoid the perpetuation of stereotypes around WWID and sex workers. Nevertheless, after contacting management at the NZPC and meeting in their office, they were very supportive of the research and agreed to place flyers in their reception area. A national women's health organisation was approached and once they were satisfied the research had Human Ethics approval they were keen to support me and agreed to have a number of flyers in their reception and a poster on the waiting room wall.

There were some locations, however, that were less supportive of assisting with recruitment. For example, at a community pharmacy, while supportive of the research topic, the head pharmacist was reluctant to place flyers in an open space. Reasons cited for this were wanting to maintain confidentiality and comfort of clients on the methadone programme who regularly accessed the pharmacy. A suburban medical centre that had various community notices in their foyer and waiting room was also approached to request if flyers could be placed alongside other flyers and notices. I approached reception staff, introduced myself and showed them my flyers and with a polite and friendly manner asked if I could place my flyers with the other community notices. The staff member responded politely back that "...they would not want to be seen to be encouraging that sort of thing". I pleasantly thanked her for her time and left, feeling like I had just peripherally experienced some of the stigma attached to injecting drug use. As discussed above, there are numerous difficulties in accessing people from a hidden population. Additionally, the recruitment period took place over the traditional holiday period in summer 
and Christmas and this may have impacted on recruiting participants.

Recruiting key workers was less complex. This could be largely due to less stigma attached to key workers as they are not part of the hidden population that WWID belong to. Five key workers were recruited from four different organisations that provided services to PWID. Three key workers from two stand-alone needle exchanges and one counsellor from a drug counselling service were recruited. In addition one pharmacist whose services had formerly included a needle exchange, and currently provided methadone as part of an opioid substitution treatment programme, agreed to be interviewed.

\section{Interviews}

As discussed earlier, the primary data for this research has come from transcripts of semistructured interviews undertaken with WWID and key workers who have worked with WWID. Interviewing is often used in qualitative research for data collection as it is advantageous for gaining insight into people's constructions of reality, their own explanations, understandings and perceptions (Punch, 2005). A set of general questions acted as a guide, although questions were open ended and encouraged the sharing of rich detail from participants. The interviews were also reconstructed in a feminist manner while traditional interviewing techniques that emphasise traits such as detachment and being objective were avoided. Feminist interviewing, particularly with sensitive subject matters, requires emotional connections and understanding alongside trust by the participants in the interviewer (Punch, 2005). In order to achieve this, according to Punch (2005), status differences should be minimised. I attempted this by exchanging texts, phone calls and in some cases emails before meeting with participants before each interview. Additionally, before the commencement of each interview I introduced myself, the topic and also showed interest in the participants as individuals by conversing about the local area and asking them about topics other than drug use. The five interviews with WWID 
were all approximately one hour in length. Two interviews were undertaken in closed meeting rooms accessible to the public in a university and a public library, two were in public cafes and one was via Skype ${ }^{11}$. All key informant interviews followed a similar question structure and the length of the interview depended on the extent of the answers and details shared by participants.

\section{First interview 'Jordan'}

The first participant interviewed had seen a flyer on one of the public notice boards I had used. I was a little nervous as this was my first participant interview. However, the location of the interview was a familiar place to both myself and the participant. 'Jordan' was a transgendered man and this caught me unawares. Although I had considered the chance of a person of transgender responding to my flyers I had not considered that it would be very likely. In the initial stages of the research planning, I had decided I did not want to exclude any non-cisgendered people. The inclusion of participants who are trans-gender is supported by Butler's point (as cited in Cattapan, 2008, p. 5) that gender is not a binary concept. 'Jordan' stated he was biologically female, although he had long identified as a man, but throughout life he has been referred to and treated as a woman in many circumstances including drug contexts. 'Jordan' was aged between 26 years and 31 years old and from a rural region in New Zealand. I did not seek to confirm the exact age of any of the participants as I was not focusing on age nor did I want to detract from the participants' storytelling by asking them to confirm statistical data. 'Jordan' estimated that his injecting use lasted for ten to twelve years in duration and he attributed curiosity as the main reason for first injecting drugs. 'Jordan's previous injecting use of mainly morphine sulphate, had altered in frequency over the last twelve years, from injecting at weekends initially to shifting to daily. 'Jordan' could not remember how long his

\footnotetext{
${ }^{11}$ Skype is a computer application that allows voice and video calls over the internet. Skype was used in this research to enable a voice call to a landline to be digitally recorded.
} 
daily injecting was for, but estimated ten years. 'Jordan' had not injected in the last eight months and although he did not cite a reason for ceasing to inject, he expressed that it was around the time of enrolling at University.

While it was an advantage that the interview location was a familiar place to both myself and the participant, I was also aware of a risk that we may see someone that knew one of us. I discussed this with 'Jordan' and we quickly agreed on an alternative reason, that we were talking about the skills taught in a workshop where we had met, if required. This was largely to maintain the confidentiality of my participant. The interview went well and I felt rapport was established quickly. 'Jordan' seemed forthcoming with his thoughts and stories. The participant stated that although he had identified as being male from a very early age, many of his peers, family, friends and wider society had identified him as female. Experiencing this seemed to have given 'Jordan' an ability to be more acutely aware of how gendered experiences could be. I listened to the recording of the interview the following day so I could identify areas for improvements in my interview technique such as where I seemed to talk out of fear of silence rather than allowing the participant more time to speak.

\section{Second interview 'Clara'}

'Clara' identified as a Māori woman and was aged in her mid to late forties. She was a mother to several children. She first injected drugs at the age of 16. After initially injecting heroin six or seven times in her teen years, she did not inject again for several years. 'Clara' recalled the main reason for not wanting to inject more in her teens as predominantly financial as she knew she did not have the funds to support regular use. Approximately seven years previous to the interview she began injecting morphine sulphate and sometimes methadone on a daily basis. 'Clara' was not currently injecting drugs and had been on an $\mathrm{OST}^{12}$ programme for

\footnotetext{
12 Opioid Substitution Treatment
} 
approximately six years where she had injected at intermittent periods during her time on the programme.

'Clara' had seen my flyer in the drug counselling reception area and contacted me keen to participate. I attempted to locate a meeting room in a public library or similar, however the service was unavailable. I had to travel to a nearby town for the interview. I was unfamiliar with this town so I had to rely on the participant to confirm that she felt secure enough having our discussion in a cafe in the town centre. As it was a small town, there was a risk my participant might know people coming into the cafe. I discussed this with 'Clara' and we chose a table near the back of the cafe. 'Clara' stated that she was fine if someone she knew saw us. I also suggested that if anyone came near our table we could change the topic of conversation to something trivial such as a soap opera on television or similar. The participant said that she was comfortable and would do that if she felt the need to. The interview went relatively well, however at times it felt like the participant may have felt pressured to provide answers to please me and appeared frustrated with herself when she did not understand my questions. The realisation of this alerted me to be flexible in how I presented the questions and be prepared to ask them in a different, perhaps more easily understood manner, as well as being prepared to reassure participants that I was not looking for any particular answers, rather their own experiences and words. This interview resulted in a crucial shift in the development of my interview skills. Some of the interview questions revolved around perceptions of being judged due to gender norms, however this participant's experiences were affected by gender and ethnicity factors and these could not be disaggregated into separate parts of her identity. This was something I had been academically aware of, but during the process of writing the interview questions and performing the interview, my focus had become overly narrowed and 
I was challenged in appreciating the multi-factored elements of this participant's experiences. I learned, in a practical sense, from this interview the importance of not becoming too narrowly focused on my topic.

\section{Third interview 'Cassie'}

'Cassie' saw my flyer referred to in an online blog and emailed me to enquire about participating in the research. 'Cassie' was in her late thirties. She grew up in an urban setting and had moved away at the age of 18 where she embarked on what she described as part of her “...adventuring..." around parts of New Zealand. She had first injected drugs when she was 18 years old. Her use was sporadic for approximately a year to eighteen months, and she described the main reason for this as being "...scared of becoming addicted to it...". From about the age of 20 'Cassie' injected morphine and other opiates on a regular basis until she was about 24 years old when she said her family staged an intervention and she attended a detox and drug counselling programme. 'Cassie' has not injected drugs since this time. As she had a small child at home, meeting me for an interview was difficult. Furthermore, as I was bound by the University's Ethics Approval, I was unable to meet her in her home, so we arranged to do an interview over Skype. In order to do this I had to create a Skype account and test how I could call and record an interview on a laptop effectively. I performed the interview from a room in my house where I could be sure I would have no interruptions and sound would not go through the walls. Although there was a slight time delay over Skype which at times affected the flow of the interview, the interview went well considering we could not see each other. It only took a few minutes into the interview to adjust to the slight delay. Additionally, I felt that good rapport was developed relatively quickly with this participant and it felt that she was at ease with me. However, 'Cassie' did have some concerns about her memory, or lack of, regarding some details around her drug use. Although as the interview got underway there appeared to be no issue with recalling experiences and feelings from many years earlier. The 
general impression gained throughout the interview was that 'Cassie' looked back upon her drug use with mixed feelings, some of affection and some of acknowledgement where times had been difficult. Throughout the interview, there was a great sense of agency expressed by the participant, particularly in where 'Cassie' describes her decisions around her drug use.

\section{Fourth interview 'Lucy'}

'Lucy' was in her mid-twenties. She first injected drugs, such as Ritalin and opioids, in her early twenties and her injecting use became regular soon after. 'Lucy' expressed that as she did not initially prepare the drugs she was not always aware of what particular substance was being injected. She injected drugs for approximately one year and stated that she stopped because she wanted to, her use had become too much and she was worried about potential harm she could cause herself. She told her mother about her use and a desire to stop injecting and then attended drug counselling sessions.

'Lucy' was recruited via attending a Narcotics Anonymous women's only meeting. We arranged via text messages to meet in a location where rooms could be hired for business meetings or similar. The participant had no problems answering any of the questions or sharing her experiences and talked about most topics freely. 'Lucy' fidgeted with a plastic drink bottle throughout the interview and while I was aware that the noise might potentially impact on the transcribing process, I was also mindful that ' $L u c y$ ' may have been a bit nervous talking about certain topics and her fidgeting could have been a result of this. Rapport and openness in semistructured interviews of a sensitive nature are crucial, and I was aware that this could create subconscious elements and expectations of friendships (Dickson-Swift et al., 2007). This was experienced at the end of the interview when 'Lucy' hugged me goodbye. I felt that I should reciprocate, and even though we were strangers, it did not seem inappropriate and I appreciated that she had shared a lot of intimate thoughts and experiences with me. 


\section{Fifth interview 'Nina'}

'Nina' was a mother, aged in her late twenties and had moved to New Zealand from Western Europe with her family when she was a toddler. She first injected morphine in her mid-teens and was placed on a methadone programme when she was 19 years old and pregnant with her first child. 'Nina' was on a methadone programme and had injected drugs regularly at different times over the previous decade. 'Nina' cited that her injecting ceased at about the same time that she got out of an abusive relationship with the support of her family. She also spoke about the difficulties of ceasing to inject while her self-worth was low.

'Nina' was recruited via the same method as 'Clara', a flyer in the reception of a drug counselling service. 'Nina' was happy for me to choose the location for the interview and as the cafe I had used for 'Clara's' interview had been suitable, we arranged to meet there. When we met for the interview I discussed where 'Nina' wanted to sit and if she felt uncomfortable being overheard at any point we could change the subject if she wished. The interview went well. 'Nina' was talkative and at times I had to remind myself to keep on subject while also allowing space for her to share her stories. 'Nina' spoke a lot about her three children and I felt that it was important to her to share stories about them. Some of her stories were about difficult times with her pregnancies and treatment by health staff, however there were other moments where she spoke of the joy of motherhood and how important those moments were to her. Additionally, I felt that 'Nina' could not show enough gratitude for the snack and coffee I had bought for her while the interview took place, as I had for all the other participants. She remarked that it was not often she had a treat. This was further reinforced when I gave her the 
koha ${ }^{13}$ of a $\$ 30$ supermarket voucher and I got the impression that the voucher was really appreciated and would make a great difference in her shopping that week.

\section{Prospective Participants that were not interviewed}

During the recruitment process, several participants contacted me that either, were not eligible for participation or were unable to meet me. As previously mentioned, a woman had contacted me but had preferred an alternative meeting place than the cafe I mentioned on the flyer. As this was my first potential participant, when she did not show up I wondered whether there had been a communication issue and I had misunderstood the time and place. I sent a text message to confirm the details and if we could re-arrange. I did not receive a response. As I had no further contact with this potential participant I am unsure of the reasons that we did not meet. My impression is that stigma may have affected this woman's participation in this research as she showed concern about being seen in certain public places Recruitment of participants that are currently injecting drugs, can be difficult as stigma operates as a barrier due to fear of being 'outed' socially and attracting legal or employment trouble (Oransky, Fisher, Mahadevan, \& Singer, 2009).

Another potential participant also contacted me by text message and expressed an interest in speaking with me. However, she wanted to discuss what the research would entail. I called her and we had a short conversation about the research. This person was enthusiastic about meeting, but was also nervous. She voiced concerns about meeting in places that potentially risked her confidentiality. There were two attempts to meet this person in a cafe chosen by her, which was located in an urban setting. On both occasions, the participant texted just before

\footnotetext{
13 A koha is a gift, donation or offering. In this context it is a recognition of the reciprocity within this research and acknowledging the importance of giving back to those who contribute to the research.
} 
the meeting time to say something else had happened and she was unable to make it. She still remained interested in meeting with me and suggested we meet in a private room in the CBD somewhere. Unfortunately, as I was bound by my ethics approval guidelines about meeting places I had to insist on meeting in a public place. Although we exchanged a few texts following this, we were never able to meet and I believe a large part of this was due to stigma and the fear of being identified. Another person also contacted me and had seen my poster on Facebook, however this person was a cis-gendered man who therefore was not eligible to participate. However I still thanked him for his interest and time. I am extremely appreciative of those participants who were unable to meet me. I acknowledge their efforts in contacting me and the consideration they took with regards to this research. I recognise that the reasons for not meeting me could be diverse and varied.

\section{Key workers}

The four interviews with key workers varied in length, between 48 minutes and 52 minutes. One interview was with a female counsellor, who was in her early thirties and had worked in the field of drug and alcohol counselling for three and a half years. She specifically acknowledged the power relationship with OST counselling and how difficult managing a therapeutic relationship can be when the counsellor can control access to clients' medication. The key worker was employed as part of a wider team, and engaged in counselling individuals who were dependent on opioids and other drugs. The key worker stated that the services offered were not only abstinence-based, but some were grounded in a harm reduction framework and treatment was offered where and when the individual was ready. The organisation also offered abstinence based services and moreover, I was aware that while some individuals may have self-referred to the service, there were also client referrals through government departments, such as the justice system and medical professionals. 
Another key worker was a male pharmacist in his early fifties who worked in a chemist that provided methadone programme services, and had provided needle exchange services in previous years. He had worked as a pharmacist for more than thirty years, with methadone programmes for a similar length of time and needle exchange services for approximately six years from the late 1980s.

Two interviews involved key workers from two stand-alone Needle Exchanges. The interviews with stand-alone Needle Exchange workers consisted of a one-to-one interview and the other was a paired interview with two key workers. The one-to-one interview was with a male worker, in an urban area, who was aged between late forties and early fifties. He had previously worked in an organisation that was not drug-centred but it had an extensive harm reduction focus, as well as working with stigmatised populations for several decades. This key worker had worked with needle exchange services for approximately three years. This worker presented as passionate and dedicated to the purpose of his role, which he described as not only about preventing the spread of BBVs, but also reducing stigma and educating the wider public about the realities of people who inject drugs. The group interview was with two male key workers in a rural area, in a stand-alone needle exchange. One of the workers, approximately in his late forties to early fifties, had worked in various needle exchanges around the North Island of New Zealand for many years. The other was of a similar age and he had been working in this particular needle exchange for about six years. The interview was held in a meeting area in the Needle Exchange and while both workers were highly welcoming, open and friendly the atmosphere had a masculine feel and I wondered if this feeling would be shared by WWID who may access the needle exchange. The workers both informed me however, that there were also female staff who worked there at times. 
The structure of each key worker interview was based on a questions surrounding the extent of gendered barriers in accessing needle exchange services and how WWID may navigate them. Additionally, the data collected aimed to gain context around services and the perception of services for WWID and whether gendered services exist in a New Zealand context. All interviews were recorded with a digital recorder, with the exception of one interview via Skype, which was recorded using the computer's recording device. Permission was obtained by all participants before recording commenced. The recordings were then transcribed verbatim. The transcripts then became the data set used for thematic analysis.

\section{Thematic Analysis}

Thematic analysis was fitting for this research for several reasons. The flexibility of this method can accommodate the multi-layered, complex and diverse essence of feminist research. Thematic analysis involves reflectively analysing the structural or thematic aspects of a particular experience - a means to get at the notion being addressed (Van Manen, 1990). Advantages often cited of thematic analysis are that it is flexible and a relatively simple method for researchers with little qualitative analysis experience (Braun \& Clarke, 2006). While noting the importance of simplicity and flexibility of thematic analysis for this research, it is also highly suitable for research within a feminist framework.

Thematic analysis complements feminist methodologies and ideals. Rich, detailed description of the data set, which is a goal of feminist research, can be organised through thematic analysis (Braun \& Clarke, 2006). As feminist research aims for women's voices to be privileged, the incorporation of rich description in the participants' own words as part of the analysis facilitates this. This is also reinforced by the accommodation of participatory methods, such as semistructured interviews, in thematic analysis. Furthermore, thematic analysis accommodates 
social interpretations of data (Braun \& Clarke, 2006). This is particularly applicable within a feminist framework, as it is crucial to acknowledge the position of the researcher, as well as understand and recognise social context and meanings within data. Thematic analysis allows themes that are socially produced to be identified and explored. As gender and actions and experiences ascribed to gender are socially constructed, thematic analysis' qualities are appropriate for this research.

One of the problems with thematic analysis is that it can be difficult to select quotations that are representative of the categories and compelling to the reader, and a sense of the individual participants is often lost (Braun \& Clarke, 2006). Additionally, in contrast to other qualitative methods of analysis, the process of thematic analysis can risk losing a sense of flow, as well as contrast across individuals' accounts of experiences (Braun \& Clarke, 2006). I have sought to mitigate these issues by providing a brief description of each key participant in the previous section so the general sense of the individual account and personality could be acknowledged. As mentioned, thematic analysis is flexible, and while this is an advantage it can also be a disadvantage if the analysis of the data is too broad (Braun \& Clarke, 2006). This means achieving a more advanced analysis can be challenging. Thematic analysis can also be problematic in its interpretive potential if it is not used in conjunction with the theoretical framework supporting the research (Braun \& Clarke, 2006). I kept this in mind when undertaking the analysis and was attentive and cognisant that the analysis must adhere to feminist ideals and values.

In the analysis of data, I followed Braun and Clarke's (2006) six step guide to the process of thematic analysis. As described by Braun and Clarke (2006) the six phases are: becoming familiar with the data, generating initial codes, identify themes, review themes, define and 
name themes and lastly producing the report of results. This process was performed for this research as follows:

1. Familiarity with the data: All interviews were recorded on a digital recorder. Then, the interview was listened to in order to be acquainted with the data and to reflect on the interview experience. Each interview was transcribed by the researcher verbatim into a word document. To complete the transcribing process, I read through each transcription while listening to the relevant interview to ensure the transcript was accurate and made any required changes. Once the transcripts were complete, they were printed, read through and notes were made in relation to initial ideas about themes. 2. Generating initial codes: This was achieved by systematically reading through each transcript. As several questions during the interviews were aimed at exploring key areas, three main themes were easily identifiable within the data. Coding was achieved by highlighting, with different colours for each theme, data extracts within the data corpus.

3. Searching for themes: This was done by systematically examining each transcript for themes and coding was done via highlighting, in relevant colours, of the data extracts. Some data extracts could be coded into more than one theme.

4. Reviewing themes: The themes were then discussed and reviewed with the researcher's supervisor. Coded extracts were checked to ensure they corresponded accurately to the identified theme. This process supported the validity of the analysis. Verbatim quotes from the data extract were placed into one of three thematic files.

5. Defining and naming themes: Each of the three themes were then further analysed to examine, understand and highlight prevalent experiences by the participants. An overall sense of each theme was gained through this level of analysis. Names and definitions for three themes were confirmed as: how stigma permeates the lives of 
WWID, barriers in accessing harm reduction services, and how experiences within a drugs context are gendered.

6. Producing the report: A selection of significant, verbatim quotes were chosen. These examples were deemed to facilitate participants in having a voice and to gain an understanding of their experiences. The extracts were then finally analysed and related back to the key research questions of this thesis and to the literature that informed this study.

\section{Practical Limitations}

The small sample size of this research (five key participants) affects the generalisability of the data. However, generalisability was not a goal of this thesis and the qualitative methods used, instead, aimed to explore and provide a platform for WWID to share their personal stories. Acknowledging the participants' experiences as valid and learning from them was a crucial part of this research. This was guided by the feminist belief that women's stories should be accepted as they are shared. As a feminist researcher, it is inappropriate to place any expectations or judgement on their behaviour. This also informed the duty that I had to demonstrate how WWID are members of a vulnerable and marginalised group, but also, that all key participants showed strength, resilience and courage in their lives and their stories. Although this research incorporated experiences of both women who identified as Māori ${ }^{14}$ or Pākehā ${ }^{15}$, there is no analysis of the women's experiences in relation to ethnicity, as the focus is on gender. To address ethnicity and class is beyond the scope of this thesis and this limitation could be addressed with further intersectional research in this area. Furthermore, the key participants all reported that they were not currently injecting. As recruitment of participants

\footnotetext{
${ }^{14}$ Māori is a term that describes the indigenous people of New Zealand.

${ }^{15}$ Pākehā is a Māori term, meaning foreigner, which is commonly used to describe New Zealanders of European descent.
} 
who were currently injecting was unsuccessful, this has placed some limitations on the data.

\section{Personal Challenges}

Undertaking this research has been a personal, emotional and transformative journey for me. Challenges I had underestimated emerged, and were both emotional and academic. The stories directly shared by participants affected me in various ways. I was saddened by some of their experiences, however the tenacity and strength shown by key participants also energised and inspired me to ensure the thesis conveyed their thoughts as accurately as possible. At times, I was emotionally affected by their stories, particularly regarding experiences of stigma related to the participants' gender and drug using status. Although it would be impossible to fathom how enduring stigma may feel to WWID, there were moments where I felt I stood on the periphery of stigma attached to injecting drug use. As noted earlier, one particular moment was when my recruitment flyers were rejected by the receptionist at a community medical centre for the reason: “...we wouldn't want to encourage that sort of thing”. There were, however other more subtle encounters with attitudes of stigma. These usually centred around friends, family and academic colleagues inquiring about the research topic. When I expressed how I had a few participants who had cancelled or had difficulty meeting me, the response usually included a comment that assigned the reason for this was probably because they were women who used drugs. Additionally, a common reaction to hearing about this research was either one which pathologised WWID, labelled them as bad or assumed they all engaged in sex work. These experiences reflected, as Goffman (1963, as cited in Lloyd, 2010) describes 'courtesy' stigma; where people experience stigma due to their proximity of stigmatised populations. At times, I felt challenged by these reactions and views and I had to work hard to not take them personally, rather, to reflect on how this confirmed what others have argued (AIVL, 2011; Lakhani, Sacks, \& Heltberg, 2014; Lloyd, 2010). Instead, I tried to transform 
those moments into opportunities to humanise WWID and challenge dominant perceptions.

I have also acknowledged, reflected and addressed the use of my own stigmatising language. In the initial stages of this research I frequently used the term "IV drug user", however after conversing with two prominent harm reduction leaders and reading more widely on the topic I realised that a more acceptable and less stigmatising term is a "person who injects drugs" (PWID). Dickson-Swift, James, Kippen, and Liamputtong (2007) highlight potential effects, such as emotional changes, sleeplessness, feelings of anger, sadness and frustration that researchers can experience when undertaking studies of sensitive topics. Emotionally, I was also affected by the interviewing process. Organising interviews, times and locations, alongside having to travel and prepare for interviews, was much more taxing on my energy than I had anticipated. Meeting, engaging and listening to the participants, then transcribing the interviews and performing the data analysis was also emotionally exhausting.

Ethical considerations ${ }^{16}$ are vital with studies around sensitive subjects that also includes marginalised participants. In any research about sensitive topics, ethics need to be considered throughout the research process (Liamputtong, 2007). From the outset of this research, there was a need to be aware that this thesis encompasses contributions from people who are judged doubly deviant in popular discourse, first as drug users and second as women who use drugs (Ettorre, 2007). As previously discussed, depictions of women who inject drugs often contain negative stereotypes (Ettorre, 2004). Semi-structured interviews complement feminist research as they are able to provide women's own voices a platform which can prevent the perpetration of negative portrayals of WWID.

\footnotetext{
16 Ethics approval (number 20347) for this research was granted by the VUW Human Ethics Committee on November 182013 and a subsequent amendment was approved on 1 December 2013 (Appendix C). The amendment was sought to widen the recruitment search to include the Facebook page explained earlier.
} 
When considering the ethical aspects of this research I was aware that it was important that the research was carried out in a manner that ensured the participants gave informed consent. Participants were advised, and the consent form stated (see Appendices D and G), that they could withdraw from participating at any point during the interview and up until 31 March 2014, shortly after the interview process finished. Participants were each given the consent form and information sheets (see appendices C, D, F and G) to read before each interview. I also summarised the consent form verbally and let participants know they could ask any questions if they wished. Pseudonyms were assigned to each participant for confidentiality. Key informants were also assigned pseudonyms and it was expressed that their views would not be attributed to their organisation if they preferred. In the process of obtaining consent, the participants had to be fully aware of the purpose of the research and what was expected of them. It was also crucial to safeguard their, and the people in their lives, privacy. As this research was around the use of illegal drugs and possibly other illegal activities, confidentiality was crucial. Self-disclosure can be an issue in sensitive research and particularly when the research involves participants sharing intimate knowledge (Liamputtong, 2007). I explained verbally, and via the consent form, that the only information about the participants I would be obliged to share was anything that revealed they may harm themselves or anyone else. Additionally, I had anticipated the possibility of stories of criminal activities being shared during the interviews, but that it was likely to be past activities and lacking in specific detail.

First and foremost, the participants in this research are people, with different personalities, feelings and experiences. They have a variety of emotions, feelings and worries. When I began this research I was aware that I would be grateful that any, potential and otherwise, participants were generously giving up their time, as well as sharing their own personal stories. I was 
conscious of this, as well as continually grateful for the privilege of hearing the participants' stories and respectful of the trust that they placed in me to share their experiences. One of the aims of this thesis is to facilitate a platform for women to share their experiences and their own opinions. Additionally, guiding me in this research, the participants' rights were to be regarded and safeguarded first.

I was acutely aware of my position in the research and the necessity to reflect on the hierarchy between interviewer and interviewee with the interviewer assuming the dominant role in the relationship. This included efforts to ensure that participants were protected from real or perceived abuse of power such as a breach of participants' confidentiality. Recruitment via agencies or organisations, or interviews undertaken in local or public places could be particularly risky. This was taken into account alongside practical measures to maintain confidentiality while interviews were being undertaken as participants may have wanted to keep drug use unknown from friends, family, employers and some organisations.

As required by ethics approval processes, it was necessary to demonstrate and detail how identified ethical issues were going to be mitigated. Part of these issues was ensuring that participation was voluntary and no coercion was involved. A non-voluntary situation could have arisen when recruiting participants via a gate-keeper such as a Needle Exchange outlet, or a drug counselling centre or any other organisations that had allowed me to place recruitment flyers or posters in their reception areas. I sought to mitigate any issues with participants being 'public' through their interest in the research by excluding the use of 'pull-tabs' on my flyers and instead ensured my phone number was large enough to read from a distance.

Undertaking sensitive research means going into people's lives and sometimes talking in detail 
about emotional issues or stressful experiences (Dickson-Swift et al., 2007). Feminist researchers strongly support the relationship between researcher and participant to be reciprocal (Dickson-Swift et al., 2007). Part of qualitative research of marginalised people also includes the acknowledgement of the need to negotiate potential differences between myself and key participants. As all participants can have disparate views and backgrounds, I was also aware that my personal experiences may differ to participants in cultural, geographical and social contexts. While undertaking research, I remained cognisant of differences between the experiences of participants and myself as a researcher, and 'outsider'. I sought to mitigate this by establishing rapport with each participant by sharing some personal information about myself and also by engaging in general conversation at the beginning of each interview. As Brooks and Hesse-Biber (2007a) suggest, in order to bridge some differences, during general conversation with each participant, I sought out some shared attributes or experiences at the beginning of each interview. Nonetheless, I was not naïve enough to assume having some aspects in common with my participants equalled an understanding of their lives and experiences, nor bridged sufficient differences to become an 'insider' of their worlds. Conversely, 'outsiders' can also be in a position to use lack of knowledge as an advantage (Brooks \& Hesse-Biber, 2007a). As I had disclosed my lack of personal experience with injecting drug use I was able to ask questions about issues or situations where knowledge may have been assumed if I was an 'insider'. Such situations arose around discussions of obtaining drugs, sterile injecting equipment or even colloquial language. Chapters four, five and six move on to discuss the results of the thematic analysis of data as described above. 


\section{Chapter Four: Stigma}

Generally stigma has not been recognised, examined, or discussed extensively in relation to harms, harm reduction and PWID. However, the literature that does exist highlights the stigmatisation experienced by PWID and the effects of stigma on their access of NEPs, and other health and social resources. WWID experience stigma in a multi-faceted way associated with their drug use, gender and other characteristics. Stigma operates on different levels: self, social and structural, and acts as a harm to WWID. As discussed earlier, a consequence of the internalised stigma experienced by PWID is that it acts as a significant harm in the form of an often hidden barrier to accessing multiple services. This is intensified through institutional and individualised discriminatory practices directed at PWID (Lloyd, 2010).

Drawing from data gained via key participants in this study, this chapter will show how stigma is paramount to this thesis' themes and to the key issues that WWID experience. In building a foundation in understanding and acknowledgement of the impact of stigma on WWID, the commentaries provided by the key participants are salient as they bring first-hand knowledge and experience of stigma. This chapter firstly demonstrates how stigma becomes attached to someone who injects drugs. An analysis of key participants' expressions of their changing self-worth alongside Goffman's (1963) theoretical arguments of a 'master-status' illustrates the attachment of stigma. The chapter then continues by examining the impacts on WWID of stigmatising attitudes and actions of healthcare professionals. This is followed by an exploration of the intersectionality of stigma, with particular focus on gender and gendered factors such as sex-work and a motherhood status. Finally, the chapter will then examine how accessing two different types of needle exchanges impacted on participants' experiences of stigma. 


\section{'Feeling the Stigma' - How the 'Master Status' of being a WWID is experienced}

Goffman argues that once stigma becomes the attribute most focused on, the stigma then overshadows the rest of an individual's identity and becomes the 'master status' (Lloyd, 2010). Problem drug use is recognised as a 'master status' (Lloyd, 2010). As the 'master status', being a drug user becomes a defining feature for the individual, their whole identity is consumed by their master - 'drug-using' - status (Lloyd, 2010). All actions and expressed thoughts by the person can become entirely associated with the 'master status', and all other facets of the individual's lifestyle and character are funnelled through the 'master status' of being a drug user (Lloyd, 2010). For WWID, the 'master status' can be more dominant due to the intersections with stereotypical beliefs around gender and injecting drugs (Van Olphen, Eliason, Freudenberg, \& Barnes, 2009). The nexus of governing notions around drug consumption, the pollution of women's bodies, and actions that deviate from gender norms contribute to the belief of 'marking' the body (Ettorre, 2007). As discussed in the literature review, stigma is multi-layered for WWID due to expectations and norms based on gender stereotypes (Van Olphen et al., 2009). Furthermore, the 'master status' of a problem drug user can considerably affect interactions with others, such as doctors, nurses, pharmacists, other healthcare workers, criminal justice workers and the public (Lloyd, 2010). This is significant with regards to WWID's experiences of accessing needle exchange and health services because experiences of stigma, while navigating services, can be worsened by attitudes of others and their treatment of those possessing a 'master status'.

\section{Self-Stigma}

People who use drugs (PWID) are not oblivious to the negative stereotypes and perceptions that the public hold about people who inject drugs. As an individual progresses to self-identify with the master-status and characteristics deemed unacceptable by others, they have taken on 
the central elements of a 'spoiled identity' (Goffman, 1963 as cited in McKeganey \& McIntosh, 2001). Goffman (1963, as cited in Lloyd, 2010) posited that the 'spoiled identity' informs and shapes how a stigmatised individual interacts with others. The 'spoiled identity' of participants in McKeganey and McIntosh's study (2001, pp. 50-51) that explored the thoughts of people ceasing dependent drug use was expressed in various ways: unhappiness from the kind of person they perceived they had become, a dislike of the activities they were involved in, or a loathing towards the drug world and drug users. The participants in this study also expressed thoughts and beliefs associated with a 'spoiled identity', and the self-identification of a 'master status'. As demonstrated by participants in this study, WWID's expressions of self-worth often illustrate the internalisation of negative labels:

“... all that feelings of 'I'm a junkie', 'I'm a loser', 'I've done something bad', 'I've done something wrong'...you feel so stink it actually makes you feel worse so your desire to use drugs is even stronger to feel better cos you're feeling so bad... a bit of a cycle really" (Jordan)

“...just like I wasn't worth anything like I was a parasite on society...” (Lucy)

Goffman (1963) notes that stigma is experienced in different stages (Lloyd, 2010). Within an injecting drugs world, the impact of stigma develops from the initial stages of drug use with behaviours that encompass the avoidance of being 'known' and as time continues or once the master status is embraced, PWID can self-identify with their master status until it forms a selfstigma (Livingston et al., 2012). In these stages the stigma is experienced in a different way, however once the master status is revealed and the 'spoiled identity' is realised, Goffman (1963) argues that users are not as afraid of the status being ascribed to them (Ahern, Stuber, $\&$ Galea, 2007). At this stage, PWID may endorse negative stereotypes and perceptions about PWID (Livingston et al., 2012). Demonstrative of how stigma operates on a continuum and permeates an individual's identity, participants in this study shared initial feelings of selfstigma. The notion of a 'spoiled identity' is evident in the following commentaries where two 
participants acknowledge as their injecting use continued, the feelings of stigma were reinforced and they began to embrace the status more.

“...I had almost got to the stage where I was over the real... I was starting to feel pretty bad about myself as well. Although, I pushed it down a lot and kind of saw myself as, born to do it [inject]..." (Jordan)

“...I didn't think it was a scungy thing to be doing till ages later that I had a bit of shame about it..." (Cassie)

Another participant reflected on how she associated frequent drug use as a physically unhealthy activity that impacted on her low self-worth.

“...I just had no self-worth, no self-love, I love the person I am today, I wouldn't put myself through that, I wouldn't... I've been trying so hard to keep myself healthy and place importance in that, I would never put my body through that...” (Lucy)

\section{Social Stigma}

Public attitudes towards PWID are often based on negative stereotypes rather than on real experiences and evidence (AIVL, 2011). PWID are aware of this and often try to 'cover' their drug using status. Participants often worked to hide their drug using status and avoid the feeling of being stigmatised or enduring discrimination from the public. 'Passing' as normal refers to being able to keep the master status of being a drug user hidden from others. This is done through a process of 'image management' (AIVL, 2011). If drug users are unable to negotiate or modify knowledge about themselves and their drug using status they cannot 'pass' as normal, or a non-drug user (Lloyd, 2010). Areas of knowledge about individuals that may be controlled, other than drug using, are associated with negative stereotypes of PWID, such as hygiene, employment status or more subtle aspects associated with the manner in which someone speaks or walks or dresses (AIVL, 2011). 
'Passing', alongside her image management, is central to 'Nina's interactions with others who know her as a mother. 'Nina' reflects on the importance to her of 'covering' potential judgement of being an unfit mother due to her drug use.

“...People don't imagine that I would use drugs that know me at the kindy ${ }^{17}$ and school and I do heaps at school and I'm really active at kindy. I've done lots of parenting courses...I've done a play centre diploma... and they couldn't imagine it [that I have used drugs] ..." (Nina)

The participants thought about how others might judge them.

“...I'd always had everyone crowd around me for the good things so when I was doing the wrong thing I was always really aware with what people are thinking, really embarrassed" (Nina)

In some circumstances it is not possible to 'pass'. The presence of the public can intensify shame and stigma. Goffman (as cited in Lloyd, 2010) refers this to being 'discredited'. As a result of stigma, participants were affected by negative labels and 'othering'. 'Lucy' said that her and her peers would refer to the non-injecting populations as 'normies', the label implying that non-users are normal and PWID are not. Accessing needle exchange services within a pharmacy provides unavoidable opportunities of the juxtaposition of the stigmatised and nondrug using public (Lloyd, 2010). Pharmacies often offer little in the way of protecting confidentiality for PWID's accessing sterile injecting equipment (Aitken, 2002). 'Lucy' reflects on how it felt when accessing needle exchange services within a pharmacy and having the general public present.

"It just made me feel embarrassed, cos there was like all these, we call them 'normies' [non-drug users], were around me, kids around and shit. I had to walk through all these fucken people [in the chemist]... I'm holding this frickin' bag of old needles, you

17 'Kindy', a common colloquial shortening of 'kindergarten' 
just feel really embarrassed and ashamed, like they shouldn't have to witness this and I shouldn't have to be around them." (Lucy)

Whereas 'Cassie' recalls one experience where on reflection she feels that her drug using status was apparent and obvious and she demonstrates that in retrospect, 'passing' would have been difficult.

“...some girls came up to us once...probably younger than us, so we were 22-23 [years old], at the most...they must have been in their late teens or mid-teens and asked us if we would [supply them with drugs], we wondered how they knew that we used, but it would have been really obvious, very thin and very, y'know, looked the part..." (Cassie)

Needle Exchange workers in this study were fully aware of the stereotypes and stigma associated with injecting drug users and also how the ability to 'pass' may be easier for some PWID more than others. Key workers had an awareness of stereotypes and how those stereotypes matched, or conflicted with the reality of PWID. One key worker reported:

“I think there's a stereotypical view of drug users. They're viewed poorly by society. But some of the clients we have, no one would ever know [that they inject drugs] that they are IV drug users or were. So I think it's a bit of a double standard." (Key worker - pharmacy)

People who use illicit drugs face greater stigma than those who use legal drugs (Ahern et al., 2007). One of the many adverse effects resulting from the criminalisation of drugs is the stigmatisation of those who consume illegal drugs (AIVL, 2011). The irrational bifurcation of drugs into 'legal' and 'illegal' is reductionist and has distorted understanding and perceptions about drugs, their associated harms and those who use drugs (Young \& Buchanan, 2000). The bifurcation of drugs, stigma against those who use drugs and notions of gender impact women greater than men. Women who use drugs often have their social circumstances reduced to criminogenic factors, such as biological determined issues (Malloch, 2004). As Campbell (2000) argues, the ways that women who use drugs are regulated, reflects how society places 
expectations on women in general. One key worker's comments perhaps reflect how the societal expectations of 'deviant women' are judged to be more manipulative compared with men:

"...women tend to be more clever [sic] with their covering of their tracks, of lying and playing people off against each other to kind of have their needs met. This is just a sense of when you work with women versus men that tends to be some of the difference between them..." (Key worker - counsellor)

A key worker notes how the legal status of a drug impacted stereotypes and affected PWID more than people who drink alcohol. This further evidences how the bifurcation between illegal and legal drugs, compounds stigma and marginalisation for PWID (Anderson, 2001).

“...they're often seen as second class, but it is particular to the drug that people are using...And often society's views towards people that struggle with alcohol issues is quite different to people that struggle with opiates or methamphetamine. Certainly, society does not look favourable [sic] on people that use drugs or are struggling with addiction. It's not often seen that by general society that it's actually a mental health issue. It's often seen as a lack of will power or a life style choice." (Key Worker counsellor)

This key worker is describing why stigma can be more severe for PWID than other stigmatised groups. Where it is perceived that the individual has some agency over the 'master status' of their stigma, they are assumed to be responsible or at fault for being stigmatised. Furthermore, opiates, compared with other drugs, are perceived to be the most 'harmful' and injecting as a method of consuming is further associated with problematic drug use (AIVL, 2011). The key worker goes on to explain how she thinks PWID are affected by stigma compared with others who do not inject.

“...IV drug users are really one end of the spectrum ... historically, IV drug users have been associated with diseases like Hep C and HIV... I think society probably sees them as the really dirty drug users." (Key Worker - counsellor) 
This point is emphasised by another key worker, who also highlights how inaccurate the stereotype of PWID can be:

“As 'junkies'. Especially injecting drug users, there's probably not much else you can say, they are viewed as a 'waste of space', 'society-sucking junkies'. That's what the general populous think of anyone who injects drugs. It's very sad...they [society] don't even appreciate that some people never form an addiction habit, I think they think that everyone who injects has an addiction habit and they don't realise that there's more recreational than there is addiction drug abuse in the community. We see that, we see people come in in their suits on their way home from work and they lead really productive healthy lives and come the weekend this is their choice of how they 'get out of it'... “ (Key Worker - Needle Exchange 1)

This key worker's observations supports findings that people can use heroin in a regulated manner (Shewan \& Dalgarno, 2005). While this is an area that is under-researched, it does suggest that 'unobtrusive heroin use' (Shewan \& Dalgarno, 2005, p. 45) alongside the acknowledgement of a continuum of drug use, would challenge pervasive stereotypes and assumptions of those who inject drugs.

\section{Structural Stigma}

In accessing healthcare services such as counselling and medical treatment, discrimination against PWID is so pervasive that many PWID do not notice that they are experiencing discrimination due to their drug using status. Furthermore the effect of discrimination can intensify with each incident and result in PWID's avoiding or postponing accessing services and providers (AIVL, 2011).

Stigma and discrimination, unfortunately, are still faced by women who use drugs via health care workers. As previously discussed, studies have shown that some healthcare workers admitted stigmatising against PWID with the mistaken view these negative attitudes can discourage problematic use (AIVL, 2011). Stigma from health care professionals is argued to be the most damaging to physical and mental wellbeing as well as being frequently experienced 
in healthcare domains (AIVL, 2011). Nurses were said to have less time for PWID than the general patient population, whereas pharmacists were cited as being worried about PWID stealing or the reaction by so-called 'normal' customers due to the presence of PWID (AIVL, 2011).

Additionally, although PWID are affected by the same spectrum of sicknesses and accidents that the non-injecting population experience, their time with a doctor is regularly negatively influenced by the doctor's assumption that the PWID is drug-seeking ${ }^{18}$ (AIVL, 2011). There are a myriad of effects from the stigma and discrimination acted out by health professionals. Direct effects include that if PWID are suspected of drug-seeking behaviour, they may be denied medication, care and treatment that they have a right and need to access. This can have serious consequences such as serious illnesses or pain being dismissed due to health professionals assuming the PWID is lying (AIVL, 2011). Other repercussions are that PWID may find the discrimination too much of a barrier and not be able to access the appropriate care resulting in their wellbeing being compromised (AIVL, 2011). Compounding the issue of stigma being a barrier to healthcare, PWID are unlikely to or unable to report the adverse treatment to authorities due to a number of factors, such as the criminalisation of injecting drugs (AIVL, 2011).

Research from New Zealand suggests the situation is no different in comparison to international findings. In a study examining health problems and access to health care of those enrolled on a methadone programme, it was found that pharmacists can narrowly focus on the master status of the methadone client and therefore everything about the client is hidden behind drug use (Sheridan, Wheeler, \& Walters, 2005b). Sheridan et al. (2005b) assert that this can lead to insufficient attention paid by pharmacists to general health problems which can be the same as

\footnotetext{
18 'drug-seeking behaviour' is defined by one medical organisation as "false reporting of symptoms to obtain a prescription or request of a drug in order to maintain dependence" (Robinson, 2008).
} 
the non-injecting population but are associated with drug use instead. Furthermore, the impact of stigma is significant where pharmacy employees have treated methadone clients seeking cough and cold remedies with suspicion, or assumed that clients are not 'genuine' in their need for the products (Sheridan et al. (2005b).

Doctors also make judgements based on negative stereotypes and this affected the quality of the service they provided. While seeing a doctor for treatment of migraines which had affected 'Jordan' all his life:

"the specialist and I went in and I sat down and he took one look at me and said 'you're nothing more than a drug-addict, you don't know if you're a woman or a man and you're only here to try and get drugs out of me'. I started crying cos I was really, really, desperate to get help for my pain and as soon as I walked in and sat down he just looked at me and he just judged me. All this judgemental crap came out of his mouth. I couldn't believe it, I just got up and walked out, I've never been back and I've never had anything done about my migraines." (Jordan)

He also seemed disappointed about being discriminated against by women who were health professionals:

"...I used to have a psychiatrist that was a woman, and I think she judges me more harshly as an IV drug user, [her] being biologically female than she would have someone that was biologically male. I always got the feeling from her that I was letting my gender down. That I was letting the girls down by being a drug addict, rather than if I was a guy she wouldn't have identified as closely with me and therefore wouldn't have judged me like that" (Jordan)

\section{Impacts of multi-faceted stigma}

Stigma and its impacts can be worse for women who are pregnant or mothers (Poole, Health, \& Isaac, 2001). Socially constructed images of the archetypal mother are not synonymous with injecting drugs (Lewis, Klee, \& Jackson, 1995). Traditionally research and policy associated with women and problematic drug use has tended to focus on the so-called risks women pose 
to their children and families (Poole \& Dell, 2005). Additionally, as Ettorre (2007) argues, the transformation of PWID's bodies into 'lethal foetal containers' highlights the disproportionate judgement women receive. Participants' thoughts and ideas often demonstrated how they had awareness of the stigma and negative stereotypes that women who inject face from society. The notion of double deviancy, as discussed earlier, did not escape participants.

“...I think that women that use are more likely to be judged as sort of, [long pause], bad...not bad, but sort of loose maybe or, I think the judgement on guys that use is, it's a more manly thing to do, I just think there's a judgement that guys that use, It's sort of seen more normal than women that use. Or more 'ok' maybe...I think women generally are more likely to have low self-esteem. I think... it's because women are still not treated as equally as men. There's still that sort of boys club thing that women aren't a part of..." (Jordan)

Sometimes there were different perceptions on whether the participants were judged or not.

“...I remember asking the guys [I was with], 'do you feel like they looked at you judgementally?' and they were like 'I don't really care'. I was like 'I feel like they did' (Lucy)

The notion of double deviancy was also felt in accessing the pharmacy's needle exchange. 'Lucy' remembers her thoughts around how the pharmacy workers judged women who injected more than they judged men.

"I think she [worker in the pharmacy], with guys it's just 'it's just another junkie guy' but with me they gave me this look of 'what the fuck', 'it's a woman doing it'... "(Lucy) Participants are not immune to the influence of society's stigma. Research suggests that the stigmatised can stigmatise their peers by making a favourable comparison, in order to distance themselves from the negative stereotypes around injecting drug users (Lloyd, 2010). As discussed earlier, for mothers, accessing the needle exchange with their children can be an issue due to the stigma associated with being an injecting user, a woman, and a mother. Other members of the drug injecting community are not exempt from the prejudice the wider public 
displays, one participant shared his thoughts on acceptability and mothers with children accessing the needle exchange services:

“...it's not really appropriate to take your kids into the needle exchange...” (Jordan)

Society's expectations of fathers do not mirror those of mothers and are bound in socially constructed notions of gender roles (Connell, 2002). These views are also relevant with a drug using community. One participant remarked about a woman partaking in drug use and how this had a negative effect regarding the children, however, 'Lucy' did not mention the children's father in relation to this observation.

“...so every weekend we'd be at his house and we'd do it together. It was young kids, the mum was doing it with us and I felt really bad so I was trying to spend time with the kids..." (Lucy)

Managing discreditable identities can also involve views that may be pejorative to others within the same stigmatised group. Stigma against peers can increase self-esteem by a 'downward comparison' (p.122) in an attempt to raise the individual's own status (Simmonds \& Coomber, 2009). 'Nina' described how hard she had worked to prove how good she was as a mother despite the perceptions of being on the methadone programme, however she distinguished herself from other mothers that may be on methadone programmes.

“...I think a lot of mums that have babies [and are on methadone], they have them and just leave the nurses to deal with it...I had to prove myself that I was a good mother, that I cared about this baby and I wasn't just like the other drug using mothers who would only care about herself and would want to get the baby out and bugger off back home and carry on with her life..." (Nina)

As well as stigma affecting PWID, it also overlaps with constructs of gender and class. Skeggs (1997, as cited in Bailey, 2012, p. 49) posits the discursiveness of respectability in relation to class and femininity. 'Positioned othering' (Hutton, Griffin, Lyons, Niland, \& McCreanor, forthcoming 2015) is undertaken as an attempt to separate the person from others bearing the 
same stigma. As with the women in Skeggs' research (as cited in Bailey, 2012), 'Nina' worked hard to distance herself from negative stereotypes of PWID being lazy or unwilling to work:

“... and I'm a really good worker, I work really hard, I went to good schools, I've got a good work ethic, I've been brought up with a working family. I have heaps to offer an employer..." (Nina)

Additionally, 'Nina' speaks about her perceptions of some users that are mis-using the methadone programme.

"They're in it to gain something they want a drug script or they want a prescription for some pills. They just want free methadone so they don't need to hang out [withdraw]. But they don't want anything, other than a place that they can get what they want. It's a shame cos a lot of people that do need it. That can't get on it cos of those spaces aren't available and they can only take on so many people..." (Nina)

Conversely, demonstrating how heterogeneous experiences are, some participants felt that within the drug culture there was less stigma and judgement.

“...inside the drug world, inside the drug world pretty much everyone's on a even platform ...especially for people that are selling it. God, they don't care if you're male, female or alien ...the judgement is much less I think than outside the drug world looking in" (Jordan)

Despite pregnancy and motherhood sometimes being a motivator to address problematic drug use, stigma and fear of negative reactions from healthcare workers can prevent women from accessing services (EMCDDA, 2009). The media also contribute to this stigma and discrimination through bifurcated representations of mothers being either 'good', non-drug using mothers or 'bad', drug using mothers (AIVL, 2011). In an opinion piece in 2011 in a major European daily newspaper, the columnist called for the sterilisation of 'junkies' and associated their injecting drug use and motherhood with being less than human (Bingham, 2012). Injecting drugs and motherhood are often judged as incompatible and although the media are careful about using discriminatory language against some groups such as women 
and people who are homosexual, the same cannot be said for PWID (UK Drug Policy Commission, 2012). Assumptions and stereotypes, rather than evidence-based information, inform the general public and healthcare workers about pregnancy, motherhood and drugs (Stengel \& Fleetwood, 2014). Furthermore, there is often a lack of knowledge based on evidence around pregnancy, motherhood and drug use. Even if healthcare workers are benevolent and supportive, specialist knowledge is often lacking and causes distress and upset to women who use drugs (EMCDDA, 2009). Multiple studies have revealed a need for training with regards to healthcare staff working with PWID or WWID. 'Nina' had her first child less than ten years ago and found the experience traumatic for multiple reasons. She felt the hospital staff lacked appropriate knowledge and negatively judged her due to her status as a pregnant women dependent on opiates. As 'Nina' was recalling her experience she was visibly distressed and appeared to be emotionally affected by the memory.

“...it was just really scary, as a new mum and a young mum, to not know what's going on at all and basically, some of the nurses were quite understanding, others were absolutely [I was] being blamed and treated like less of a person. Everything that your baby needs is down the list, it's under everyone else, it's less important and a really unprofessional attitude. I went through all sorts in the hospital there" (Nina)

Women who use drugs are seen to be a risk to current and future children, society and themselves and are portrayed as unfit or 'bad' mothers (Boyd, 2006). Discrimination from state departments against women who are mothers is often experienced. In some countries, such as the United States of America, women who are pregnant and use illicit drugs face criminal prosecution related to their drug use and unborn child (Simpson \& McNulty, 2008). Canada has also experienced efforts to criminalise drug use during pregnancy which are argued to be grounded in a rhetoric of unfit mothers and ill-informed information of the effects of some drugs (Boyd, 2006). Adverse outcomes from pregnancy have been solely blamed on maternal drug use, despite the lack of evidence confirming this (Boyd, 2006). These negative 
representations of mothers ignore the vast amount of research that establish numerous variables, other than drug use, affecting outcomes in pregnancy (Boyd, 2006). This is representative of how stigma is magnified when factors such as gender, ethnicity and class are considered. The relevance of an 'intensified stigma', similar to the notion of 'double deviancy' (Heidensohn, 1985), for women who inject drugs is illustrated in these double standards. When asked about whether she ever felt judged in a negative light as a mother and someone who has used drugs, 'Nina' recalled that this judgement was evident as she was pressured to undertake parenting classes as well as having to prove she was a capable mother after the birth of her first child. As discussed, WWID experiences of stigma is greater than for MWID due to factors around double deviance. For women, the greater impact of stigma was appreciated and acknowledged by some key workers:

"It's even worse [for women]. We live in a patriarchal world where guys seem to get away with a bit more and it's cool to be a little bit naughty when you're a male but I don't think the same for [women] ...there's inequality, it's just harder isn't it..." (Key Worker - Needle Exchange 1)

AIVL (2011) and Lloyd (2010) argue that stereotypes around mothers who inject drugs show that it is an impossibility to have any positive notion of parenting or caring for their children. Key workers also noted that the impact of pregnancy and or motherhood on WWID and stigma was even harsher.

“...I imagine there's all sorts of snide comments around pregnancy, around the fact that you can reproduce, guys don't get that. I'm sure if you talk to any women who have had children and have had a habit [drugs] I bet they've copped some pretty negative shit. I think that makes it much harder. We just live in a society where if you can put someone down you do and for women using drugs it's just another reason to put them down and make them second rate citizens. Complete crap isn't it?" (Key Worker - Needle Exchange 1) 
While a correlation between street-based sex work and injecting drugs has been explored in a significant proportion of the literature, it must be noted that global estimates of correlations of WWID and street-based sex work vary widely (Roberts et al., 2010), and not all WWID engage in sex work and vice versa. WWID experience additional stereotyping and stigma associated with working in the sex industry (Roberts et al., 2010). Sex workers, particularly street-based sex workers who use, or inject, drugs are likely to be placed at the lowest point in a hierarchy of women (Armstrong, 2011), and therefore face multiple forms of social marginalisation. Furthermore the stereotypes of WWID and sex work are pervasive within popular culture and among, the general public, health workers and even within the drug world. This stereotype has further contributed to the stigmatisation of women in both groups (Armstrong, 2011). The assumption persists that women who inject drugs fund their drug use via sex work, and vice versa (Roberts et al., 2010). When asked if society sees women who inject drugs differently to men, 'Nina' refers to the stereotype about the association of sex work with drug use.

"They think most of them are like prostitutes, it's like they're the old, junkie ones...[they're seen as] junkie whore and all that sort of stuff" (Nina)

'Clara' recalls how a few decades ago, the stereotype of the WWID who was also a sex-worker was much more common than in contemporary times, due to the lack of knowledge about women within the drugs community.

“...back in the $80 \mathrm{~s}, 90 \mathrm{~s}$, people were still quite green [uninformed] to how women should be in the drug scene. I think for women, a lot of people thought you were a prostitute, you were a drug user or vice versa. If you were a prostitute, you were a drug user. If you were a drug user you were a prostitute" (Clara)

Whereas 'Clara' felt that this stigma of association between sex work and drugs was not attached to men who used drugs.

“...no, they [men] don't have that stigma...” (Clara) 
However, rather than an historic view, 'Cassie' saw the stereotype of sex-work and injecting drugs a contemporary issue. In response to a question about whether women who inject might experience different judgements to men who inject, 'Cassie' immediately refers to the stereotype of women who inject and sex work correlations.

"Everyone assumes that there's a sex work connection..." (Cassie)

As noted earlier, stigma and judgements are also made within the drug world. 'Nina' remembers how she was believed to be a sex worker by other sex workers due to her drug use.

"...A lot of them that have done it, and they judge other people on things they've done. I've had fights with women who used to be prostitutes and assume that I'm one..." (Nina)

\section{Experiences of stigma directly related to the Needle Exchange}

A lack of adequately trained staff within pharmacies providing needle exchange services was noted as an issue by participants. One of the effects of a lack of training is the discrimination and stigma felt by PWID accessing needle exchange services. Treatment from staff in the pharmacies that offer needle exchange services was often remembered for its negative and discriminatory actions. Accessing the needle exchange services within a pharmacy involved feelings of stigma and discrimination intensified by treatment from the staff. Discrimination and negative treatment from health care workers causes shame and embarrassment to people who inject. Furthermore, evaluations of the Needle Exchange services in New Zealand have revealed similar issues and reported a need for better attitudes from pharmacy workers (Aitken, 2002; Lungley \& Baker, 1990).

"It was really embarrassing and they repeat what you want really loud, so everyone in the pharmacy can hear...the chemist lady will yell, only the pharmacist would actually give it to you,... 'oh, she wants a 3ml' and the whole chemist looks at you" (Nina) 
"I was pretty embarrassed...I was so self-conscious and the way the lady looked at me when she handed me the needle. It was just like disgusted" (Lucy)

'Clara' also recalls how a few years ago she was aware that the pharmacies differed in their treatment and some workers caused her to avoid accessing the service in the particular location.

“...it depended which chemist you went to as well because there was some chemists that they would just flatly look at you...one of them there used to actually just dispense methadone back in the day and he had a very unhealthy attitude against people like myself. If I went in there to get a clean outfit or something, which I never did in that chemist he'd go 'oh how are you? CLEAN?' [a sarcastic tone]" (Clara)

The treatment by staff was inconsistent in how stigma was delivered, however the judgement was always felt by 'Lucy':

"It depended who was doing it. Some people just looked at me like they felt really sorry for me. They'd give you that motherly 'you poor girl' kind of look...all the time it was mostly just judgement." (Lucy)

The impact of stigma and discrimination can result in PWID being deterred in utilising services (Lloyd, 2010). In accessing needle exchange services attached to a pharmacy the treatment by staff had the following effect

"It made me feel like, it re-informed that I was doing the wrong thing and made me feel like it wasn't worth the embarrassment and the bad feeling to actually go there..." (Nina)

'Lucy' sums up how she felt overall and about the needle exchange services and the shame provided by the pharmacy:

"I think it serves as a way to embarrass you into not using. In all honesty I think...I guess it helps because at the end of the day you're using clean needles, you're not getting sick, but it is pretty embarrassing." (Lucy)

This research explored five key participants who accessed services via pharmacies and all reported negative interactions with staff. The above experiences as described by various 
participants, highlight an urgent need for training to be further implemented throughout pharmacies that offer needle exchange services within New Zealand. Despite the lack of training being signalled as an area for improvement as far back as the 2002 Needle Exchange review (Aitken, 2002), discrimination and negative treatment by pharmacy staff continue to be flagged by PWID as an issue.

Within stand-alone needle exchanges, research shows that PWID are less likely to experience direct stigma from staff (Sheridan et al., 2005a). However, indirect stigma still prevents people from accessing services, due to the risk of being associated with injecting drug use. PWID do not want to risk being associated with drug use, particularly in the initial stages of injecting drugs. When 'Cassie' first started injecting she depended on others to obtain sterile needles for injecting as she did not want to be associated with drug use. 'Cassie's experiences of injecting were 15 to 20 years ago and in the initial needle exchange scheme she had concerns of not wanting non drug using people to know.

“...when you go into a chemist or even the hospital, you're going to see people who are born and raised in [city] and went to school in [city] and know people, way outside the drug using circles and we weren't 'out' so to speak it's not like everyone knew we were using. So you're almost getting busted if you went to take it [used needles] to a chemist and just drop it off..." (Cassie)

Key workers were aware of stigma acting as a barrier and how it could affect and restrict how needle exchanges can 'advertise' their services.

“...We can't put big signs out, we're not allowed to." (Key Worker - Needle Exchange 2)

Furthermore, key workers recalled how the impact of stigma also affected where the needle exchange could be located due to attitudes from the community. 
"Originally, they were looking at opening it up at [street] next to the tattoo parlour and [owner of tattoo parlour] kicked up about it. 'I don't want dirty junkies here, coming round my tattoo parlour'...” (Key Worker - Needle Exchange 2)

Treating a person who injects with respect and non-judgemental attitudes can have a positive effect. This entails a compassionate, fair, supportive and caring service that can give users a sense of self-worth. This means that if they do have a problem with drugs, they are more likely to receive help for drug and other issues, and be able to access services. The service provided by the needle exchange services, such as access to sterile injecting equipment, gave participants a sense of empowerment and self-worth.

“...At least if you've got a clean needle or barrel every time you feel a bit better about yourself. You're still using IV drugs, you're still got that, but you feel quite a bit better about yourself if you're ripping open a clean pack every single time. At least that's something to be pleased about" (Jordan)

However, it was not only access to sterile equipment that increased self-worth: participants who had experienced accessing Needle Exchanges where the staff are largely peer workers, rather than services via a pharmacy, overwhelmingly spoke about how good they felt about themselves due to the non-judgemental services they received.

...they make you feel good, they make you feel like you're doing the right thing by coming in there and getting clean needles. They encourage you, they're always happy to see you, say 'gidday' and 'how is it?' and 'how's your day going?' and that. They actually wanna know how your day's going. They're really supportive... any time you need to, you can go and have counselling. Or go out the back to talk to someone about problems and whatever. They're really good, they make you feel a lot better about yourself...so emotionally you feel your self-worth and self-esteem is a lot higher because of the Needle Exchange...It [needle exchange] impacts on all areas of your life" (Jordan) 
Following on from this analysis of stigma for WWID, chapter five will analyse the barriers to accessing needle exchange, and other services, for WWID. 


\section{Chapter Five: Barriers to access}

This chapter analyses the barriers that women face in accessing needle exchange services. Due to the lack of literature around barriers and WWID accessing needle exchange services, it is necessary to use research based on a broader picture. Therefore research exploring the barriers that WWID face, when accessing other services such as drug treatment, social and health services will be discussed. As mentioned in the introduction to the results chapters, barriers can be categorised as systemic, structural, social, cultural and personal (Roberts et al., 2010, p. 73). It is crucial to understand what barriers are, in order to mitigate or overcome them and therefore facilitate women's access to drug and harm reduction services.

Systemic barriers for WWID stem from a patriarchal legacy, service design, and those who work within services. In accessing needle exchange services, they include: a lack of decision making power to barriers that emanate from service staff, a lack of knowledge of women's specific needs, insufficient services relevant to women's needs, and the cost of services (Roberts et al., 2010, p. 18). Studies have also found that stigma and discrimination are both significant systemic barriers which affect women more than men (Roberts et al., 2010). Stigma also features across all three categories of barriers demonstrating its pervasive effects. Due to this, stigma was explored in depth in the previous chapter.

Structural barriers are associated with how services operate. Structural barriers specific to women consist of the lack of services catering for mothers, for women who are pregnant (UNODC, 2015), as well as the geographical location of a service, unsuitable opening hours, cost of services, a lack of discretion or safety in the design of the service and perceived confidentiality issues (Roberts et al., 2010). Negative and judgemental treatment by staff also serves as a barrier for women (Roberts et al., 2010). 
Lastly, social, cultural and personal factors can act as a barrier for women in accessing needle exchange services. These can include issues such as discrimination, lack of personal support, disadvantaged social circumstances, low confidence in services, lack of finances and risk of intimate partner violence (Roberts et al., 2010, p. 18). WWID often have access limitations to other social and health services such as welfare and adequate housing (VANDU Women CARE Team, 2009). Research that identified barriers to access of needle exchange services in Vancouver for PWID highlighted factors such as mental health problems, sexuality and a history of sexual abuse contributing to difficulties in accessing services (Ashton, 2004). This data, although not disaggregated by gender, can also be applied to women when considering the evidence from a separate study that emphasised the same issues as barriers for women in accessing other primary care services in the same region (VANDU Women CARE Team, 2009). Personal barriers are associated with personal issues of the individual accessing the service. For women this can be fear affiliated with family violence, fear of losing custody of their children or their own financial situation (Roberts et al., 2010). Some barriers and issues associated with WWID may intersect and overlap with multiple categories. While acknowledging the complexities of these factors, in the following discussion, relevant barriers will appear in only one category.

\section{Systemic Barriers}

As mentioned previously, systemic barriers are associated with women's socially constructed positions in society. Patriarchal ideals are embedded in governmental, organisational and community institutions and these beliefs influence those who work with, and design services for WWID. The women who participated in this research shared various experiences that can be identified as systemic barriers. The following discussion will highlight some of these experiences.

Although it is often accepted that men and women have different needs and constraints, it is 
surprisingly rare to have gender-sensitive, or women-specific services (EMCDDA, 2006). Furthermore, treatment services for drugs are often designed around men's needs with few exceptions such as, for women who are pregnant (EMCDDA, 2006). For example, in a review of drug treatment services in the Republic of Georgia, it was revealed that staff lacked knowledge around women's specific needs (Otiashvili, Kirtadze, O’Grady, Zule, Krupitsky, Wechsberg, \& Jones, 2013). In this New Zealand study, when asked about women-specific services that either the needle exchange, methadone programmes or drug counselling offered, the responses from key workers revealed a lack of existence of distinct services designed for women.

"The actual protocols within the programme are the same for both [genders]..." (Key Worker - Pharmacist)

In response to the same question, another key worker could only recall one gender-sensitive policy. When a client was suspected of cheating during the urine drug screening process, female clients would only be observed by the same gender:

"In terms of urine drug screening, most of the time we don't observe [clients urinating], but if we suspect somebody to be doing something a little bit dodgy, bringing somebody else's urine in, we've got two females, myself and a nurse who is on the programme and a male, so we would match the gender." (Key Worker - Counsellor)

Despite providing services that have been praised for the inclusion of PWID's needs and engaging peer workers (Aitken, 2002), the stand-alone needle exchanges also appeared to lack in women-specific services as well as the acknowledgement of their importance. Although respect for diversity was expressed, the key workers in stand-alone needle exchanges also provided little confirmation when asked about the provision of women specific services:

"I don't think we do [have different management polices] between genders. We try and be culturally sensitive and we really respect diversity so we are equally as welcome to 
trans [people], as we are to Māori to male or female. We're quite strict on nonjudgemental, it doesn't matter who you are." (Key Worker - Needle Exchange 1)

"We treat everybody the same” (Key worker - Needle Exchange 2)

The key workers' thoughts mirror the literature with regards to the lack of knowledge around the necessity of women-specific services and their importance to the design and implementation of harm reduction services (Pinkham et al., 2012a). Further, though one key worker had previously noted women and men could experience drug use and services differently, stigma and discrimination was not considered to be gendered.

“...I think a drug user is in that box of that negative stereotype and I don't think they differentiate too much whether they're women or men...” (Key worker - pharmacist)

The above views fit the dominant discourse where women-specific services in relation to drug services are slowly gaining more attention, although their existence continues to remain an exception. Exceptions tend to be based around WWID who are pregnant or have children, however this is usually in relation to drug treatment programmes as opposed to harm reduction initiatives like needle exchanges (EMCDDA, 2006).

Being a mother or woman that is pregnant and injects drugs carries a double stigma. This was discussed in depth in the chapter on stigma, and will be briefly explored here to demonstrate how it functions as a barrier to needle exchange services. In an Australian study, by far the most significant barrier to needle exchange access that was reported by mothers who injected drugs, was the concern about negative consequences related to their drug using status and pregnancy or motherhood (AIVL, 2003). Community services, family and others discriminate against WWID and the fear of being judged to be a bad mother also impacts access to services (AIVL, 2003). Of the two key participants in this study that are mothers, one in particular confirms this evidence when she shared her thoughts about whether she felt comfortable as a mother accessing counselling or needle exchange services within the pharmacy: 
“...when you're a mother and you're going in [to counselling], you make yourselffeel a little bit small because you feel that you shouldn't have this addiction at your age and with children ... the chemist is, well [makes a disapproving face] the only place I did feel comfortable using is the Needle Exchange" (Clara)

During her access of harm reduction services, the judgement against being a mother who injects that 'Clara' felt demonstrates that double judgement and stigma can be a barrier for WWID. Additionally, with regards to feeling judged, 'Clara' notes the difference between accessing counselling and pharmacy based exchanges compared with stand-alone exchanges. However, judgement is not limited to the pharmacy staff, as injecting peers, including a participant in this study, also have opinions about mothers, injecting and children in terms of accessing needle exchange services.

"The only difficulties I could think of would be, I mean it's funny because these days a man is quite likely to be looking after kids, instead of a woman but maybe if she has her kids with her...I don't think they would like children in there... so it's not an appropriate place to take your kids in my opinion" (Jordan)

'Jordan's thoughts corroborate the notion of stigmatising attitudes within the drug using community. AIVL's (2011) report describes peer to peer stigma and discrimination related to particular drugs and consumption methods, and cites the symbolism of injecting drugs possessing such power in comparison with drinking alcohol or snorting amphetamines. Although the peer to peer stigma demonstrated in 'Jordan's thoughts do not mirror AIVL's (2011) notion, the strength in multiple deviancies of being a women who injects drugs and a mother is evident here. This highlights the pervasiveness of stigma as a barrier to services for mothers who inject. One key worker acknowledged that the children's presence could serve as a barrier due to the mother's desires to manage her injecting use, and the associated stigma without children's knowledge: 
“It would be a part of their life that they wouldn't want their kids to see so they're probably trying to sneak in when they haven't got the kids or they're got to live a tighter life don't they? Very rarely do we have people rock up with kids so there's probably a feeling that they don't want their kids to see this behaviour" (Key worker - Needle Exchange 1)

In attending counselling, one key worker shares that children's presence could impact what women felt able to disclose to their counsellor or their ability to focus in counselling sessions:

"Whether they bring their children here or they leave their children at home, sometimes that's a part of, they're mindful about how much they share in front of their kids. So that can be a bit of a barrier... when there's three kids and mum's trying to concentrate on what you're saying..." (Key worker - counsellor)

The literature is devoted to identifying the presence of children being a bureaucratic barrier, rather than how a mother might feel if her child or children are present. Taylor (1993) reported that the mothers who injected in her study expressed attitudes towards motherhood which mirrored mothers who did not inject, such as expecting to be caring towards their children. Three of the participants in Taylor's (1993) study did not want their young children to be present when drugs were injected. The above comments suggest child-care responsibilities may be a practical issue for mothers accessing services, but that emotional issues around a desire to prevent children seeing or hearing events, may also be present.

As previously mentioned, while barriers to access of needle exchange services have lacked a gendered analysis, the evidence suggests a disproportionate number of men access services compared with women (Pinkham et al., 2012b). In considering what contributes to this disparity, one key worker believes that stigma associated with being a mother and a WWID could act as a systemic barrier, and therefore, mothers who inject, may instead, assign their male partners to obtain sterile equipment. 
“'You've just had a baby, forget about it, I'll go collect them, that's part of my job now'...that could be why we have high numbers of men coming through and maybe in reality there's 50/50 as far as using, it's the man's job to pick up the family fit. It's [the risk of a mother being seen, is] lessened.” (Key worker - Needle Exchange 1)

The above key worker's comment reflects a complex combination of the accepted gendered obligations and the multiple layers of stigma a mother who injects could face. Ascribed gender roles within heterosexual relationships increase the difficulties for women in accessing harm reduction services (Pinkham et al., 2012a). Further, women are more likely to be the caretakers within the home and to carry the domestic responsibilities (Roberts et al., 2010), and as noted in the literature review, drug using contexts mirror wider society.

A lack of knowledge of the location or even the existence of needle exchange services is also a significant barrier to accessing harm reduction services. It is difficult to know the proportion of PWID that are unaware of the services or their locations, as the efficacy of needle exchanges are largely evaluated from a public health perspective. Additionally, reviews of services tend to recruit participants via needle exchange services themselves (Aitken, 2002), therefore unknown users to the exchange are a more hidden population. Several studies that did recruit more widely reported a range of $22 \%$ to $50 \%$ of respondents citing access difficulties around needle exchange services were due to a lack of awareness (Klein, 2007). Though gender was not acknowledged as a factor, some research suggests there is a correlation of a lack of awareness of needle exchange services as a barrier and factors such as age, ethnicity and duration of injecting (Cao \& Treloar, 2006; Treloar \& Cao, 2005). Duration of injecting can be a factor as information about safer injecting is often from other peers or by word of mouth (Treloar \& Cao, 2005). As it is also argued that WWID are more likely to conceal their injecting use compared with men, lack of awareness and less information sharing could affect women more, though more research is needed in this area. In demonstrating the importance of peer knowledge, one interviewee in this study, who had started injecting in a small city, had 
been unaware of where to obtain sterile injecting equipment and had only been supplied such by peers. However upon moving to a bigger city he was given information by a MWID:

"As soon as I arrived in [city], as soon as I saw my first pill, I got the needles from him [guy who supplied pills] but he told me about the Needle Exchange. He was 'just go down', told me the lady to see... “ (Jordan)

Peer knowledge was influential for one participant in this study in learning about the existence of the local stand-alone exchange. 'Nina' reflects on her surprise of learning about the presence of her local stand-alone needle exchange.

"I didn't even know there was one here [rural area]. Somebody told me a couple of years ago and said 'oh there's this vending machine' and I was 'what? You're joking me cos I'd always gone to the chemist." (Nina)

Needle exchange workers were aware of the issue of the Needle Exchange not being well known to PWID.

“...There's still people that still go there [the pharmacy]. I don't know why...I suppose they don't know [about the stand alone Needle Exchange]..." (Key worker - Needle Exchange 3)

Not promoting the needle exchange could be attributed to a lack of money as funding is often restricted (Klein, 2007). Though it is thought to be more likely due to the stigmatisation of the injecting drug community and the desire to maintain a discreet and confidential service. This can contribute to the lack of awareness of its existence and location (Klein, 2007). One key worker acknowledges the main method of advertising:

"It's word of mouth. That's our biggest lot of advertising..." (Key worker - Needle Exchange 2)

The lack of formal advertising in New Zealand is also mirrored in an international context. For example, many needle exchange providers in Australia have written policies establishing limitations on advertising, this can be attributed to the effects of stigma and are justified in part 
by an obligation to keep client confidentiality. However it is also argued that this is due to avoiding negative attention at a wider level (AIVL, 2010). In response to a question about how well known the existence of the needle exchange is, one key worker responded with:

"It's not [known], and a lot of people go 'what's this place?", (Key Worker - Needle Exchange 1)

Improving the visibility is an important issue for needle exchanges. Furthermore, the balance between providing a discreet location, confidentiality and ensuring awareness of the needle exchange, is an issue for operators of this service (AIVL, 2010).

Women report feeling a lack of power in relationships between themselves and key workers within harm reduction services. The imbalance in power is reported as power over prescriptions, services and children (Roberts et al., 2010). In the design of some programmes, a key worker can possess official power over a client's access to prescribed substances. This is particularly notable in the case of methadone, or similar maintenance programmes, where some women have reported feeling overwhelming pressure to present themselves as well behaved or be at risk of having their medication restricted (VANDU Women CARE Team, 2009). The acknowledgement and understanding of the power dynamic between workers and PWID is important, particularly when the worker has power over a PWID's prescriptions and access to services. One key worker was aware of this barrier at a systemic level:

"In counselling study, a part of what we look at is power. It doesn't matter whether it's a counselling appointment or doctor's appointment, there is a power dynamic there of somebody that is in a position, or seen as a position of authority. That seems to be particularly poignant working with methadone and the methadone programme because we have influence over their medication..." (Key worker - counsellor)

\section{Structural Barriers}

As noted, structural barriers come from service design, implementation and operation. In reviewing relatively new needle exchange programmes in Vancouver, evidence suggests that 
binge injecting acted as a barrier in accessing sterile injecting equipment (Ashton, 2004). It is suggested that binging prevented access to sterile needles due to a combination of the frequency required to visit exchange outlets, the limits of quantities of sterile kits available for each visit, opening times of outlets, mis-timing visits to mobile outlets and police confiscations of injecting equipment (Ashton, 2004). Therefore binge injecting often leads to PWID reusing their own needles, which is risky as used needles lack sterility and become blunted quickly (Ashton, 2004).

In the scant literature evaluating women-specific barriers in accessing needle exchange services issues around women specific services are highlighted. Women who had accessed services in the nation of Georgia highlighted that the lack of services catering for child-care needs, attention/knowledge about childhood abuse traumas, drug use during pregnancy and reproductive healthcare adversely impacted their capacity to access treatment (Otiashvili et al., 2013, p. 4). A lack of knowledge about available services further prevented access, however the evidence suggested this was not necessarily gendered (Otiashvili et al., 2013). There is a difficult balance needle exchange outlets must find, between maintaining confidentiality of clients by keeping the location discreet, and ensuring that the location is known.

In the context of accessing treatment for problematic drug use, it is worthwhile to note that prior to drug decriminalisation in Portugal, criminalisation was deemed to be a significant barrier to treatment and other drug services (Greenwald, 2009). In particular, fear of arrest was cited as the most prominent barrier (Greenwald, 2009). Similarly, a barrier to access of needle exchange services is related to the avoidance of potential legal issues around injecting drug use. Globally, there is a diverse legal status around possession of sterile injecting equipment. Notwithstanding whether possession is legal or not, multiple studies suggest that PWID fear legal consequences (Klein, 2007). Despite the fact that Needle and Syringe Exchange outlets 
are legal in New Zealand, fears of being searched for illegal substances, or being identified and surveilled by police can prevent PWID from accessing services.

Although the Needle Exchange programme in New Zealand was first implemented in 1987, it did not effectively enable PWID to legally possess injecting equipment, sterile or used, only the sale of equipment was decriminalised (Aitken, 2002). This gap was not addressed until 1998 when a legal defence of possession for injecting equipment obtained via the Needle and Syringe Exchange Programme (NSEP) was inserted into the Misuse of Drugs Act (MDA) 1975 (Aitken, 2002). Additionally, the legal defence only effectively applies with unused equipment, as used equipment can contain substance residue (Law Commisson, 2011). Furthermore, until 2005, the onus of proof to show needles and syringes had been obtained legally from the needle exchange was on the individual user rather than police (Law Commisson, 2011). It is a well-documented barrier, that the danger and risks of being stopped, searched, arrested, prosecuted and convicted deter WWID from accessing Needle Exchange services (Aitken, 2002; Ashton, 2004). In a review of the needle exchange services in Vancouver, the fear of police presence and surveillance was associated with an almost doubling of the risk of sharing needles (Ashton, 2004). In the survey that formed part of the New Zealand Needle Exchange programme review, 37\% of PWID that reported not returning their used equipment said it was due to fear of the police (Aitken, 2002). It was not until 2005 that an amendment was made to the New Zealand Misuse of Drugs Act (1975) to transfer the responsibility of proof to police with regards to possession of needles and syringes rather than on individuals accessing the services (Luke, 2007). More recently, the Law Commission has noted that the existence of any offence of possession of injecting equipment can compromise the effectiveness of Needle and Syringe Exchange Programmes and it is recommended that the offence of possession of utensils for drug use be abolished (Law Commisson, 2011). 
'Cassie' was injecting drugs during the 1990s before a legal defence of possessing injecting equipment existed. As she was accessing services before this law change, 'Cassie' remembers being very aware of the risks associated with taking an illegal substance and being identified as an injecting drug user. The fear associated with this risk, at the time, prevented her from accessing the needle exchange services.

"I wouldn't even go into the chemist. I would just not want to be associated with that and be terribly scared...just not wanting any heat or getting caught or anything like that...maybe scared because of the illegality of the drug and the seriousness of [it] ...even at home when I was in [city], I had all those needles, you could be charged for having needles which had the remains of drugs in them. So I wouldn't be paranoid taking the clean ones home, but bringing the dirty ones back to be recycled...I'd cleaned them out but yeah, I was pretty paranoid." (Cassie)

Accessing services other than needle exchanges are also an issue due to the criminalisation of injecting drug use. A study from Portugal reported that the principal barrier to treatment being offered for PWID was fear of state officials due to the illegal nature of injecting drug use (Greenwald, 2009). In New Zealand, PWID have reported that being able to talk to people about accessing treatment for illicit drug misuse was difficult due to the activities' illegal status (Ministry of Health, 2009). Furthermore, criminalisation as a barrier is recognised by key workers in this study, one key worker below notes how this can cause issues for PWID accessing services:

“...Our whole drug policies are around criminalising, there's no policy around health and injecting. It's all around the criminal aspect of it. So, that's a real barrier for everyone..." (Key worker - Needle Exchange 1)

The earlier section exploring systemic barriers to the needle exchange included a lack of acknowledgement of women specific issues. As a structural barrier, this refers to the specific lack of women staff who have direct contact with WWID. The masculine space of a needle exchange can have an effect if there are no other women workers present. The lack of a gender 
balance can affect how women feel and experience services (Pinkham et al., 2012b), or marginalise their access. While this did not necessarily prevent access for 'Cassie', she recalled how the atmosphere felt masculine.

"Yes, and just aware of gender. Aware that they were guys. I think I thought one of them was cute. That's about all I remember. It probably would have been good to have some more women in there." (Cassie)

Research suggests that women who inject drugs may be more likely to have experienced trauma than men, and that there is a need for women workers to be available to provide key services, particularly harm reduction of health services (EMCDDA, 2009; Malloch, 2004). Despite the lack of recognition previously for the need of explicitly gender friendly services, some key workers did acknowledge that women accessing drug services may have specific needs.

The importance of the availability of a female doctor was noted by a key worker for WWID:

“...for some of them, there's a really high incidence of trauma and post-traumatic stress disorder, particularly with the client group I work with. Some of the women don't necessarily feel entirely comfortable and safe going to see a male GP [General Practitioner]..." (Key Worker - counsellor)

As highlighted in the introduction, evaluations of needle exchange services have revealed the disparity between experiences of services offered in peer supported outlets compared to services attached to pharmacy outlets. Overwhelmingly, participants who had accessed needle exchange services reported negative experiences with staff located within pharmacies, rather than in a stand-alone needle exchange outlet. While not every service experience received from pharmacy staff was negative, participants commonly reported feeling poorly treated by staff. In the 2002 Needle Exchange programme review, negative staff attitudes within a pharmacy setting were perceived to be present by $79 \%$ of PWID, and it was recommended that a systematic approach be implemented to address it (Aitken, 2002). Despite the scant research around pharmacy workers' attitudes and their training regarding drug management in New 
Zealand, the salience of the attitudes and the importance of training is acknowledged (McCormick, Bryant, Sheridan, \& Gonzalez, 2006). While some studies report that providers of needle exchange services in pharmacies present more positive attitudes towards PWID than pharmacies without the services (McCormick et al., 2006), PWID continue to report negative attitudes impacting their experiences. In a recent study by the $\mathrm{MOH}$ (2009), clients on methadone programmes still reported unfavourable service by staff in pharmacies.

Negative staff attitudes served as a barrier to access for participants in this study. The manner in which staff treated WWID accessing sterile needles affected interviewees in a number of ways, ranging from experiencing a feeling of shame, to not accessing the pharmacy at all. 'Clara' in particular recalled a particular occurrence:

“Where they're just right out there like, 'How are we today? CLEAN?' and the next person could think I'm smelly and don't wash or god knows what they're thinking when someone says that to somebody" (Clara)

This treatment acted as a strong barrier for 'Clara', as when asked how she then managed future access to that particular needle exchange, she responded:

“...nah, [I] would not even go there..."

'Nina's first experience was also negative and this significantly impacted how access was managed in future. 'Nina's response to her experience was to alter her means of obtaining injecting equipment through either asking another person to go in for her or to re-use her needles and syringes.

"It was really embarrassing and they say it, they repeat what you want really loud, so everyone in the pharmacy can hear...it puts you off wanting to do it [go to the Needle Exchange]...especially in the years just before I stopped I always made someone else do it. If I had one that was sharp enough on me I'd use that again rather than go get another one cos it's embarrassing." (Nina) 
Bearing this experience in mind, 'Nina' recalled how she felt about the service after the negative treatment:

"...you really have to have an understanding, a bit of discreetness [sic] and a bit of knowledge about it, instead of 'we know you better than me' [better than I know myself], you don't put a needle in your arm, you don't know me and what I feel like now and just do your job, a professional attitude towards it. You don't want to go in there and be told whether it's right or wrong cos if it was they wouldn't sell [needles]. You're there to get a product, it's the same people that are able to separate their personal opinion and do their job and do it in a professional way. "(Nina)

Furthermore, 'Nina' highlighted that the negative treatment she experienced was not limited to one particular staff member

“...some of them were alright, but others, they just look at you like you're the scum of the earth, they won't touch your hand and it's just really apparent and it does put people off and makes you think - this is a service for that, don't you want to encourage people to use it" (Nina)

One respondent noted that, in addition to feelings of shame and being judged by others, it also felt like the pharmacy worker was embarrassed.

"I think she was embarrassed...I don't know it was weird that she didn't want it to be known I think that we're [the pharmacy] a needle exchange or something but she just 'oh no no, over here' hushing me up and moving me to the side.” (Lucy)

Additionally, these experiences negatively reinforced how participants felt about the service. This is argued to reinforce shame and stigma, lessens confidence in the service and increases barriers to access by further contributing to a lack of a PWID's self-worth (AIVL, 2011).

“The first time I went in I wasn't sure where to go so I went straight up to the counter and I was 'hey where's the needle exchange', she went 'oh no' she kind of really shushed me up and said 'come over here, come over here' and she made me go round to the side of the counter. She just said 'where's the bag' and I slowly looked at her and she gave me a bag, and then from then on I just knew that you go to the side of the 
counter, you just hold the package and there's literally no words exchanged, and then you'd walk away." (Lucy)

A New Zealand study examining attitudes, processes and training towards PWID and pharmacy-based services suggested that pharmacy-based exchanges had more positive attitudes in contrast with pharmacies without exchanges. Numerous pharmacists reported that they had ceased with providing needle exchange services due to their feelings that "clients were abusive and difficult" and "the services...gave the pharmacy a bad name" (McCormick et al., 2006, p. 567).

Due to the associated shame and stigma around injecting use, particularly for women, the impact of the location and design of a needle exchange can prevent access for WWID. Pharmacies that include needle exchange services have issues with confidentiality due to members of the public being in the same space. Accessing services in a public space can exacerbate experiences of stigma and this has been discussed in greater detail in the chapter regarding stigma. The 2002 review of the New Zealand needle exchange services reported that $41.6 \%$ of PWID suggested that they preferred better anonymity as an improvement to pharmacy based services (Aitken, 2002). Furthermore, a lack of a private area in the pharmacy has been highlighted as a barrier to accessing some exchange services (Sheridan et al., 2005a). One worker also noted that:

"You're pretty much publicly outed at the chemist anyway cos you're sitting there amongst the rest of the public." (Key Worker - Needle Exchange 2)

A lack of a discreet location or assurance of confidentiality can act as a barrier to access. Some participants travelled to avoid going into needle exchanges in pharmacies they felt were too local and increased the risk of being identified using the services. It has been suggested that in bigger cities like Auckland, PWID are less concerned with anonymity as there are more outlets available for them to use (Aitken, 2002). Whereas rural communities with a lack of services, 
present concerns about anonymity, particularly in pharmacy based exchanges (Gay Men's Health Crisis, 2009). The feeling and risk of confidentiality varied with participants, and was also dependent on the geographical location of their residence and the needle exchange services. However small towns were perceived as riskier due to the likelihood of people knowing each other more. Feelings of insecurity relating to being 'outed' by accessing the needle exchange were experienced

"I felt unsafe in the way that I'd see someone I knew. Because it's the [urban area] and it's very small. I was like 'fuck, if someone sees and my parents didn't know at this point that I was using IV drugs. So it was like 'fuck, if they find out and tell my parents'. That scared me." (Lucy)

Return of used needles to a pharmacy needle exchange rather than a stand-alone service could be seen as a problem, as in the pharmacy, WWID risk encountering someone who knows them. The lower rates of return to pharmacies, compared with stand-alone outlets could also be due to a large proportion of pharmacies not offering the one-for-one ${ }^{19}$ service (Aitken, 2002), which is a lower cost for PWID, or due to pharmacies largely not offering 'credit' ${ }^{20}$ to any clients (Sheridan et al., 2005a). However, participants in this study mainly cited anonymity as the main reason to avoid returning used equipment to pharmacies.

“...I'd pick a chemist that wasn't anywhere near someone I knew, that I didn't want to see me. It's the same as when you have to go and drink your methadone anyway, you might see somebody in the shop that 'oh, what are you up to?',"(Clara)

Additionally, the containers designated for returning used needles and syringes could be an issue due to their prominent features. One participant recalled what she thought about the containers when she was returning used equipment:

\footnotetext{
${ }^{19}$ One-for-one refers to the service of every used syringe returned to a NE, a free $3 \mathrm{ml}$ barrel (part of a syringe) with needle will be supplied.

${ }^{20}$ Some needle exchanges allow customers to defer payment for injecting equipment
} 
“...they're like big, red containers with a big needles on it - 'Hi, I have a sharps object inside' [laughs] in a big packet and a big sticker [laughs]...Ten needles, a sterile container, like it was a big bag. Not discreet that's for sure." (Nina)

Despite the needle exchange services being considered confidential within pharmacies (McCormick et al., 2006), if clients are on methadone programmes and are seen to be obtaining injecting equipment, their place on the methadone programme can be compromised. One key worker within a pharmacy acknowledged that confidentiality of clients on a methadone programme and who also access needle exchange services, for whatever reason, may be at risk.

“...If you were a methadone client you wouldn't be coming in and asking for needles 'cos then we'd know that they were using. Even though the scheme's totally confidential we're not...So those people [injecting] would go into the city to get their needles and syringes..." (Key Worker - pharmacist)

If drug services are in a location that does not protect and maintain confidentiality for women, their access could be prevented. One key worker noted that the confidentiality of some of her clients could be compromised due to the location of the drug services she worked for:

“...the public nature of the building, where we're situated we're almost across the road from the main medical centre and McDonalds, which is quite popular in [town]. Some of our clients sometimes feel it's a bit conspicuous coming in here..." (Key Worker counsellor)

Not wanting to be 'outed', or identified as a PWID operates as a barrier to accessing the needle exchange services. The possibility of being recognised, particularly in New Zealand, during a visit to a needle exchange, as a stand-alone service or in a pharmacy, can prevent people accessing the services they need.

“...we live in a small town so if you're trying to hide your habit or you're not comfortable with it that could be a barrier. But that's a barrier for everyone. I don't think there's specifically a barrier for women..." (Key Worker - Needle Exchange 1)

Confidentiality can be an even greater issue in rural or small town locations in New Zealand 
“...we're in a little town, a small population. You've got to be very wary of that. That's where confidentiality is a big thing...” (Key worker - Needle Exchange 2)

“...because it's [a] smaller [town]. Somebody sees somebody from the [methadone] clinic coming in [here], oh 'bang, they've just been in here [to the methadone service]'..." (Key worker - Needle Exchange 2)

Although the key workers do not consider that this barrier is gendered, the evidence suggests it is, due to stigma and issues of double deviancy affecting women specifically (Pinkham et al., 2012b). Finally, some key needle exchange workers believed many potential clients incorrectly believed that stand-alone needle exchanges were run by or connected to District Health Boards and/or Alcohol and Drug Services (AODs). This prevented them from accessing the stand-alone services as PWID did not want to risk their injecting-drug use to be 'outed':

“...everybody thinks we're run by the District Health Board and they think that we're in partnership because the other AOD services are all funded by them pretty much. So they think we all collaborate..." (Key Worker - Needle Exchange 2)

Quite often geography plays a part in preventing people accessing the needle exchange, particularly if they are sick or have limited funds. In a relatively sparsely populated country, New Zealand's rural areas are often considered to be under-serviced (Gay Men's Health Crisis, 2009). However participants revealed that living in urban areas also presented travel issues. Financial constraints can also present a barrier (VANDU Women CARE Team, 2009). Here participants noted that issues around transport, or lack of, prevented them access to sterile needles.

"We never really used during the early hours of the day, but the last time I did use, which is part of the reason I stopped, we couldn't get more needles, we were stuck out in [suburb of urban area] so we shared. And we used old needles, that we'd already used and we shared... “(Lucy)

"Often, I'd wake up, and I'd have no clean needles, I only lived in [suburb of urban area] but it would be, well I could either walk from [suburb of urban area] to the Needle 
Exchange on [Street] and then walk back again or I can just reuse my needles and obviously the easiest thing is to reuse the needles. So, you're going to do that pretty much most of the time. But then you do it and you do it and your needles get so blunt. Then you have to go [to the NE]. So, transport, money for transport, would be the biggest one..." (Jordan)

In 2002, needle exchange workers reported that they believed transport and the associated costs of accessing services were an issue for PWID (Aitken, 2002). Key workers in the needle exchange in this New Zealand study affirmed that both transportation and finances presented as potential issues. One key worker noted several reasons that could contribute to transportation issues:

“...it could be someone who's on Home $D^{21}$ or out of town or up the coast...” (Key Worker - Needle Exchange 1)

The key worker continued to share his observations that these issues may disproportionately affect Māori, but was unsure whether WWID would be more likely to have transportation issues. Statistically, women are more likely to be released for Home Detention sentences than men relative to their custodial populations (King \& Gibbs, 2003). Therefore while this could suggest that there is a gendered element to this barrier, more research is required to assess this. Participants may have preferred to access a stand-alone Needle Exchange but often continued using a pharmacy due to a lack of funds. Additionally, travelling around the country and being unfamiliar with locations of Needle Exchange services was cited as a barrier to accessing services. Although one participant had been informed via the Needle Exchange website where they could find services out of their local area, it was still troublesome:

“...I used to frequent the Needle Exchange website and it said something about, if you go to [city], then this is where to go. So I went there and it was an after-hours doctor/medical clinic/chemist. I went there and I was like 'ahhhh could I please have

\footnotetext{
${ }^{21}$ Home Detention is a home based option where someone convicted of a crime with sentenced to a custodial term, they can apply to serve some or all of the sentence at home (King and Gibbs, 2003).
} 
$2.5 \mathrm{ml}$ barrels or $2.5 \mathrm{ml}$ syringes' or whatever I said and he was 'are you diabetic?' and I was like 'ah, no' and he was like 'then what do you want them for?' and I was like 'ahhhhh', I couldn't remember what I said but he was like 'I'm going to ask you one more time, are you diabetic?' I was like 'yeah...' I couldn't remember if I said yes or no. Anyway, he wouldn't give me any. I was like 'fuck' cos I'd walked like 'ks' [kilometres] to get there, I'd walked from [suburb] into town" (Jordan)

Not only does 'Jordan's experience demonstrate the difficulty in finding appropriate services when travelling, the experience confirms training issues and attitudes, as mentioned earlier, for pharmacy staff whether they offer needle exchange services or not.

\section{Personal, cultural and social barriers}

The third and final category to be explored in this chapter are personal, cultural and social barriers. As described earlier, these barriers are associated with a WWID's individual life circumstances (Roberts et al., 2010, p. 75). They can include: experiences of stigma, fear of losing custody of children, intimate partner violence, relationship issues, financial problems, concerns around the lack of specific services for women and fear of negative treatment for pregnant women (Roberts et al., 2010, p. 75).

Research has suggested that WWID are more likely to be in a romantic relationship with another person who injects drugs than MWID (Pinkham et al., 2012a). It is argued that relationship factors can serve as, and contribute to barriers women experience in accessing harm reduction services (Pinkham et al., 2012a). It was believed by some that within the injecting culture, as well as in a wider social context, women were still subjugated to men with regards to obtaining and consuming drugs and access to sterile equipment. From his observations within the injecting drug community, and having only accessed pharmacy based needle exchanges in small cities compared with larger urban centres where he accessed standalone exchanges, 'Jordan' considered that this issue may have been exacerbated in smaller 
towns and within pharmacy based exchanges.

“... when I was in [small city], women were seen as less than ... women usually relied on the partner for everything, for the drugs, the needles, everything. Whereas down here, a woman can, not even have a partner and still access clean needles and all that sort of thing and it makes her feel more...feel better about herself and not that she has to rely on someone else to fulfil her needs. She can fulfil her own needs." (Jordan)

As argued previously, Roberts et al. (2010) and Pinkham et al. (2012a) cite traditional gender roles within heterosexual couples, such as power ascribed to men and domestic duties to women, contributing to access difficulties. Key workers recognised that relationship issues could present more barriers for women than men in accessing services.

“...I think that physical access to, getting to the pharmacy, it could be an issue...it depends on whether they're in a relationship...not because they don't want to get here it's because they're inhibited, prohibited from getting here...clients haven't been able to get here because of relationship issues. It's always the women that are the ones that don't get here..." (Key Worker - pharmacy)

One key worker noted that the cost of sterile injecting equipment in needle exchanges within a pharmacy is higher than a stand-alone needle exchange and this can be a barrier for some WWID

"It's a lot dearer going through the chemist than through here. ${ }^{22}$ " (Key worker Needle Exchange 2)

Key workers also noted that financial barriers affect access to services other than needle exchange services.

"GPs seem to be something that some of them have difficulties with because I don't know of many people in the programme that have excess money. They're just scraping

\footnotetext{
${ }^{22}$ Needle Exchange outlets are able to set their own prices for injecting equipment, with pharmacy prices generally higher (Aitken, 2002).
} 
by, some of my clients they have $\$ 20$ or $\$ 30$ a week to feed themselves on, so going to see a GP is way down on the list..." (Key Worker - counsellor)

The risk of sharing needles or re-using needles, increases when access is an issue due to illness or increased use.

"I would get huge amounts at one time and when I cleaned out my flat to go to rehab, they used to have these dark red canisters [for needle returns], I'll never forget them and I had like six or seven of those under my bed full of dirty needles that I'd used and as the addiction became more violent or more stronger I went less and less." (Cassie)

'Cassie's experience above occurred in the early 1990s. A mobile service could have mitigated this. The Needle Exchange Service currently offers one mobile van service on the West Coast of New Zealand and several, but very limited, mobile services out of stand-alone NE's located in small towns which deliver sterile injecting equipment, and collect and safely disposes of used equipment (NEP National Office, 2013). Lack of knowledge around services persists though, and mobile services provided by the Needle Exchange and the outreach service were not known by the participants in this study. Chapter six, the final results chapter, discusses the gendered nature of injecting drug use through the experiences of WWID. 


\section{Chapter Six: Gendered experiences}

As previously discussed, gender is embedded in all cultural institutions and shapes behaviours, thoughts and emotions. Conventionally, women are ascribed what are regarded as feminine traits which are to be nurturing, passive and risk-averse. This contrasts masculine associated traits such as dominance, hedonism and riskiness (Connell, 2002). Gender is enacted in diverse ways across a variety of situations. This chapter demonstrates some of the ways that participants have experienced their own worlds through gendered means. Their experiences are heterogeneous and some demonstrate structural barriers that are interwoven by gender, class and ethnicity, while others express an overt sense of agency and defiance of stereotypical views.

Doing drugs and doing gender are not mutually exclusive. Although many women who inject drugs will share experiences with their male counter-parts, it is important in understanding WWID, to highlight women's diverse experiences. This section will explore women's experiences of initiation into injecting drugs and look at how women access drugs. Following this, will be an analysis of the context in which women inject, including who women inject with and who prepares drugs and equipment.

\section{Initiation to drugs and injecting drugs}

The introduction to illicit drugs and in particular, injecting illicit drugs, is often argued to be gendered (Hankins, 2008), and women are said to be introduced to drugs by men more than the converse (Anderson, 2001). Despite the commonly accepted explanations of women's introduction to injecting drugs being passive due to patriarchal oppression, there are multiple studies that evidence women's active participation in their initiation to injecting drugs (Payne, 2007). Increasingly, research has shown the heterogeneity of women's experiences. Taylor 
(1993) found that many participants in her ethnographic work revealed they were introduced to drug experiences through other women, or the women introduced their male partners to drug use. Although, Payne (2007) argues that evidence from one study suggests that women may be active in their involvement in injecting drug use, their relationships with, and the presence of males are also paramount to women's injecting. The importance of males' presence and their influence in the context of some women's injecting highlights the extent of sociallyembedded gendered roles within heterosexual relationships (Payne, 2007). As a reflection of wider society, the drug using world is also gendered and this is argued to influence initiation to injecting experiences (Bryant \& Treloar, 2007).

As the majority of traditional drug research has been focused on men, women's initiation and introduction to drugs has been absent in the literature (Payne, 2007). Research suggests that although the majority of first-time injecting is unplanned, people can recall their reasons for injecting (Roberts et al., 2010). While the literature shows that many instigators to injecting drugs are consistent for both men and women (Roberts et al., 2010), some reasons are argued to be gendered and more likely to correlate to women's initiation than men's (Payne, 2007). From the scant literature focused on women, gendered reasons include: trust in heterosexual partners who currently inject drugs (Bryant \& Treloar, 2007; Roberts et al., 2010), increased likelihood of peer pressure than men (Roberts et al., 2010), higher levels of issues related to childhood abuse, living with family violence, experiencing post-natal depression, (Payne, 2007), and women's involvement in sex-work (Tuchman, 2015).

Research that distinguishes between men and women, involves listening to the voices of women, and highlights agency alongside varied reasons for using drugs, from pleasure to managing difficult situations has challenged the status quo (Payne, 2007). This allows the complexities around women's initiation to injecting drugs to be portrayed. As Tuchman (2015) points out, motives to begin injecting drugs are multifaceted. The following section will 
explore the participants' different motivations to injecting alongside evidence from current literature. As noted previously, for women, the majority of first time injecting is spontaneous (Roberts et al., 2010). Although spontaneous, few women report that the first time is someone else's idea (Roberts et al., 2010). In this study, the participants' referred to their decision to inject as an unplanned decision, although they may have contemplated it previously, they either did not source drugs or needles themselves, or did not prepare the drugs and needles to inject for their first time.

Some research has cited pathological reasons for women's movement into injecting drugs as a means to self-medicate or cope with trauma (Roberts et al., 2010), depression, or issues connected with surviving sexual abuse (Payne, 2007; Roberts et al., 2010). In this study, it appeared that a lack of emotional well-being for some participants influenced their introduction to injecting. Both 'Lucy' and 'Nina' note that, in part, some issues with mental well-being contributing to their initiation to injecting:

“...I'd already suffered depression ... and anxiety so I was 'I'll give it a go then'...” (Lucy)

“...I'd seen him doing it [injecting] so I thought it was really cool...I was just on a downward spiral...I was keen as to try it...” (Nina)

Although both 'Lucy' and 'Nina' described situations where they felt their state of mental health contributed to their motivation to inject, their comments also reveal agency in their decisions.

Other reasons the women in this study provided for their introduction to injecting drugs largely contrasted the well-established stereotype of women displaying signs of individual psychological pathology. These results support other qualitative research such as Tuchman's (2015) and Roberts et al. (2010) that sought women's own experiences and reported the complex and varied reasons for beginning to inject drugs. As reported by Taylor (1998) some 
women reported pleasure, curiosity and adventure behind their motivation for injecting drugs. Three of the participants in this study identified with this rationale. 'Clara', 'Jordan' and 'Cassie' reported pleasure and/or curiosity as reasons to first inject:

“...I'd heard about it and I thought 'jeepers, I dunno, well I'll have a go at that'...all I got was a really warm feeling and then just felt really, really relaxed..." (Clara)

“...I was just motivated by 'I just really want to get out of my own head', 'I want to get high', 'I want to feel good'...” (Jordan)

'Cassie' reported that she started injecting drugs with a mixed-gender group of friends and although she was unable to remember the event in great detail due to the length of time that had passed, she recalls that the decision was most likely curiosity based, rather than for any pathological reasons:

“...we decided we would do it...we were taking any other drug that was on the market... we just really wanted to feel that feeling..." (Cassie)

These findings highlight a contrast between stereotypical notions of WWID being acquiescent in their drug use, as these women expressed a level of agency. Furthermore, the women in this study recalled that, in the context of initiation, the person assisting with injecting was hesitant to show them. This supports Taylor's (1998) findings where the women in her ethnography expressed their own agency and enthusiasm to make the decision to inject drugs. One of the participants in Tuchman's (2015) study described pressuring someone to assist her. Although 'Nina' had cited feelings of melancholy that partly attributed to her initiation to injecting use, she also demonstrated some agency in the following account where she describes a need to convince a man she was with to assist her:

"I asked him and he was a bit reluctant but he was doing it so it was...men can only say no so much..." (Nina) 
Alongside the agency evidenced through the decisions WWID make in the context of their injecting, understanding the reasons that women provide for not injecting, or not continuing to inject are also significant (Roberts et al., 2010). Although there is a dearth of literature around this, studies have cited reasons such as: fear of diseases, fear of needles and fear of becoming dependent on drugs (Roberts et al., 2010). 'Clara's agency is demonstrated through her conscious decision to not continue injecting after her initial experiences:

“...I didn't want to be a prostitute to feed my habit...I had a little try of it [injecting,] I think twice when I was young...it wasn't my bag...” (Clara)

Although 'Cassie' continued to inject after her initiation, she identified with a desire to maintain control over her initial drug use and her justification was also due to a fear of becoming dependant on the drug. 'Cassie' recalls being mindful and taking caution with further injecting use:

“...we were extraordinarily careful with it for the longest time...about a year or 18 months...never did it more than once a week, at the most, it was never anywhere near that frequent to begin with... just because we were so scared of becoming addicted to it. We were very aware that it was a very addictive thing to do..." (Cassie)

The above accounts support research that counters the portrayal of women as pathetic and passive in their decisions (Payne, 2007; Roberts et al., 2010; Taylor, 1993; Tuchman, 2015). Taylor (1998) argued that none of the women in her ethnography saw themselves as passive or helpless despite how they were or who had introduced them to injecting. Additionally, women in Tuchman's (2015) study expressed various reasons for their shift to injecting, such as: to reduce the cost of obtaining a high, to receive the effect of the drug with more efficiency, curiosity, or a desire to conform to friends' or others' behaviour (p. 3). As Taylor (1998) asserts, the women in her ethnography made rational, pragmatic decisions based on the constraints around them, as did the women in this study. 
Despite the long-held notion that women are led to injecting drug use through their association with men who inject drugs (MWID) (Payne, 2007; Taylor, 1998), studies suggest that both male and female acquaintances that inject drugs can facilitate women in their initiation (Payne, 2007; Taylor, 1993; Tuchman, 2015). Payne (2007) argues that, in contrast to the traditional belief that men are the ones who introduce women to injecting drugs, the reality is far more complex. The participants in this research support Payne's (2007) argument and provided a myriad of accounts each relevant to their own experience.

\section{Who introduced injecting?}

There is contradictory evidence surrounding the relationships of women to those who introduce injecting drug use to them. Research has found that either women are more likely to have received their first injection by another man (Roberts et al., 2010), or conversely another woman (Tuchman, 2015), or similar proportions of men and women initiate women to injecting (Taylor, 1998). The women in this study substantiate these mixed findings and recalled their variable contexts of initiation.

Although the context varies greatly, particularly at a global level, there is substantial evidence suggesting that, predominantly, women are initially injected by men, usually their romantic partner, and it is done, often, in the presence of other women (Roberts et al., 2010). The women in this study gave varying accounts of who was present for the first time injecting, with some of the women reporting that there were men who initiated them. 'Nina' shared her experience of first time injecting and described how a man she met had introduced her to it:

"...I met this guy and he was into it [injecting] and I was keen as to try it and he was more than willing to help me. Everyone that tries it always has to have someone that they know...to get the drugs, make the drugs and inject the drugs... “ (Nina)

'Lucy' had previously seen injecting drug use through a boyfriend at the time. 
“...so I started going out with a guy, again, who I'd be on with for years who was an IV user and then I guess he said 'oh I'm doing this now', it was injecting and I was like 'oh ok, I've never done that'. He was 'well'..." (Lucy)

After seeing her boyfriend inject, it was one occasion with him and his male friend, that 'Lucy' first injected drugs, with assistance:

“...[we] did it with the guy I was going out with, and his friend...So he did it for me..." (Lucy)

'Lucy' further emphasised that it was her boyfriend who first injected her and often did so, as she continued her drug use:

"Yeah, a lot of the times he would inject me..." (Lucy)

In the context of his initiation, it was all males present when a male friend from high school introduced injecting to 'Jordan':

“...I was 16 [years old], one friend of mine in particular dropped out of high school and moved to [city], we were living in [region in the North Island] at the time and he moved into a flat, where he and the other flatmates were using IV drugs. I used to go over there on weekends, and that's the first time that I was ever saw it, ever did it..." (Jordan)

Although the above experiences confirm the notion of women's ${ }^{23}$ association with injecting men being attributed to women's introduction to injecting drug use, research such as Taylor's (1998) suggests that both male and female can act as initiators. This thesis reflects this notion, with some participants in this study first injecting in a mixed-gendered environment, and their initiation was through other women. Tuchman (2015) affirms that women are often initiated through other women, and via a well-established injecting drug social network.

'Cassie' recalls that it was another woman who assisted her and her friends for their first time

23 'Jordan' had stated that, at initiation to injecting drug use, other PWID had "seen him as female" 
injecting, and it was a mutual experience between a group of women and men. An older, more experienced woman showed them all how to inject:

“...I was with really good friends of mine who had moved down who were the same age as me. We'd met some older people that were already into it...an older lady, actually it was a woman as well, decided that we were probably on the course to do that anyway and decided to help us out by preparing and administering the first time..." (Cassie)

Similarly 'Clara' also recalls that her first injecting experience with women:

“...it was actually women [who I was with]. We were down at a lady's house, three women, two men and that was it." (Clara)

Additionally, 'Cassie' felt that the introduction to injecting drugs was something adventurous and not something she was coerced into, and her reasons for injecting drugs were remembered as something 'adventurous'

“...we were travelling around [regional area] doing cool things with cool people and it just sort of happened. It was a part of our sort of adventuring...so, very exotic and exciting and wild and alternative..." (Cassie)

Studies have also demonstrated that experienced WWID have acted as instructors and provided assistance to other women in their first time injecting (Tuchman, 2015). Women have also emphasised how important the skills that other experienced WWID had, were to them (Tuchman, 2015). 'Cassie' also stressed the significance of the initiator being a woman and how this provided some comfort about safer injecting:

“...she was very cool in our eyes...I would say she was being a bit like a nurse, quite motherly, and thinking 'these kids could really hurt themselves if they're going to go and do this by themselves '...I'm quite glad it was a female...I feel that way now, looking back..." (Cassie)

Sourcing drugs and equipment for the first time is argued to be gendered. Research suggests that both drugs and equipment are more likely to be supplied to women than men for their first 
injection. Furthermore, research also points out that it was common for first-time injectors to have little or no knowledge of where the drugs or the injecting equipment comes from (Roberts et al., 2010). The participants' experiences, in this study, of first time sourcing drugs and equipment were heterogeneous and although they may have had prior knowledge of drugs and injecting use, they all sourced needles and/or drugs from other PWID. 'Jordan' recalled a lack of knowledge of where the drugs or needles came from when first injecting, however he had little concern regarding the needles at the time as he believed they were sterile:

"I was so dumb...I know that, they [needles] were new ones, out of a packet... The only place I ever got them [drugs] from was from the flat in [town] " (Jordan)

'Clara's first experience injecting reflects the bulk of research that suggests women often lack knowledge of the source of needles or drugs, particularly in the context of initiation (Roberts et al., 2010).

“... as far as I remember I don't recall how the needles came in, where they came from, I really don't..., I do know who got them [the drugs]." (Clara)

As women continue injecting drugs, their experiences of sourcing, using and buying drugs change and adapt as they gather knowledge and the context of their injecting changes. As with the initiation to injecting drugs, the literature supports the notion that regular, every-day experiences of the drug world are also gendered (Bryant \& Treloar, 2007). While the participants have experienced diverse situations the gendered nature of their world is illustrated through their experiences. For those women who continue to inject drugs after their first time, particularly on a regular basis, maintaining this requires the ability to finance, source, prepare and inject drugs alongside the acquisition and preparation of sterile injecting equipment. While the conventional view is that women's roles in these activities mirror gendered power dynamics in the non-injecting world (Roberts et al., 2010), the few qualitative studies reveal some challenges to this belief (Taylor, 1998; Tuchman, 2015). 
Some studies suggest that gendered constructs result in a lack of options for women to have autonomy in accessing and buying drugs (Hankins, 2008). Furthermore it is argued that WWID are disproportionately reliant on a sexual partner for assistance in sourcing drugs than a MWID (Pinkham et al., 2012a). In spite of this, several studies show evidence to the contrary and provide a better understanding of the complexities around women's agency, actions and heterogeneity in accessing drugs. Taylor's (1993) ethnography explores how the women she interviewed accessed drugs independently for themselves and also for their male partners. Portrayals of women who inject drugs and lead chaotic lives, who are also incapable of making rational, practical decisions are often invalidated by qualitative research (Taylor, 1993).

While the literature is scant, some studies suggest that in heterosexual partnerships, MWID are more likely to procure drugs for themselves and their partners. It is suggested that this may be due to gendered reasons of protecting women from perceived violent situations or with benevolent sexism, as a means of expressing chivalry towards their partner (Roberts et al., 2010). 'Lucy' describes how it was her boyfriend that procured drugs due to his contacts and knowledge:

“..First it was his friend getting them [drugs] and then my partner started getting them from people himself...no I never had to get them. He always got them for me..." (Lucy) While also demonstrating agency, 'Lucy' further emphasised the lack of necessity for her to source any drugs and how it mitigated some negative feelings about her level of drug use she may have had.

“... [I] didn't need to cos there were so many people living [in a central area], literally users there, there's like 100s. Easier for him and I guess it made me feel like 'I'm not as bad' cos I'm not going and seeking it out..." (Lucy) 
Although 'Lucy' felt some relief and self-control about the level of drug use due to her boyfriend sourcing drugs rather than her, she also felt a negative aspect to this. Often she would have little opportunity in knowing what the drugs actually were:

“...sometimes I wouldn't actually even know, these guys would make it up ...they would mix...I wouldn't mix it up all the time..." (Lucy)

'Cassie' also accessed drugs via her boyfriend:

“...because my boyfriend at the time was supplying it to me but he was actually on the methadone [programme], so he wasn't using and my best friend that I started off with, she was still using" (Cassie)

Though these experiences of 'Lucy' and 'Cassie' reflect a more stereotypical, gendered picture, research has found that women are able to source drugs directly and can be just as busy doing so, as men (Bryant \& Treloar, 2007). Challenging the notion that women can only obtain drugs via their boyfriends, the women in Taylor's (1993) ethnography described and demonstrated the skills required to source the drugs, equipment as well as preparing the drugs and injecting them. 'Cassie' also illustrated her agency in obtaining drugs and how it encompassed other methods and sources:

“...I knew a drug dealer very well and he was a very good friend of mine, so I bought some very cheap morphine off him, about $\$ 400$ worth...” (Cassie)

The participants shared thoughts that contradicted each other and themselves around their drug and needle-sourcing experiences. This merely represents the reality of lived experiences. For example, some of the sourcing of drugs and equipment was shared between heterosexual couples and was often dependent on location and where the women were living. 'Nina' shared that while she was with her partner, she was the one that sourced drugs. Yet, when she was living in another location, the injecting equipment was sourced by other parties: 
“...the guys I was hanging out with and this girl, they pretty much used to take care of that sort of stuff...” (Nina)

\section{Regular using within a masculine context}

There is little research that examines who WWID inject drugs with and where. The majority of the evidence that explores this is through the lens that examines risky behaviours (Roberts et al., 2010). The participants in this study injected drugs in a variety of contexts with a variety of people. Some participants spoke about how the context of injecting drugs was often masculinised, and that there were often far more men in a room with people injecting than women, or they were the only woman in the room. Occasionally, the context of other drug use also reflected a patriarchal constructs. 'Lucy' remembers when she was dating a ' $\mathrm{P}$ ' ${ }^{24}$ dealer and how he controlled her use of the drug

“...He wouldn't let me do it by myself, I had to have him feed it to me, more of a power and control thing...I wasn't allowed to light it and not allowed to hold it. He'd go out for hours at a time selling it, doing stuff and getting more and I wasn't allowed to have some with his friends and if he found out he'd hit me. His friends would give it to me sometimes when he wasn't there and he'd get really mad ..." (Lucy)

'Lucy's quote clearly illustrates the gendered power relations inherent in some contexts for WWID. She also remembers that the women were always after men in using or consuming the drugs emphasising their subordinate position.

“...the guy I was seeing would always have it first, the guys always had it first and then it was the females." (Lucy)

'Jordan' remembers during the early years of his injecting that it was mostly in a house where only men lived, however women would come over and inject in mixed-gendered spaces.

“...There was [sic] no women living there. There was girlfriends of guys that lived there who used to come over and use as well..." (Jordan)

24 ' $\mathrm{P}$ ' is a colloquial New Zealand term for the drug methamphetamine. 
'Jordan' remarked on how he thought women were seen in these circumstances, again highlighting that women were seen as lower down the 'pecking order' compared with men.

“...females were treated a bit like 'you're lucky we're giving you some, so don't complain about where the needles came from '..." (Jordan)

Although 'Jordan' self-identified as male then, others had identified 'Jordan' as a 'tom boy' or a woman. 'Jordan' expressed feelings of vulnerability and being unsafe at these times.

“...I definitely felt vulnerable. I definitely felt like there was a part of me that was always scared. That was always thinking are they going to take advantage of me, are they gonna, I knew I guess, that they didn't really care about me. They didn't care about my health or wellbeing or, they were just out to have a good time really..." (Jordan)

'Cassie' also recalled that sometimes a masculine space felt uncomfortable

“...once when I was using, my boyfriend was the drug dealer in town at the time, and he lived in this notorious squat and I felt unsafe there a couple of times. Once a guy came to score off him and I had seen this guy the day before in the brothel... and, I'd had a bad experience with him, he was actually my first client when I'd first started working and he'd complained, and I probably was a bit weird with him. He'd complained and I'd been quite rude to him and then he'd turned up the next day. At my boyfriend's house [laughs nervously] to score drugs off him, I was quite negatively affected by that...I was the only woman in the house..." (Cassie)

However, 'Cassie' acknowledged that the feelings of vulnerability were not wholly related to a drug using context as she also had experienced fear relating to some men during her time in sex work.

“...that's the kind of thing that my friend and I dealt with when we were working in the sex industry in [city] and using drugs in [city] as well..." (Cassie)

'Cassie' spoke about her and her friend's ways of dealing with masculine situations she was not comfortable in: 
“...Just used more drugs. Occasionally we'd talk about it. When we were flatting together, me and my female friend...we'd talked about it and laughed about it and let off steam together but basically we drank a lot and used a lot of drugs. That was how we dealt with everything..." (Cassie)

Despite recognising how masculine an injecting situation could feel, 'Cassie' also asserted that she did not remember feeling unsafe with other men present in an injecting context. Furthermore 'Cassie' emphasised how she felt trust within many relationships she had with fellow PWID, and this included men as well as women.

“...you know that guy that I helped, it was someone I'd been to high school with, the woman that we're talking about I went to primary school with... that's how far back these relationships go. There was a lot of trust and a lot of safety and it goes for all of us. In my mind, there was safety and this guy was one of those guys from high school and I didn't mind helping him out cos he'd tried everything anyway..." (Cassie)

Conversely, in the context of her drug use, less positive experiences around the masculine space were felt by 'Lucy':

“...we'd do it in a group setting. At first it was just with him, he really didn't want me to start using it but he would give it to me but he'd be 'you're not going to be innocent anymore, you're going to start getting a taste for it'..." (Lucy)

As her use of 'P' continued, 'Lucy' noticed how men in the group attempted to control her and her female friend's use and consumption:

“...sometimes they'd give it to me and the girl after a while, leave us in a room to do it ourselves, not knowing we could do it, we were just not so great at doing it...she'd do it for me, but then her boyfriend would give it to her and other guys I went out with since would give me the pipe and I wouldn't know how to do it, like spin it cos I'd be 'well this was always fed to me'. So I was, that's kind of weird, it took me a while to realise that's what he did as a sense of control." (Lucy)

Some studies in the United Kingdom have revealed that women's access and use of drug equipment is often controlled by their male partner (Barnard, 1993). This control is not 
necessarily overt but attributed to embedded gendered ideals of women's roles, combined with stigma of their doubly deviant actions (Taylor, 1993). Hutton (2005) refers to the perpetuation of hegemonic masculinity within subcultures such as an illicit drug world and in particular, drug dealing. In this context, women can exert agency as they navigate gendered constructs and power dynamics that may constrain their choices (Hutton, 2005). One of the participants in this study acknowledged this view of women accessing drugs. 'Jordan' believed that women may be more likely to source drugs for injecting through other people rather than going to a more direct source

“...I think a girl is more likely to... go to someone who is going to get it off someone else, rather than going to the immediate source. Higher up the levels, I think guys are more likely to rob chemists as well which is a big source of drugs..." (Jordan)

The stereotypical notion of women's subjugated position to men, within a drug taking world, is reflected with 'Lucy's recollection of her routine lack of knowledge of what was being injected and how it had been prepared:

“...these guys would make it up, most of the time it was Ritalin. Sometimes Ritalin mixed with downers...they would mix, I know it's stupid but I wouldn't mix it up all the time..." (Lucy)

Contrasting the traditional notion of women being unable or lacking the skills to access drugs alone (Taylor, 1993), women were found to make practical decisions and utilise their contacts to source drugs to inject. The women in this study also sourced drugs of their own accord. Through their words it is also demonstrated how they were dynamic, and resourceful as they sought drugs. 'Cassie' recalls a time when her usual source of drugs was unavailable and she had to utilise her initiative and knowledge to source drugs alone:

“...I ran out of drugs and I just walked up to the guy, I'd never actually met him, but we knew who each other were and he was the other drug dealer in town. So then I used 
with a whole lot of other people that I didn't know. But I knew that they used. You know what I mean? It's a pretty small scene." (Cassie)

In Taylor's (1993), ethnography, the importance of being known and knowing who to purchase from within an illicit drug scene was crucial to WWID. When asked what she thought about her accessing sterile needles and sourcing drugs compared with a man, 'Clara' responded with “...I've always, I guess, and I was getting it from a woman. So it's like I was being the mother hen I think. To my partner anyway..." (Clara)

After a few years of injecting drugs 'Jordan' often self-sourced drugs:

"...well I bought it through one of the guys in the flat. I knew he used, and I just went up to him and I said 'listen man, can you get me some stuff' he was like 'hmmmm'. Because he wasn't a dealer, he was just a user and he was 'hmmmm I spose'..." (Jordan)

Some participants almost exclusively accessed drugs through their boyfriends. As 'Lucy' notes, her boyfriends have often also dealt in drugs and then enabled easy access to drugs:

“...I've always been out with dealers. I don't think I've ever gone out with a guy that hasn't dealt drugs..." (Lucy)

'Lucy's boyfriend was often the source of the drugs she injected.

"The guy would buy it for us and then my partner started buying them from people...first it was his friend getting them and then my partner started getting them from people himself and I, no I never had to get them. He always got them for me." (Lucy)

However, 'Lucy' saw this lack of access to drugs as a way of confirming that her issues with drugs were less serious than her boyfriend's, rather than her boyfriend controlling drug access:

“...I think that's my way of saying he was using more than me, he was the one forcing it and wanted it..." (Lucy)

The notion of agency in Lucy's above thoughts is supported in Roberts et al.'s (2010) argument 
that some women prefer to reduce their drug use through a lack of direct access.

The next part of the discussion examines issues around who performs the injecting for WWID. There is substantial literature examining who is more likely to perform the injecting for WWID and potential risks around this (Roberts et al., 2010). The literature is largely focused on medical and health issues, such as exposure to BBVs, therefore the power structures and dynamics of women's lives are neglected in the research. This section addresses this gap and focuses on the gendered nature of injecting. Injecting drugs is an activity that requires skill, care and knowledge. The disadvantages of being injected by someone else are associated with less autonomy over where on the body the injection will take place, the origin of the drugs and how the drugs have been prepared (Oretti \& Gregory, 2005). Though self-injecting can pose some difficulties such as a lack of knowledge of safer injecting practices, and notably for women there are some biological differences that can make it more difficult, such as finding a suitable vein to inject (Roberts et al., 2010).

Research suggests than women are more likely to report that they are injected by someone else than men (Hankins, 2008). Furthermore the other person is often a sexual partner and is often intoxicated by alcohol and other drugs (Roberts et al., 2010). The reasons for this are argued to be complex and varied. A demonstration of the lack of autonomy due to gendered reasons has been cited as one of the reasons, although sociological factors, such as gendered risks in intimate personal relationships, lack attention in the research literature (Martin, 2010). Furthermore, the significant proportion of women injected by their male partners is also argued to be a reflection of women's subordinate role in a heterosexual relationship within a patriarchal society (Roberts et al., 2010). Conversely, some research suggests that women are expressing their agency in a strategic manner by allowing their male partners to inject them as it can offer a protection from sexual harassment from other men within the injecting scene (Martin, 2010). Moreover, research also shows that WWID may feel a level of social 
respectability and stability within a stigmatised community when injecting with a male partner (Martin, 2010).

Women's disproportionate numbers of self-injecting compared with men also exacerbate risks to BBVs and other physical health issues (Martin, 2010). Though, as stated previously, the focus here is how the participants in this study experienced and navigated their injecting. There are contradictions across and within participants' injecting practices, though this reflects the diversity and complexities of people's lives, and how their injecting career develops and changes. Most of the women were injected by others in their first injecting experience. Some were injected by their male partners and some were injected by other women. The injecting practices changed over time for the majority of the women. 'Jordan' described where a heterosexual relationship with two injecting partners can be viewed with a gendered context:

“... it would be normal for me to inject a girl but it wouldn't be normal for me to inject another guy ['Jordan' identifies as male] ... men are seen as the caretakers of women, and so they're in charge of the women...it would be completely normal for me and I have done on several occasions, injected women. I've never injected a guy. But, I've injected several different women on several different occasions. I often see, the boyfriend injecting the girlfriend, but I've never seen the girlfriend injecting the boyfriend!" (Jordan)

While some of the women in this study were injected by their male partners, their own experiences did not refer to a power imbalance. 'Cassie' recalls how in her initial days of injecting, her boyfriend at the time did the injecting of himself, her and a friend

"...the boyfriend of mine I discussed earlier... used to inject me and my friend..." (Cassie)

Whereas 'Lucy' and her boyfriend injected each other as a reciprocal activity:

“...he was doing it for me and I would do it for him ...” (Lucy)

Another perspective on the reasons behind male partners injecting women is that it is 
demonstrative and symbolic of love, trust, intimacy and togetherness (Roberts et al., 2010). Men can be trusted more to inject women justified by the belief that men are more skilled at injecting practices (Roberts et al., 2010). Trust in their male partners to inject them was not specifically discussed by the women in this study, in contrast, some of the woman highlighted how they preferred women to inject them. 'Clara' believed women were more skilled to inject and preferred their assistance to men's:

“...actually there's quite a lot of women who usually do it, I prefer a woman cos men are quite rough" (Clara)

Whereas, while 'Cassie' was also glad that a woman helped her inject, her reasons were due to feeling the potential gendered power dynamics:

“...Ifeel glad because often the older guys were often a little bit sleazy...we were young women, attractive. It probably could have had slightly seedier undertones. Whereas she obviously wasn't like that at all" (Cassie)

Tuchman (2015) notes that it is more common for WWID to inject drugs in a social setting, particularly with their MWID partner and other women. Some of the women's experiences in this study reflected this. The dominant focus of who-injects-who is around risks involved, such as exposure to BBVs, sexual risks and injecting risks (Roberts et al., 2010). This can overlook or mask the importance of social networks, how relationships function and how women 'do gender' in injecting situations. Furthermore, the literature is centred on women being injected by their male partners, rather than simply other injecting peers. The women is this study were often injected by other PWID who were not their sexual partners. 'Clara' remembers that injecting was often done in a mixed-gender group setting with different people injecting each other.

“...Usually [inject in] a group of us. Cos, believe it or not, we didn't used to inject ourselves, we'd get someone else to do it..." (Clara) 
While 'Nina' had initially been injected by her partner, this was not done exclusively. 'Nina' remembers how she helped a female friend to inject and in return:

\section{"She did it for me as well" (Nina)}

'Nina' also describes mixed-gender injecting practices

"...I was using with her, the way she worked was she had the contacts for the drugs and a guy she scored off was getting them through people, so I paid her and she got it...she did it [injected] for me as well.” (Nina)

While the evidence suggests that women are more likely to continue to be injected by others after their first injection (Roberts et al., 2010), some women do learn how to self-inject and will shift to this as their primary method. Almost all of the women in this study had attempted self-injecting, with only one participant performing this from initiation. Three of the participants continued to self-inject as their drug use progressed, with two of these women noting how the ability to self-inject marked a significant shift in their drug use and how they felt about it.

Becker (1963) posits that within the world of drug consumption social context and skills mark the shift from a fledgling to becoming an experienced user (as cited in Mayock, 2005, p. 365). Within injecting drug worlds, this shift can be marked where people learn to self-inject. From the brief research exploring self-injecting and women, there is evidence to suggest that selfinjecting can lower vulnerability around riskier injecting practices (Tuchman, 2015). Selfinjecting can be significant, especially for women, as women may have limited control over drugs due to their lower social status within the drug using context. Learning to self-inject, although it can generally take longer to learn for women than men, can be a symbol of becoming a more frequent and experienced user (Roberts et al., 2010). Just as Taylor's (1998) research reflects heterogeneous practices and circumstances, the participants in this study reflected on their self-injecting experiences in a variety of ways. Becker's (1963) argument of 
the shift from novice to more experienced WWID is demonstrated through self-injecting as a mark of independence. For the women in Tuchman's $(2015$, p. 4) study the move to selfinjection was associated with independence, self-sufficiency, autonomy over the injection site, as well as control over drugs, and time and location of injecting. Some participants' feelings in this study mirrored this notion:

“...there was a big change in my life, it was significant when I learned how to inject myself...because, from there, I was able to go and use as an independent person without having to get someone else involved... Other people were having to inject me before then and after that I was able to inject other people..." (Cassie)

'Nina's' experiences also mirrored a feeling of autonomy with the ability of-self injecting.

"I did it. And I was so proud of myself, 'yes this is excellent now, I don't have to pay for three or four people to have some just to get me some! I can just get my own, this is great'..." (Nina)

As in Taylor's (1998) ethnography, it can be argued that some women feel a sense of empowerment from self-injecting. While self-injecting women report feelings of pride and independence, like 'Cassie' and 'Nina' above, women who are injected by others share a sense of fear of causing harm to themselves and a lack of agency (Tuchman, 2015). Not all the participants decided to continue to self-injecting. This can be for several reasons such as: a method to restrict or control one's drug use or fear of incorrectly injecting (Roberts et al., 2010). Physiologically, it can be more difficult for women to self-inject than men due to different vein and skin tissue (Roberts et al., 2010). 'Lucy's' reflection of self-injecting was not as positively remembered as the other participants and she generally preferred to be injected by someone else.

“...I actually learnt how to do it myself but it was kind of scary cos if you miss a vein..." (Lucy) 
Research into self-injecting at initiation is scarce, particularly exploring women's experiences. Of the research that does exist, reports are mixed as to the proportion of women who self-inject at initiation. It is widely accepted that initiates' self-injecting is rare (Roberts et al., 2010). While the women in Bryant and Treloar's (2007) study reported self-injecting at initiation proportionately to the men, other evidence suggests that women are far less likely to self-inject at initiation than men (Oretti \& Gregory, 2005; Roberts et al., 2010).

The participants in this study validate the extent of current evidence with only one participant self-injecting at initiation. 'Jordan' shares his first injecting experience:

“...the first time [that] I used myself, the needle, myself, I didn't usually, often, people that when they start, they get other people to inject but I injected myself with the advice of other people as to where to find the vein and that type of thing..." (Jordan)

The above thoughts reflect the only two from 26 participants in Tuchman's (2015) study that self-injected from initiation and both managed to do so with instructions and advice from friends who were present. Although 'Jordan' often injected alone, it was acknowledged that others injected in a group setting

“...only on weekends, by myself, in my room by myself. Traditionally, I've just always done it by myself. I'm really not, it's not a social type of thing, people do it in groups but it's not a social activity..." (Jordan)

Chapter seven provides some concluding discussion of the issues raised throughout this thesis. 


\section{Chapter Seven: Conclusion}

"One of the things that really drew me to [being interviewed] ...I saw something in the information you sent me about needle exchanges and that really excited me, cos I thought that's great that there's people doing research that might be helpful in that area. The other thing for me is just that it's a part of my life that was really intense and you just don't [get to] talk about it." (Cassie)

As stated at the beginning of this thesis, there were two main research aims. The first was to explore whether women who inject drugs experience gendered barriers in accessing needle exchange services. The second was to understand how women who inject drugs may have navigated and responded to these barriers. This chapter will bring together the key ideas, research questions, and results from this thesis. As is a dearth of research in this area, this qualitative study provides a platform for WWID to share their thoughts, feelings and ideas about their drug using experiences, and access to needle exchanges. A feminist methodology formed the framework for this research and semi-structured interviews were used to provide a platform for the women's voices in this study.

While this thesis cannot speak for all WWID, there is an anticipation that it can contribute in addressing the gap of literature in this area, and provide insight for improvements to needle exchange management. A number of key issues were raised in exploring the issues related to injecting drugs and gendered experiences, harm reduction and needle exchange services.

The effects of gender and policing of women's bodies impact on women who inject drugs in a multitude of ways. Although women are a significant minority of people who inject drugs, literature dedicated to them and harm reduction services sensitive to their needs is either nonexistent or inadequate. It has been highlighted how women, their thoughts and bodies are governed and policed, and a further focus showing the effects on women when gender norms 
are violated, was provided. Chapter two documented how the scant explanations of women's criminality are largely reductionist and over-simplistic, however remain influential on policies and services. From the few notable studies that challenge traditional literature and notions, women's agency, structural constraints relating to 'doing gender' and drugs in a patriarchal world were explored. The issue of stigma for people who inject drugs was identified, noting that despite stigma affecting women more than men, a paucity of literature addressing this, remains. The literature review also explored the philosophy and implementation of harm reduction at global and New Zealand levels.

This thesis evidenced the overwhelming harm and impact that stigma has on WWID. The chapter dedicated to stigma, evidenced through the participants' commentaries, the stigma that WWID experience, relating not only to their drug using 'master status', but also at a multifaceted level. WWID experience stigma at social, structural, and individual levels while 'passing' through 'positioned othering' or by managing their 'discredited status'. It was illustrated by the participants how pervasive stigma is in their lives, and how gender and other factors increase the impact of stigma. The main findings from this thesis confirm that women face and navigate gendered barriers in their access, with stigma as an overwhelmingly significant barrier for WWID. The 'master' status of WWID permeates and was shown to operate at different levels: self, social, and structural (Lloyd, 2010). The participants in this study all confirmed their own experiences of self-stigma and how pervasive a 'spoiled identity' affected their self-worth. The public, or social, stigma against WWID was demonstrated by the women and their descriptions of 'passing', 'managing' their image status, and navigating public spaces where their status may be known or revealed. The key workers provided an acknowledgement of how stigma can be multi-faceted for WWID, in particular, where motherhood, pregnancy or sex work is a factor and these findings concur with the scant research addressing similar issues (Ettorre, 2007). Notably, participants highlighted how health 
professionals also showed stigmatising attitudes towards WWID. Particularly relevant to this study, it was demonstrated by the results chapters that stigma presents a significant barrier in accessing needle exchange services, specifically within pharmacies. As the literature available suggests, the stigma and discrimination experienced by the participants was stronger via pharmacy based services (Sheridan et al., 2005a). Overall it was shown that stigma presents as a significant harm to WWID and further research into this and how it operates as a barrier is crucial in the provision of more effective needle exchange services.

Other barriers have also been explored, with commentaries by participants that supported relevant literature. Several areas were highlighted by participants that could be addressed in current and future, needle exchange designs. Key workers' thoughts about the design and implementation of programmes revealed a gap in the acknowledgment of women's different needs. Barriers such as these, can be mitigated without the need for significant, additional funding. It is important in the provision and design of gender-sensitive services for WWID that barriers are understood so they can be reduced or mitigated.

This thesis has also highlighted the impact of gender on injecting practices. The final results chapter provided an analysis of how the participants navigate their world while adhering to gender norms. An examination of their injecting practices demonstrated their agency and confirmed other literature that has challenged traditional notions of passive victims coerced into injecting drugs. The experiences of the women in this research have confirmed findings in key studies that suggest women's reasons for injecting, their initiation into and regular experiences of, are complex and heterogeneous.

Overall, this thesis has highlighted the overwhelming impact of stigma on WWID, as a barrier to needle exchange access as well as related to other harms in their lives. This, combined with 
the other barriers presented in chapter four, and discussed above, signal the crucial need for gender-sensitive needle exchange services to be acknowledged, designed and implemented.

\section{Appendices}




\section{Appendix A: Ethical Approval}

\begin{tabular}{|c|c|c|}
\hline & Phone & $0-4-4635676$ \\
\hline & Fax & $0-4-4635209$ \\
\hline & Email & Allison.kirkman@ \\
\hline
\end{tabular}

\begin{tabular}{l|l}
\hline TO & Kirsten Gibson \\
\hline COPY TO & Fiona Hutton \\
\hline FROM & Dr Allison Kirkman, Convener, Human Ethics Committee \\
\hline
\end{tabular}

\begin{tabular}{l|l}
\hline DATE & 18 November 2013 \\
\hline PAGES & 1 \\
\hline SUBJECT & $\begin{array}{l}\text { Ethics Approval: } 20347 \\
\text { Examining the barriers and facilitators for IV drug using women } \\
\text { accessing needle exchange services }\end{array}$ \\
\hline
\end{tabular}

Thank you for your application for ethical approval, which has now been considered by the Standing Committee of the Human Ethics Committee.

Your application has been approved from the above date and this approval continues until 6 October 2014. If your data collection is not completed by this date you should apply to the Human Ethics Committee for an extension to this approval.

Best wishes with the research.

Allison Kirkman

Human Ethics Committee

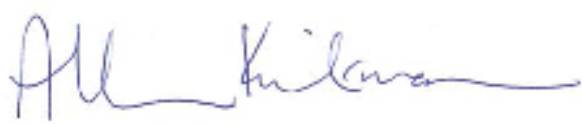


MEMORANDUM

\begin{tabular}{l|l}
\hline TO & Kirsten Gibson \\
\hline COPY TO & Fiona Hutton \\
\hline FROM & Dr Allison Kirkman, Convener, Human Ethics Committee \\
\hline
\end{tabular}

\begin{tabular}{l|l}
\hline DATE & 1 December 2013 \\
\hline PAGES & 1 \\
\hline
\end{tabular}

SUBJECT

Ethics Approval: 20347

Examining the barriers and facilitators for IV drug using women accessing needle exchange services

Thank you for your request to amend your ethics approval. This has now been considered and the request granted.

Your application has approval until 6 October 2014. If your data collection is not completed by this date you should apply to the Human Ethics Committee for an extension to this approval.

Best wishes with your research.

Allison Kirkman

Human Ethics Committee

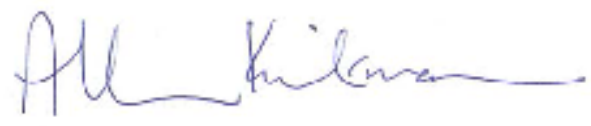




\section{Appendix B: Recruitment Flyer}

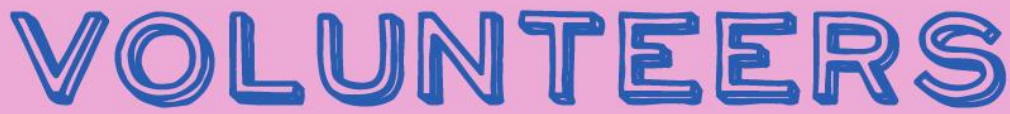 \\ NE⿷DED F@R A \\ RESEARCH STUDY \\ Have you ever used IV Drug:s?}

Explanation of Study

To give women a chance to tell their stories about their experiences of IV drug use.

Who can participate?

Any woman over the age of 18 years who has ever used, or currently uses, drugs intravenously

What does it involve?

- up to I hour talking about your own drug experiences

* Whatever information you choose to share will be kept confidential

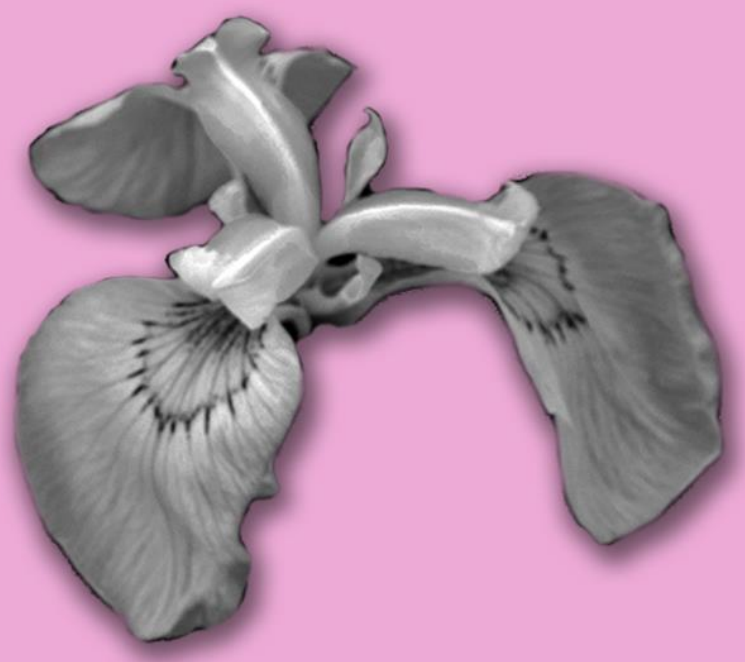

you can text with your name and I can call you back.

Contact me on 0220734698 or email kirsten.gibson@vwu.ac.nz for any further questions.

Victoria University of Wellington, Institute of Criminology 


\section{Appendix C: Participant Information Sheet}

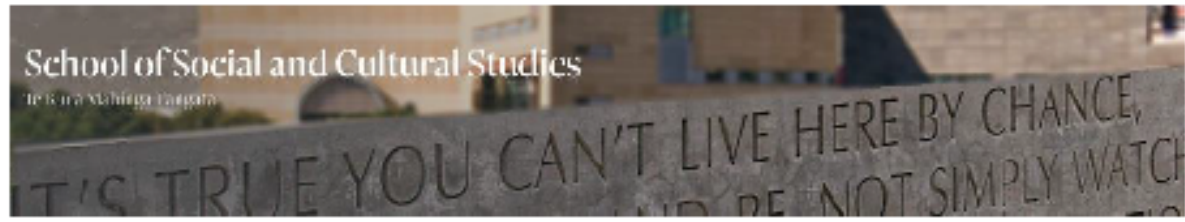

Participant Information Sheet for a Study on Experiences of Accessing the Needle Exchange

Researcher: Kirsten Gibson, Institute of Criminology, Victoria University of Wellington

I am a Masters student in Criminology at Victoria University of Wellington. As part of this degree I am undertaking a research project. The study I am doing is looking at the experiences and knowledge of women who have ever used IV drugs. It is also looking at their experiences of needle exchange services. This is an area that is under researched in New Zealand and one of the aims for the study is to give women that use IV drugs a chance to speak about their own experiences and highlight the good things about the needle exchange and improvements that could be made around these services.

This research has received approval from the Victoria University Human Ethics committee, application number 20347.

I am inviting women over 18 years of age who have used IV drugs (past or current use) to talk with me about their experiences.

Taking part in this research will involve meeting with me, (the researcher), in a public place, for approximately 1 hour to talk about your experiences with IV drugs.

The interview will be flexible and you will not have to answer any question you are not happy with. You will be able to talk about any issues that you feel are important to this research. You are welcome to look over the transcript of your interview at any time and make changes to anything you have said.

Participation and Confidentiality

Participation in this project is entirely voluntary.

I will keep everything you say strictly confidential and will only use the information for the purpose of this study. If you feel that you do not want anything you've said to be used in the study you can let me know by 31 March 2014 before I include the data in writing up of the main themes.

Your name and any other factors that may identify you will not be used in the published material. If, for any reason, I feel that you or anyone else is at serious risk of harm I may break confidentiality. However, I will discuss this with you beforehand if I need to.

The interviews will be tape recorded and may be typed up by someone other than me. If this is the case, the person typing up the interview will sign a confidentiality agreement so they cannot discuss anything you have said.

If you have any questions regarding this research, or would like to participate, please contact myself or my supervisor Dr Fiona Hutton using the details below.

Thank you in advance for your time

Kirsten Gibson

Master of Arts Candidate

Dr. Fiona Hutton

Victoria University of Wellington

Senior Lecturer

Kirsten.Gibson@vuw.ac.nz

Victoria University of Wellington

0220734698

Fiona.Hutton@yuwacenz

044636749 


\section{Appendix D: Participant Consent form}

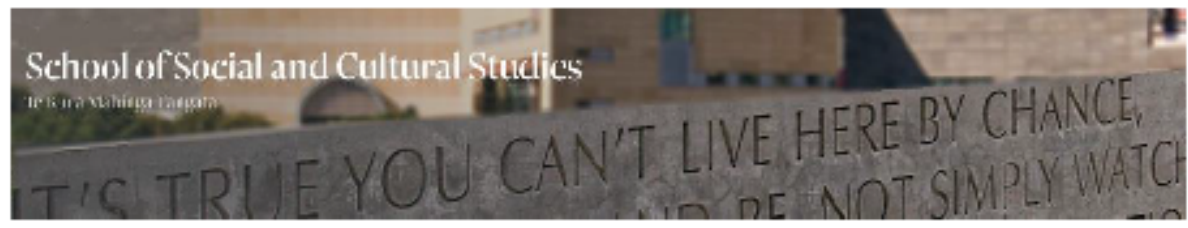

\section{PARTICIPANT CONSENT FORM}

Victoria University of Wellington

Consent to participation in research

Experiences of IV drug using women

I have been given and have understood an explanation of this research project. I have been given the opportunity to ask questions and have them answered to my satisfaction. I understand that I am able to withdraw myself (or any information I have provided) from this project before 31 March 2014, without having to give reasons.

I understand that any information I provide will remain confidential to the researcher and her supervisor Fiona Hutton. I also umderstand that the published results will not use my name as an identifier, a psendonym will be used, and no information attributed to me that will identify me will be published. I understand that the tape recording of my interview will be electronically wiped at the end of the project, unless I indicate that I would like the audio file to be returned to me.

- I agree to take part in this research.

- I understand that I do not have to answer any question I feel uncomfortable with.

- I understand that I can stop the interview at any time for any reason.

- I understand that the data provided in this research will not be provided to any other person.

- I understand that the only exception to this is that if I, or someone else, was at risk of serious harm and if this was the case it will be discussed with me first.

- I understand that I will have an opportunity to check the interview transcript before publication and make amendments as I see fit.

- I understand that the data provided in this interview may be used for publication in academic journals and presentation at academic conferences.

․ I would like the tape recordings returned to me at the completion of the project.

a I would like to receive a summary of this research when it is completed.

\section{Participant contact details for return of transcripts/recordings:}

Email address:

Postal address:

Signed:

Name of participant:

(Please print clearly)

Date: 


\section{Appendix E: Participant Interview Guide}

Drug Use

Firstly, can you tell me about what you remember about your first experience with drug use?

Can you remember who you were with at the time?

Do you remember what circumstances there were when you first saw drugs injected?

Can you tell me about the first time you injected drugs? How old were you? Who injected you or did you inject yourself?

Who did you usually inject drugs with? Where would you normally inject drugs?

Where did you source drugs to inject? How did you find your drug use?

Needle Exchange

Did you think about where the needles came from?

What did you know about sterie injecting?

What can you remember getting sterle needles for the first time?

How did you feel about going to the needle exchange? How safe did you feel?

Was there any difference in needle exchange services between the pharmacy and stand-alone needle exchanges?

Was there anything that helped or prevented you from accessing the needle exchange?

Was there ever a time when you could not access sterle needles?

Did you feel that there was anything the services offered you as a woman? What did they do that impressed you? Is there anything they could do better? 


\section{Appendix F: Key Worker Information Sheet}

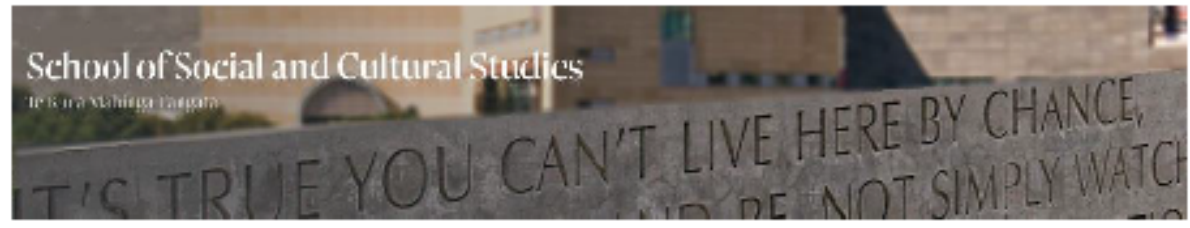

Key Informant Information Sheet for a Study on Experiences of Accessing the Needle Exchange

Researcher: Kirsten Gibson, Institute of Criminology, Victoria University of Wellington

I am a Masters student in Criminology at Victoria University of Wellington. As part of this degree I am undertaking a research project. The study I am doing is looking at the experiences and knowledge of women who have ever used IV drugs. It is also looking at their experiences of needle exchange services. This is an area that is under researched in New Zealand and one of the aims for the study is to give women that use IV drugs a chance to speak about their own experiences and highlight the good things about the needle exchange and improvements that could be made around these services.

This research has received approval from the Victoria University Human Ethics Committee, application number 20347

I am inviting people who work with IV drug using women to take part in some key informant interviews.

Taking part in this research will involve meeting with me (the researcher) for approximately 1 hour to talk about your experiences of working with women who use or have used IV drugs and their access of the needle exchange services.

The interview will be flexible and you will not have to answer any question you are not happy with. You will be able to talk about any issues that you feel are important to this research. You are welcome to look over the transcript of your interview at any time and make changes to anything you have said.

Participation and Confidentiality

Participation in this project is entirely voluntary.

I will keep everything you say confidential and will only use the information for the purpose of this study.

Your name and any other factors that may identify you will not be used in the published material. If, for any reason, I feel that you or anyone else is at serious risk of harm I may break confidentiality. However, I will discuss this with you beforehand if I need to.

The interviews will be tape recorded and may be typed up by someone other than me. If this is the case, the person typing up the interview will sign a confidentiality agreement so they cannot discuss anything you have said.

If you have any questions regarding this research, or would like to participate, please contact myself or my supervisor Dr Fiona Hutton using the details below.

Thank you in advance for your time

Kirsten Gibson

Dr. Fiona Hutton

Master of Arts Candidate

Victoria University of Wellington

Kirsten.Gibson@vuw.ac.nz

0220734698

Senior Lecturer

Victoria University of Wellington

Fiona.Hutton@vuw.ac.nz

044636749 


\section{Appendix G: Key Worker Consent form}

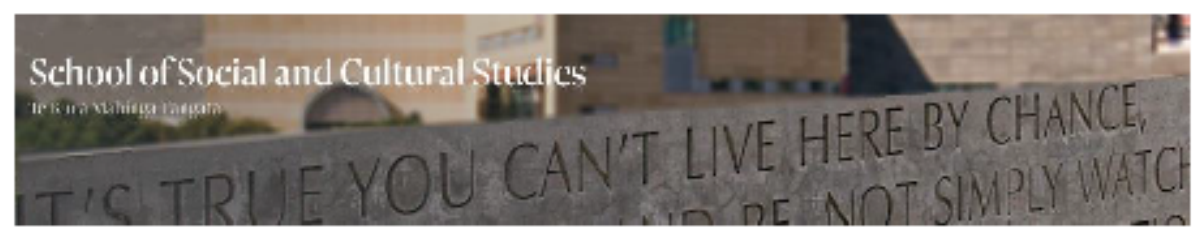

Victoria University of Wellington

\section{Consent to participation in research}

\section{Experiences of IV drug using women}

I have been given and have understood an explanation of this research project. I have been given the opportunity to ask questions and have them answered to my satisfaction. I understand that I am able to withdraw myself (or any information I have provided) from this project before 31 March 2014, without having to give reasons.

I understand that any information I provide will remain confidential to the researcher and her supervisor Fiona Hutton. I also understand that the published results will not use my name as an identifier, a pseudonym will be used, and no information attributed to me that will identify me will be published. I understand that the tape recording of my interview will be electronically wiped at the end of the project, unless I indicate that I would like the audio file to be returned to me.

- I agree to take part in this research.

- I understand that I do not have to answer any question I feel uncomfortable with

- I understand that I can stop the interview at any time for any reason.

- I understand that the data provided in this research will not be provided to any other person.

- I understand that the only exception to this is that if I, or someone else, was at risk of serious harm and if this was the case it will be discussed with me first.

- I understand that I will have an opportunity to check the interview transcript before publication and make amendments as I see fit.

- I understand that the data provided in this interview may be used for publication in academic journals and presentation at academic conferences.

- I understand that with my agreement, my views could be linked to the organisation that I work for

I would like the tape recordings returned to me at the completion of the project.

口 I would like to receive a summary of this research when it is completed.

Participant contact details for return of transcripts/recordings:

Email address:

Postal address:

Signed:

Name of participant:

(Please print clearly)

Date: 


\section{Appendix H: Key worker interview guide}

Professional knowledge of Dnug Use

What do you remember about first hearing about people using drugs and illegal drugs?

And what about injecting drugs?

Working with women who inject drugs

How did you end up working at XXX?

And what does your job entail?

How do you think drug users are viewed by society?

How do you think IV drug users are viewed by society?

How do you think women IV drug users are viewed by society?

What does the needle exchange do for women? Are there any specific policies that cater for women's needs?

Is there anything you think that could be done to improve access for women?

How do you think the needle exchange caters for women?

Are there any reasons you can think of that could prevent women from accessing the Needle Exchange?

What are the barriers/facilitators for women in accessing the needle exchange?

Are you aware of any other services that cater for IV drug using women? 


\section{$\underline{\text { References: }}$}

Ahern, J., Stuber, J., \& Galea, S. (2007). Stigma, discrimination and the health of illicit drug users. Drug and alcohol dependence, 88(2), 188-196.

Aitken, C. (2002). New Zealand needle and syringe exchange programme review Final Report (Vol. 27): The Centre for Harm Reduction.

Anderson, T. L. (2001). Drug Use and Gender. In C. E. Faupel \& P. M. Roman (Eds.), Encyclopedia of Criminology and Deviant Behavior, Volume IV: Self-Destructive Behavior and Disvalued Identity (pp. 286-289). Philadelphia: lor \& Francis Publishers.

Anderson, T. L. (2008). Dimensions of Women's Power in the Illicit Drug Economy. In T. L. Anderson (Ed.), Neither Villain nor Victim: Empowerment and Agency Among Substance Abusers (pp. 15-32). New Brunswick, United States of America: Rutgers University Press.

Anderson, T. L. (2013). Dimensions of Women's Power in the Illicit Drug Economy. In M. Chesney-Lind \& L. Pasko (Eds.), Girls, women, and crime (pp. 155-174). Los Angeles, USA: Sage.

Armstrong, L. (2011). Managing Risks of Violence in Decriminalised Street-Based Sex Work: a Feminist (Sex Worker Rights) Perspective. (Doctor of Philosophy), Victoria University of Wellington.

Ashton, M. (2004). Needle Exchange: The Vancouver Experience. Addiction Research and Theory, 12(5), 445-460. doi: 10.1080/16066350410001729513

Australian Injecting and Illicit Drug Users League (AIVL). (2003). The Young Women Injecting Drug Users' Project Final Report. Canberra, Australia: Australian Injecting and Illicit Drug Users League.

Australian Injecting and Illicit Drug Users League (AIVL). (2010). Legislative and Policy Barriers to Needle \& Syringe Programs and Injecting Equipment Access for People Who Inject Drugs. Canberra, Australia: Australian Injecting and Illicit Drug Users League.

Australian Injecting and Illicit Drug Users League (AIVL). (2011). Why wouldn't I discriminate against all of them? A Report on stigma and discrimination towards the injecting drug user community. Canberra, Australia. 
Bailey, L. (2012). Young women and the culture of intoxication: Negotiating classed femininities in the postfeminist context. (Doctor of Philosophy), University of Bath, Bath, England.

Bancroft, A. (2009). Drugs, intoxication and society. Cambridge, United Kingdom: Polity Press.

Barnard, M. (1993). Needle sharing in context: patterns of sharing among men and women injectors and HIV risks. Addiction, 88(6), 805-812.

Becker, H. (1963). Outsiders: Studies in the Sociology of Deviance. London, England: Macmillan

Beals, F. (2002). Playing with the Discursive: A feminist post-structural exploration of the words 'criminal woman'. (Masters of Education), Victoria University of Wellington, Wellington, New Zealand.

Bean, P. (2010). Legalizing Drugs: debates and dilemmas. Bristol: The Policy Press.

Beirness, D., Jesseman, R., Notarandrea, R., \& Perron, M. (2008). Harm Reduction: What's in a Name? Ottawa, Canada: Canadian Centre on Substance Abuse.

Bingham, T. (2012). Irish Press Ombudsman upholds complaint from coalition of drug services. Human Rights and Drugs, 2(1). 70-72.

Boland, P. (2008). British drugs policy: Problematizing the distinction between legal and illegal drugs and the definition of thedrugs problem'. Probation journal, 55(2), 171-187. doi: $10.1177 / 0264550508089120$

Boyd, S. C. (2006). Representations of Women in the Drug Trade. In G. Balfour \& E. Comack (Eds.), Criminalizing Women: Gender and (in) justice in Neo-liberal Times. Halifax, Canada: Fernwood Publishing.

Braun, V., \& Clarke, V. (2006). Using thematic analysis in psychology. Qualitative research in psychology, 3(2), 77-101. doi: 10.1191/1478088706qp063oa

Brooks, A., \& Hesse-Biber, S. N. (2007a). An invitation to feminist research Feminist research practice (pp. 1-24).

Brooks, A., \& Hesse-Biber, S. N. (2007b). An invitation to feminist research. In S. N. HesseBiber \& P. L. Leavy (Eds.), Feminist research practice: A primer (pp. 1-24). Thousand Oaks, California: Sage Publications. doi: http://dx.doi.org/10.4135/9781412984270

Brown, N. L., Luna, V., Ramirez, M. H., Vail, K. A., \& Williams, C. A. (2005). Developing an effective intervention for IDU women: A harm reduction approach to collaboration. AIDS Education \& Prevention, 17(4), 317-333. 
Bryant, J., \& Treloar, C. (2007). The gendered context of initiation to injecting drug use: Evidence for women as active initiates. Drug and alcohol review, 26(3), 287-293. doi: $10.1080 / 09595230701247731$

Buchanan, J. (2006). Understanding problematic drug use: A medical matter or a social issue? British Journal of Community Justice, 4(2), 387-397.

Butler, J. (2004). Undoing Gender. New York, United States of America: Routledge.

Campbell, N. (2000). Using women: Gender, drug policy, and social justice

Cao, W., \& Treloar, C. (2006). Comparison of needle and syringe programme attendees and non-attendees from a high drug-using area in Sydney, New South Wales. Drug and alcohol review, 25(5), 439-444. doi: 10.1080/09595230600891282

Carlen, P., \& Worrall, A. (1987). Introduction. In P. Carlen \& A. Worrall (Eds.), Gender, crime and justice. Milton Keynes, UK: Open University Press

Cattapan, A. (2008). Open Arms and Crossed Legs? Subjectivity and Trans-Inclusion in Canadian Feminist Organizations. Paper presented at the Paper presented at the Annual Meeting of the Canadian Politcal Science Association, University of British Columbia, Vancouver.

Cohen, S. (1972). Folk Devils and Moral Panics. London, England: MacGibbon and Kee

Connell, R. W. (2002). Gender. Cambridge: Polity.

Danaher, G., Schirato, T., \& Webb, J. (2000). Understanding Foucault. St Leonards, NSW, Australia: Allan \& Unwin.

Dickson-Swift, V., James, E. L., Kippen, S., \& Liamputtong, P. (2007). Doing sensitive research: what challenges do qualitative researchers face? Qualitative Research, 7(3), $327-353$.

Durrant, R., Adamson, S., Todd, F., \& Sellman, D. (2009). Drug use and addiction: evolutionary perspective. Australian and New Zealand Journal of Psychiatry, 43(11), 1049-1056. doi: 10.1080/00048670903270449

Eldred-Grigg, S. (1984). Pleasures of the Flesh: Sex \& Drugs in Colonial New Zealand, 18401915. Wellington, New Zealand: Reed Ltd.

Ettorre, E. (1992). Women and Substance Use. Hong Kong: Macmillan Press Ltd.

Ettorre, E. (2004). Revisioning women and drug use: gender sensitivity, embodiment and reducing harm. International Journal of Drug Policy, 15(5), 327-335. doi: 10.1016/j.drugpo.2004.06.009

Ettorre, E. (2007). Revisioning women and drug use: Gender, power and the body. Basingstoke, England: Palgrave Macmillan. 
European Monitoring Centre for Drugs and Drug Addiction (EMCDDA). (2006). A gender perspective on drug use and responding to drug problems. Belgium: European Monitoring Centre for Drugs and Drug Addiction.

European Monitoring Centre for Drugs and Drug Addiction (EMCDDA). (2009). Womens Voices: Experiences and perceptions of women who face drug-related problems in Europe. Lisbon, Portugal: European Monitoring Centre For Drugs and Drug Addiction. Gay Men's Health Crisis. (2009). Syringe exchange programs around the world: The global context. New York, New York: Gay Men's Health Crisis.

Goffman, E. (1963). Stigma: Notes on the management of spoiled identity. New Jersey: Prentice-Hall.

Greenwald, G. (2009). Drug decriminalization in Portugal: lessons for creating fair and successful drug policies Cato Institute Whitepaper Series: Cato Institute.

Griffiths, P., Gossop, M., Powis, B., \& Strang, J. (1993). Reaching hidden populations of drug users by privileged access interviewers: methodological and practical issues. Addiction, 88(12), 1617-1626.

Grundetjern, H. (2015). Women's Gender Performances and Cultural Heterogeneity in the Illegal Drug Economy. Criminology, 53(2), 253-279. doi: 10.1111/1745-9125.12068

Hankins, C. (2008). Sex, drugs, and gender? High time for lived experience to inform action. International Journal of Drug Policy, 19(2), 95-96. doi: 10.1016/j.drugpo.2008.01.001

Harding, S., \& Norberg, K. (2005). New feminist approaches to social science methodologies: An introduction. Signs, 30(4), 2009-2015.

Harm Reduction International. (2014). The Global State of Harm Reduction 2014. London, United Kingdom: Harm Reduction International.

Heidensohn, F. (1985). Women and Crime. Basingstoke, UK: Macmillan Publishing.

Heidensohn, F. (1987). Women and Crime: Questions for Criminology. In P. Carlen \& A. Worrall (Eds.), Gender, crime and justice (pp. 16-27). Milton Keynes,, UK: Open University Press.

Hesse-Biber, S. N. (2007). The Practice of Feminist Indepth Interviewing. In S. N. Hesse-Biber \& P. L. Leavy (Eds.), Feminist research practice (pp. 110-149). Thousand Oaks, CA: SAGE Publications, Inc. doi: http://dx.doi.org/10.4135/9781412984270

Hunt, G., Joe-Laidler, K., \& Evans, K. (2002). The meaning and gendered culture of getting high: gang girls and drug use issues. Contemporary Drug Problems, 29(2). 
Hunt, N. (2012). Recovery and Harm Reduction: time for a shared, development-oriented, programmatic approach? In R. Pates \& D. Riley (Eds.), Harm Reduction in Substance Use and High-Risk Behaviour (pp. 155-183). Chichester: John Wiley \& Sons.

Hutton, F. (2005). Risky business: Gender, drug dealing and risk. Addiction Research \& Theory, 13(6), 545-554. doi: 10.1080/16066350500338237

Hutton, F. (2006). Risky Pleasures? : club cultures and feminine identities. Aldershot, England: Ashgate.

Hutton, F., Griffin, C., Lyons, C., Niland, P., \& McCreanor, T. (2016). "Tragic Girls" and "Crack Whores": Alcohol, Femininity and Facebook. Feminism \& Psychology. 26 (1), 73-93.

Ingram, D. (1999). HIV-positive mothers and stigma. Health Care for Women International, 20(1), 93-103. doi: 10.1080/073993399245999

Inter-Agency Committee on Drugs. (2015). National Drug Policy 2015 to 2020. Wellington, New Zealand: Ministry of Health.

International Harm Reduction Association. (2010). What is harm reduction? A position statement from the International Harm Reduction Association Retrieved October (Vol. 14). London: International Harm Reduction Association.

King, A. (2004). The prisoner of gender: Foucault and the disciplining of the female body. Journal of International Women's Studies, 5(2), 29-39.

King, D., \& Gibbs, A. (2003). Is home detention in New Zealand disadvantaging women and children? Probation journal, 50(2), 115-126.

Klein, A. (2007). Sticking points: Barriers to access to needle and syringe programs in Canada. Toronto, Canada: Canadian HIV/AIDS Legal Network = Réseau juridique canadien $\mathrm{VIH} /$ sida.

Ksobiech, K., Somlai, A. M., Kelly, J. A., Benotsch, E., Gore-Felton, C., McAuliffe, T., . . . Kozlov, A. P. (2004). Characteristics and HIV Risk Behaviors among Injection Drug Users in St. Petersburg, Russia: A Comparison of Needle Exchange Program Attenders and Nonattenders. Journal of Drug Issues, 34(4), 787-804. doi: $10.1177 / 002204260403400404$

Lakhani, S., Sacks, A., \& Heltberg, R. (2014). 'They are Not Like Us': Understanding Social Exclusion World Bank Policy Research Working Paper: The World Bank Sustainable Development Network.

Law Commisson. (2011). Controlling and Regulating Drugs: A Review of the Misuse of Drugs Act 1975. Wellington, New Zealand: Law Commission. 
Lewis, S., Klee, H., \& Jackson, M. (1995). Illicit drug users' experiences of pregnancy. An Exploratory Study. Journal of reproductive and infant psychology, 13(3-4), 219-227. doi: 10.1080/02646839508403251

Liamputtong, P. (2007). Researching the vulnerable: a guide to sensitive research methods doi:http://dx.doi.org.helicon.vuw.ac.nz/10.4135/9781849209861

Link, B., \& Phelan, J. (2006). Stigma and its public health implications. The Lancet, 367(9509), 528-529.

Link, B. G., \& Phelan, J. C. (2001). Conceptualizing stigma. Annual Review of Sociology, 27, 363-385.

Livingston, J. D., Milne, T., Fang, M. L., \& Amari, E. (2012). The effectiveness of interventions for reducing stigma related to substance use disorders: a systematic review. Addiction, 107(1), 39-50. doi: 10.1111/j.1360-0443.2011.03601.x

Lloyd, C. (2010). Sinning and sinned against: The stigmatisation of problem drug users York: University of York: The UK Drug Policy Commission.

Luke, S. (2007). Needle Exchange Networks: The emergence of 'peer-professionals'. (Doctor of Philosophy), University of Canterbury.

Lungley, S., \& Baker, M. (1990). The needle and syringe exchange scheme in operation: an evaluation of the first year. Wellington, New Zealand: Department of Health, Health Research Services.

Macrory, F., \& Boyd, S. C. (2007). Developing primary and secondary services for drug and alcohol dependent mothers. Seminars in Fetal and Neonatal Medicine, 12(2), 119-126. doi: 10.1016/j.siny.2007.01.005

Malloch, M. (2004). Missing out: Gender, drugs and justice. Probation journal, 51(4), 295308.

Martin, F. S. (2010). Becoming vulnerable: Young women's accounts of initiation to injecting drug use. Addiction Research \& Theory, 18(5), 511-527. doi: $10.3109 / 16066351003611653$

Mayock, P. (2005). 'Scripting'risk: Young people and the construction of drug journeys. Drugs: education, prevention and policy, 12(5), 349-368. doi: $10.1080 / 09687630500183020$

McCormick, R., Bryant, L., Sheridan, J., \& Gonzalez, J. (2006). New Zealand community pharmacist attitudes toward opioid-dependent clients. Drugs: Education, Prevention, and Policy, 13(6), 563-575. doi: 10.1080/09687630600790153 
McCosker, H., Barnard, A., \& Gerber, R. (2001). Undertaking sensitive research: Issues and strategies for meeting the safety needs of all participants. Forum Qualitative Sozialforschung/Forum: Qualitative Social Research, 2(1).

McKeganey, J., \& McIntosh, N. (2001). Identity and recovery from dependent drug use: The addict's perspective. Drugs: Education, Prevention, and Policy, 8(1), 47-59. doi: $10.1080 / 09687630124064$

McNay, L. (1992). Feminism and Foucault. Cambridge, England: Polity Press.

Measham, F. (2002). 'Doing gender'-'doing drugs': conceptualizing the gendering of drugs cultures. Contemporary Drug Problems, 29(2).

Measham, F. (2006). The new policy mix: Alcohol, harm minimisation, and determined drunkenness in contemporary society. International Journal of Drug Policy, 17(4), 258-268. doi: 10.1016/j.drugpo.2006.02.013

Ministry of Health. (2009). Research into knowledge and attitudes to illegal drugs. Wellington, New Zealand: Ministry of Health.

Ministry of Health. (2010). Drug Use in New Zealand: Key Results of the 2007/08 New Zealand Alcohol and Drug Use Survey. Wellington, New Zealand: Ministry of Health.

Moore, K., \& Measham, F. (2013). Exploring emerging perspectives on gender and drug use. In W. Mistral (Ed.), Emerging Perspectives on Substance Misuse (pp. 80-97). Hoboken, New Jersey: Wiley.

Neale, J. (2004). Gender and illicit drug use. British Journal of Social Work, 34(6), 851-870. doi: 10.1093/bjsw/bch105

NEP National Office. (2013). Needle Exchange Programme Comprehensive Service Model: Needle Exchange Services Trust.

Nutt, D., King, L., \& Phillips, L. (2010). Drug harms in the UK: a multicriteria decision analysis. The Lancet, 376(9752), 1558-1565. doi: 10.1016/S0140-6736(10)61462-6

Olszewski, D., Giraudon, I., Hedrich, D., \& Montanari, L. (2009). Women's Voices: Experiences and perceptions of women who face drug-related problems in Europe. Lisbon, POrtugal: European Monitoring Centre for Drugs and Drug Addiction.

Oransky, M., Fisher, C., Mahadevan, M., \& Singer, M. (2009). Barriers and opportunities for recruitment for nonintervention studies on HIV risk: Perspectives of street drug users. Substance use \& misuse, 44(11), 1642-1659. doi: 10.3109/10826080802543671

Oretti, R., \& Gregory, P. (2005). Women and injecting. In R. Pates, A. McBride \& K. Arnold (Eds.), Injecting Illicit Drugs (pp. 59-68). Oxford, United Kingdom: Blackwell Publishing Ltd. 
Otiashvili, D., Kirtadze, I., O’Grady, K. E., Zule, W., Krupitsky, E., Wechsberg, W. M., \& Jones, H. E. (2013). Access to treatment for substance-using women in the Republic of Georgia: Socio-cultural and structural barriers. International Journal of Drug Policy. doi: 10.1016/j.drugpo.2013.05.004

Pates, R., \& Riley, D. (2012). Introduction. In R. Pates \& D. Riley (Eds.), Harm Reduction in Substance Use and High-Risk Behaviour (pp. 3-5). Chichester, West Sussex: John Wiley \& Sons.

Payne, J. (2007). Women drug users in North Cumbria: what influences initiation into heroin in this non-urban setting? Sociology of health \& illness, 29(5), 633-655. doi: 10.1111/j.1467-9566.2007.01016.x

Pereira, M. (2013). Governing drug use among young people: Crime, harm and contemporary drug use practices. (Doctor of Philosophy), Queensland University of Technology.

Phillips, J. (2015). Alcohol - Colonial drinking, 1800-1880. Retrieved 25 May 2015, from http://www.TeAra.govt.nz/en/alcohol/page-1

Phoenix, J. (2006). Regulating Prostitution: Controlling Women's Lives. In F. Heidensohn (Ed.), Gender and justice: New concepts and approaches (pp. 76-95). Cullompton, England: Willan.

Pinkham, S., Myers, B., \& Stoicescu, C. (2012a). Developing Effective Harm Reduction Services for Women Who Inject Drugs. In C. Stoicescu (Ed.), The Global State of Harm Reduction 2012: Towards an Intergrated Response. In H. R. International (Series Ed.) (pp. 125-136). London, UK: Harm Reduction International.

Pinkham, S., Stoicescu, C., \& Myers, B. (2012b). Developing effective health interventions for women who inject drugs: key areas and recommendations for program development and policy. Advances in preventive medicine, 2012. doi: 10.1155/2012/269123

Poole, N., \& Dell, C. A. (2005). Girls, women and substance use. Ottawa, Canada: Canadian Centre on Substance Abuse.

Poole, N., Health, B. C. o. E. f. W. s., \& Isaac, B. (2001). Apprehensions: barriers to treatment for substance-using mothers

Punch, K. F. (2005). Introduction to social research: Quantitative and qualitative approaches. London, England: Sage.

Radcliffe, P., \& Stevens, A. (2008). Are drug treatment services only for 'thieving junkie scumbags'? Drug users and the management of stigmatised identities. Social science \& medicine, 67(7), 1065-1073. 
Ransom, J. S. (1997). Foucault's discipline: The Politics of Subjectivity. Durham, North Carolina: Duke University Press.

Riley, D., Pates, R., Monaghan, G., \& O’Hare, P. (2012). A Brief History of Harm Reduction. In R. Pates \& D. Riley (Eds.), Harm Reduction in Substance Use and High-Risk Behaviour (pp. 5-16). Chichester, West Sussex: John Wiley \& Sons Ltd.

Roberts, A., Mathers, B., \& Degenhardt, L. (2010). Women who inject drugs: A review of their risks, experiences and needs. Sydney, Australia: Secretariat of the Reference Group to the United Nations on HIV and Injecting Drug Use.

Robinson, D. G. (2008). Prescription drug misuse: how to identify and manage drug seekers. Best Practice Journal, 16, 18-23.

Russell, S. J., \& McVeigh, J. (2011). Next generation challenges: An overview of harm reduction 2010, IHRA's 21st conference. International Journal of Drug Policy, 22(1), 82-86. doi: 10.1016/j.drugpo.2010.10.005

Seddon, T. (2010). A history of drugs: Drugs and freedom in the liberal age. Abingdon, Great Britain: Routledge.

Sheridan, J., Henderson, C., Greenhill, N., \& Smith, A. (2005a). Pharmacy-based needle exchange in New Zealand: a review of services. Harm Reduction Journal, 2(10). doi: 10.1186/1477-7517-2-10

Sheridan, J., Wheeler, A., \& Walters, C. (2005b). Health problems and help-seeking activities of methadone maintenance clients at Auckland Methadone Service (AMS): potential for community pharmacy service expansion. Harm Reduction Journal, 2(1), 25. doi: $10.1186 / 1477-7517-2-25$

Shewan, D., \& Dalgarno, P. (2005). Evidence for controlled heroin use? Low levels of negative health and social outcomes among non-treatment heroin users in Glasgow (Scotland). British journal of health psychology, 10(1), 33-48. doi: 10.1348/135910704X14582

Shiner, M. (2006). A dubious equality? Drug use and the discovery of gender. In F. Heidensohn (Ed.), Gender and justice: New concepts and approaches (pp. 15-31). Portland, Oregon, USA: Taylor \& Francis.

Simmonds, L., \& Coomber, R. (2009). Injecting drug users: A stigmatised and stigmatising population. International Journal of Drug Policy, 20(2), 121-130.

Simpson, M., \& McNulty, J. (2008). Different needs: Women's drug use and treatment in the UK. International Journal of Drug Policy, 19(2), 169-175. doi: 10.1016/j.drugpo.2007.11.021 
Smart, C. (1976). Women, crime, and criminology : a feminist critique London, United Kingdom: Routledge.

Smart, C. (1977). Criminological theory: its ideology and implications concerning women. British Journal of Sociology, 89-100.

Sprague, J. (2005). Feminist methodologies for critical researchers: Bridging differences. Walnut Creek, California: Lanham.

Stafford, N. (2007). Using words: The harm reduction conception of drug use and drug users. International Journal of Drug Policy, 18(2), 88-91. doi: 10.1016/j.drugpo.2007.01.001

Stengel, C. (2014). The risk of being 'too honest': Drug use, stigma and pregnancy. Health, risk \& society, 16(1), 36-50. doi: 10.1080/13698575.2013.868408

Stengel, C., \& Fleetwood, J. (2014). Developing drug policy: gender matters. Swansea, Wales: Global Drug Policy Observatory.

Stimson. (2007). "Harm Reduction-Coming of Age": A local movement with global impact. International Journal of Drug Policy, 18(2), 67-69. doi: doi:10.1016/j.drugpo.2006.12.012

Stimson, G., \& Metrebian, N. (2003). Prescribing heroin: what is the evidence? York, England: Joseph Rowntree Foundation.

Stimson, G., \& O'Hare, P. (2010). Harm reduction: Moving through the third decade. International Journal of Drug Policy, 21(2), 91-93. doi: 10.1016/j.drugpo.2010.02.002

Stockwell, T. (2006). Alcohol supply, demand, and harm reduction: What is the strongest cocktail? International Journal of Drug Policy, 17(4), 269-277. doi: 10.1016/j.drugpo.2005.10.007

Stoetzler, M., \& Yuval-Davis, N. (2002). Standpoint theory, situated knowledge and the situated imagination. Feminist theory, 3(3), 315-333. doi: $10.1177 / 146470002762492024$

Sutton, B. (2011). Playful cards, serious talk: a qualitative research technique to elicit women's embodied experiences. Qualitative Research, 11(2), 177-196. doi: $10.1177 / 1468794110394070$

Tate, C. C. (2012). Considering Lesbian Identity from a Social-Psychological Perspective: Two Different Models of "Being a Lesbian". Journal of lesbian studies, 16(1), 17-29. doi: 10.1080/10894160.2011.557639

Taylor, A. (1993). Women drug users: An ethnography of a female injecting community. Oxford, UK: Clarendon Press. 
Taylor, A. (1998). Needlework: The lifestyle of female drug injectors. Journal of Drug Issues, 28, 77-90.

Taylor, S. (2008). Outside the outsiders: Media representations of drug use. Probation journal, 55(4), 369-387. doi: 10.1177/0264550508096493

Treloar, C., \& Cao, W. (2005). Barriers to use of needle and syringe programmes in a high drug use area of Sydney, New South Wales. International Journal of Drug Policy, 16(5), 308-315. doi: 10.1016/j.drugpo.2005.06.005

Tuchman, E. (2015). Women's injection drug practices in their own words: a qualitative study. Harm Reduction Journal, 12(1), 6. doi: 10.1186/s12954-015-0041-6

UK Drug Policy Commission. (2012). Dealing with the Stigma of Drugs. A Guide for Journalists. Crowborough, England: UK Drug Policy Commission.

United Nations Office on Drugs and Crime (UNODC). (2015). World Drug Report 2015. Vienna, Austria: United Nations Office on Drugs and Crime.

Van Manen, M. (1990). Researching lived experience: Human science for an action sensitive pedagogy: Suny Press.

Van Olphen, J., Eliason, M. J., Freudenberg, N., \& Barnes, M. (2009). Substance Abuse Treatment, Prevention, and Policy. Substance Abuse Treatment, Prevention, and Policy, 4, 10. doi: 10.1186/1747-597X-4-10

VANDU Women CARE Team. (2009). Me I am Living it: The Primary Health Care Experiences of Women who use Drugs in Vancouver's Downtown Eastside VANDU Women's Clinic Action Research for Empowerment. Vancouver, BC.

Wilkins, C., Sweetsur, P., \& Griffiths, R. (2011). Recent trends in pharmaceutical drug use among frequent injecting drug users, frequent methamphetamine users and frequent ecstasy users in New Zealand, 2006-2009. Drug and alcohol review, 30(3), 255-263.

Witkiewitz, K., \& Marlatt, A. (2006). Overview of harm reduction treatments for alcohol problems. International Journal of Drug Policy, 17(4), 285-294.

Wodak, A., \& Cooney, A. (2005). Effectiveness of sterile needle and syringe programmes. International Journal of Drug Policy, 16, 31-44.

Young, J. (1971). The drugtakers: The social meaning of drug use: Paladin London.

Young, L., \& Buchanan, J. (2000). The War on Drugs - a war on drug users? Drugs: education, prevention and policy, 7(4), 409-422. 